
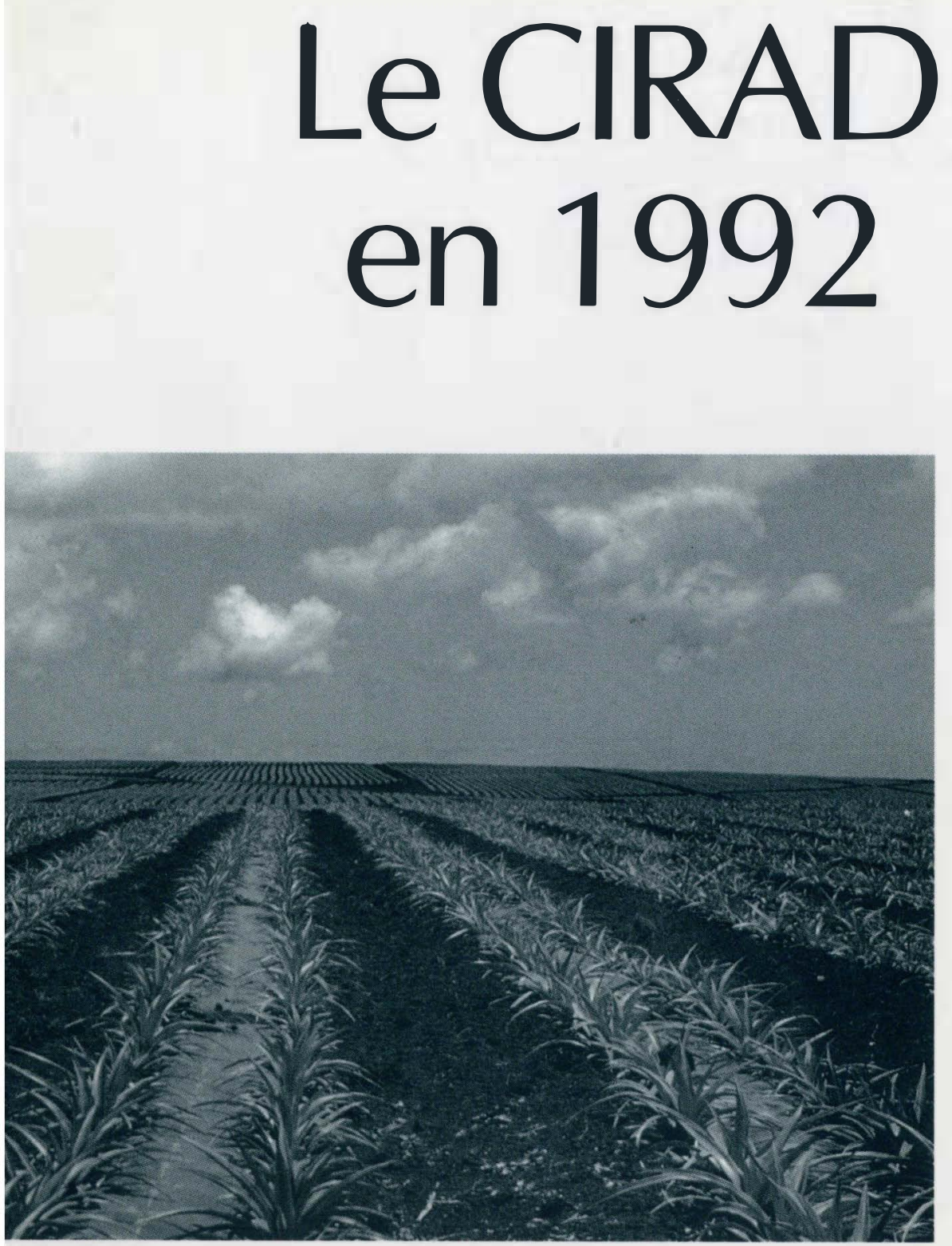


\section{Le CIRAD en 1992}


Le CIRAD, Centre de coopération internationale en recherche agronomique pour le développement, est un organisme scientifique spécialisé en agriculture des régions tropicales et subtropicales. Sous la forme d'un établissement public, il est né en 1984 de la fusion d'instituts de recherche en sciences agronomiques, vétérinaires, forestières et agroalimentaires des régions chaudes.

Sa mission : contribuer au développement de ces régions par des recherches, des réalisations expérimentales, la formation, l'information scientifique et technique.

Il emploie 1800 personnes, dont 900 cadres, qui interviennent dans une cinquantaine de pays. Son budget s'élève à près de 1 milliard de francs, dont plus de la moitié provient de fonds publics.

Le CIRAD comprend sept départements de recherche : cultures annuelles (CIRAD-CA); cultures pérennes (CIRAD-CP) ; productions fruitières et horticoles (CIRAD-FLHOR) ; élevage et médecine vétérinaire (CIRAD-EMVT) ; forêts (CIRAD-Forêt) ; systèmes agroalimentaires et ruraux (CIRAD-SAR) ; gestion, recherche, documentation et appui technique (CIRAD-GERDAT). Le CIRAD travaille dans ses propres centres de recherche, au sein de structures nationales de recherche agronomique des pays partenaires, ou en appui à des opérations de développement. 


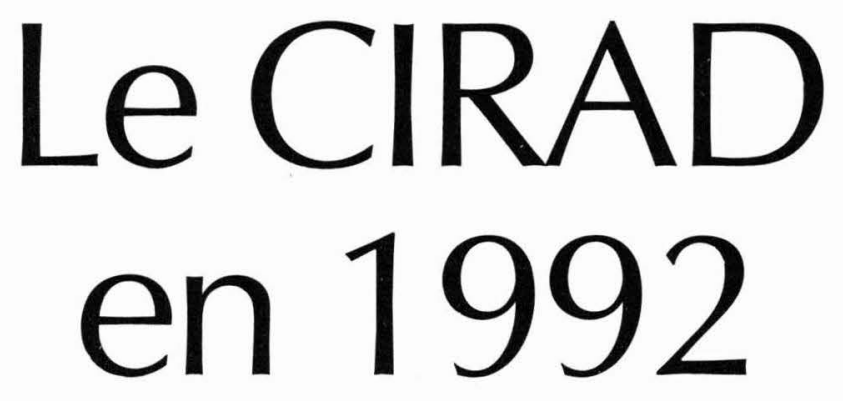


Recherche et coopération

par Guy Paillotin

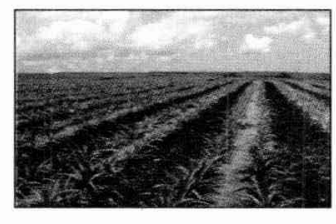

Un nouveau visage

pour le CIRAD

Département

des cultures annuelles

Département

des cultures pérennes

Département

des fruits et agrumes 


\section{SOMMAIRE}

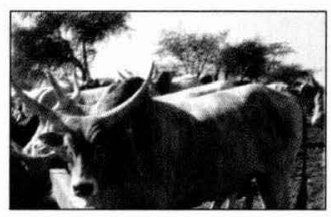

Département

d'élevage

et de médecine vétérinaire

56

Département

des forêts

68

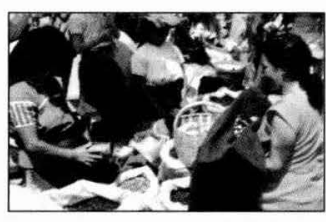

Département

des systèmes agroalimentaires

et ruraux

78

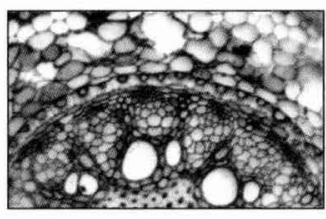

Département de gestion, recherche, documentation et appui technique

Le CIRAD en bref

Annexes 



\section{Recherche et coopération}

Successeur de Jacques Poly à la présidence du conseil d'administration du CIRAD depuis quelques mois seulement, j'ai pu mesurer l'œuvre qui avait été accomplie sous son autorité depuis la création du CIRAD.

J'ai trouvé ici une entreprise de recherche en coopération unie et solidaire, et en même temps très ouverte vers les communautés scientifiques française et internationale. Idéal partagé, motivation et confiance dans les missions de l'entreprise sont autant de conditions réunies qui permettent de faire face aux difficultés de la période présente.

Difficultés budgétaires, certes, mais surtout difficultés rencontrées par les pays du Sud eux-mêmes. II semble aujourd'hui bien difficile de faire reculer la pauvreté dans le monde. Les expatriés du CIRAD, vers lesquels se tournent tout particulièrement mes pensées, le savent mieux que quiconque. Mais ils savent aussi la richesse que recèlent les sociétés rurales de ces pays, leur capacité d'évolution, leur dynamisme, qui s'expriment dans de nombreux cas.

Le mérite de nos expatriés est de connaître, sur le terrain, la réalité des sociétés rurales. Leur mission particulière est de la faire connaître à leurs collègues de métropole pour que tous ensemble s'attachent toujours et toujours mieux à investir leurs énergies et leurs compétences dans les vrais problèmes du développement économique et social des pays avec lesquels le CIRAD coopère.

Cette solidarité et cette cohérence dans I'action sont strictement nécessaires pour que le CIRAD puisse remplir ses missions. Le projet d'entreprise adopté en 1991 et mis en application à partir de 1992 a permis d'ores et déjà une profonde rénovation du centre. La voie qui est suivie permettra au CIRAD, j'en suis sûr, d'accroître encore son efficacité.

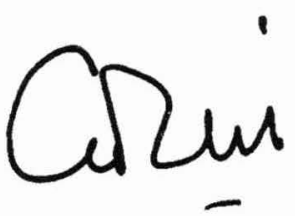

Guy Paillotin

Président du CIRAD 


\section{L'APPLICATION DU PROJET D'ENTREPRISE}

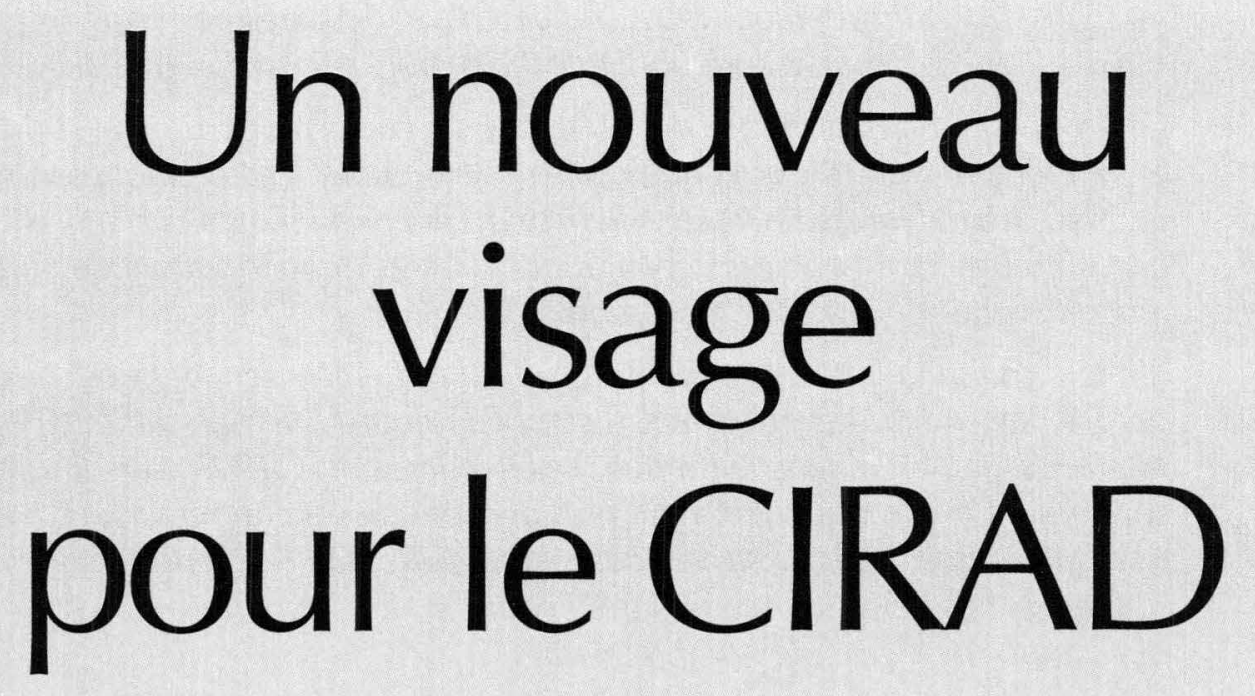

"Renouveler notre coopération dans un monde qui change», le titre du projet d'entreprise du CIRAD, dont 1992 a constitué la première année de mise en œuvre, annonce clairement I'ambition et la volonté du centre. A travers son projet, le CIRAD a confirmé et précisé son identité d'entreprise de recherche agronomique au service du développement économique et social des régions chaudes, et donc son rôle - chercher et coopérer. II a choisi, après I'analyse des enjeux à l'échelle de la planète, une stratégie de recherche et une politique d'alliances soutenues par une organisation rénovée. 


\section{Une stratégie scientifique}

La stratégie scientifique du CIRAD est établie en partant des besoins réels des sociétés rurales du Sud. Pour y répondre efficacement, il faut remonter aussi loin qu'il est nécessaire dans I'analyse des problèmes, en distinguant à chaque étape ce qui relève de l'adaptation de connaissances aux conditions locales ou de l'acquisition de nouveaux savoirs. L'approfondissement et l'élargissement des compétences que cela implique passent par la combinaison de plusieurs voies.

\section{Des réformes internes}

Renforcer l'efficacité sur le terrain des programmes et la qualité scientifique des recherches reste le premier objectif. Pour ce faire, le CIRAD s'est d'abord attaché à améliorer son organisation selon les recommandations du projet d'entreprise, fondées notamment sur les conclusions des revues externes des départements.

Depuis sa création, en 1984, le CIRAD comptait onze départements. Cette structure, héritée de I'histoire, présentait des avantages - l'existence de communautés fortement solidaires, forgées par un passé commun - mais aussi des inconvénients, au premier rang desquels l'éparpillement des moyens scientifiques mis au service des programmes en coopération. De même, la fragmentation des champs de compétence conduisait à multiplier les interlocuteurs dès que les questions posées par les partenaires dépassaient le cadre d'une seule filière de production.

Regrouper les moyens de coopération devenait nécessaire. La fin du premier cycle de revues externes des départements et le début du deuxième ont été l'occasion de réfléchir à la cohérence du dispositif du CIRAD. Décision a été prise de constituer de grands ensembles en réunissant les départements dont les activités étaient complémentaires.

Le département des cultures annuelles (CIRAD-CA) est né de la fusion entre I'IRCT (cotonnier), I'IRAT (cultures vivrières annuelles) et la division oléagineux annuels de l'IRHO. Son organisation 
en programmes fondés sur les systèmes de culture et les niveaux d'intensification lui permet de mieux répondre aux questions actuelles de la recherche agricole pour le développement : Comment gérer de façon optimale l'espace cultivé ? Comment exploiter durablement le milieu ? Comment rentabiliser les unités de production ?

Le département des cultures pérennes (CIRAD-CP) réunit les moyens du CIRAD concernant ces cultures, autrefois partagés entre I'IRHO (programmes palmier à huile et cocotier), l'IRCA (programme hévéa) et I'IRCC (programmes caféier et cacaoyer). Disposant de bases scientifiques renforcées, le nouveau département va pouvoir mettre en place un dispositif géographique plus cohérent dans la zone tropicale humide, zone confrontée à des problèmes aigus de rentabilité économique et de protection de l'environnement.

La création du département des systèmes agroalimentaires et ruraux (CIRAD-SAR) à partir du CEEMAT (mécanisation agricole et technologie) et du DSA (systèmes agraires) offre de nouvelles possibilités pour analyser globalement les unités de production et de transformation et le fonctionnement des sociétés rurales, au moment où ces systèmes subissent d'importantes mutations liées aux changements économiques et politiques des Etats.

Ces mêmes changements ont incité à étendre le mandat du département des fruits et agrumes du CIRAD à l'ensemble de l'horticulture (culture des fruitiers, maraîchage, horticulture florale), avec une mission particulière pour l'analyse des filières des produits végétaux frais, notamment ceux destinés à l'exportation : c'est la création du CIRAD-FLHOR.

Aux côtés des départements des forêts (CIRAD-Forêt) et d'élevage et de médecine vétérinaire (CIRAD-EMVT), le département de recherche et d'appui technique (CIRAD-GERDAT) complète ce dispositif. Outre sa fonction de gestion des services centraux et de la direction générale du CIRAD, il gère des unités de recherche communes aux départements.

En 1992, chaque nouveau département a élaboré son schéma pluriannuel de programmation : $\mathrm{s}^{\prime}$ appuyant sur une analyse de la situation et des perspectives d'évolution dans son domaine d'activité, il a fixé le cadre général de sa politique scientifique 
et de coopération pour les cinq années à venir, a défini son organisation et des projets opérationnels, après l'analyse de ses forces et de celles de ses partenaires.

Parallèlement à la restructuration du centre, une politique active de constitution d'unités de recherche communes à plusieurs départements a été menée, pour rassembler les forces scientifiques œuvrant dans un même domaine, tant en métropole que dans les départements d'outre-mer. L'objectif est d'avoir une plus grande efficacité tout en s'assurant, grâce à un comité de pilotage ad hoc, que les recherches conduites dans les laboratoires de ces unités répondent bien aux besoins des départements qui y sont associés. En 1992, Biotrop, unité commune de biotechnologies appliquées à l'amélioration des plantes tropicales (gérée par le CIRAD-GERDAT), s'est enrichie d'un laboratoire d'ingénierie génétique et de pathologie moléculaire, et une unité de recherche sur l'économie des filières (gérée par le CIRAD-CP) a été créée. D'autres unités communes sont en projet, en particulier dans le cadre de la construction de la Maison de la technologie sur le centre de Montpellier : physicochimie des produits (gérée par le CIRAD-CP), transformation et procédés (gérée par le CIRAD-SAR), stabilisation des produits frais et arômes (gérée par le CIRAD-FLHOR).

Des départements moins nombreux, mais plus forts et dotés de mandats rénovés, un plus grand nombre d'unités communes : tel est le nouveau visage du CIRAD à la fin de 1992. Cette évolution n'est pas une rupture, elle s'inscrit dans la logique qui avait prévalu à la création de l'entreprise, en 1984, de regrouper, pour plus d'efficacité scientifique et une économie de moyens, les forces qui peuvent l'être. L'installation prochaine à Montpellier du CIRAD-Forêt et du CIRAD-EMVT, à la suite des mesures de délocalisation décidées par le gouvernement en 1992, relève du même souci.

\section{Des alliances dans la communauté scientifique}

L'ampleur des besoins de recherche pour le développement dépasse les seules forces du CIRAD. Un point central de sa stratégie scientifique consiste donc à nouer des alliances avec les organismes les plus performants, en France et dans le monde, pour renforcer les capacités d'appui aux pays du Sud et à leurs institutions. 
Les unités de recherche communes du CIRAD sont, dans certains cas, associées à d'autres institutions françaises de recherche. Il s'agit alors de monter des laboratoires communs qui tirent bénéfice du rassemblement des moyens scientifiques et matériels, même si les objets de recherche - le monde tropical d'un côté, les régions tempérées de l'autre - sont différents. C'est le cas depuis plusieurs années avec l'ORSTOM, dans les domaines de la phytovirologie et des symbiotes des espèces forestières. A court terme, $d$ 'autres unités mixtes devraient voir le jour en nématologie, lutte biologique contre les ennemis des cultures, écophysiologie et modélisation. Dans ces trois dernières, I'INRA sera partenaire du CIRAD. L'ENSIA-SIARC s'associera au centre dans le cadre de la Maison de la technologie, qui ouvrira ses portes au début de 1994.

Si les collaborations ne se concrétisent pas toujours par des laboratoires communs où les chercheurs des différentes institutions travaillent côte à côte en utilisant les mêmes équipements, il existe de nombreuses relations, formelles ou non. Les missions par champ disciplinaire du CIRAD en sont les lieux privilégiés. Ces missions, au nombre de huit, couvrent les grands domaines d'activité du centre. Elles sont chargées de l'animation scientifique des départements, de la formation continue des chercheurs, de la conduite de recherches communes (actions incitatives). Chacune est dotée d'un comité scientifique formé d'un représentant de chaque département et de personnalités extérieures au CIRAD. Un solide réseau de correspondants - une soixantaine de scientifiques éminents - assurent ainsi le relais entre le CIRAD et les institutions auxquelles ils appartiennent : universités françaises et européennes, CNRS, INRA, ORSTOM... Le rôle de ces comités est complémentaire de celui du conseil scientifique du CIRAD. Leurs conseils et leurs avis sont d'autant plus précieux qu'ils se fondent sur une bonne connaissance des objectifs du centre et de ses forces scientifiques.

A cet effet, des visites sur le terrain, outre-mer, en appui aux agents du CIRAD et de ses partenaires, sont nécessaires. L'une d'entre elles a eu lieu en 1992 dans l'océan Indien (Réunion et Maurice); elle a permis de faire avancer le projet de création, à la Réunion, d'un pôle de recherches en défense des cultures, qui accueille d'ores et déjà un chercheur de I'INRA et un universitaire américain. 


\section{LE CIRAD EN 1992}

De son côté, la mission agronomie, gestion de l'environnement et des ressources naturelles organise un séminaire dans le nord du Cameroun. II rassemblera en 1993 les chercheurs expatriés et africains de la région pour des échanges sur le thème "Analyse de la diversité des situations agricoles et conséquences sur la programmation de la recherche».

Enfin, des participations réciproques nombreuses aux conseils scientifiques, aux procédures d'évaluation des institutions et des chercheurs facilitent une meilleure connaissance mutuelle.

A l'échelle européenne, on soulignera l'initiative majeure prise en 1992 par le NRI (Grande-Bretagne), le KIT (Pays-Bas), I'IICT (Portugal) et le CIRAD de créer un consortium européen pour la recherche agronomique tropicale (ECART), au service des pays en développement. Les capacités conjuguées des quatre institutions dépassent 2000 scientifiques, qui travaillent aussi bien sur le terrain, en réponse aux besoins du développement, qu'en laboratoire. La gestion de l'environnement et des ressources naturelles, le conseil en organisation et en management de la recherche sont parmi les priorités d'ECART. Ce consortium d'institutions autonomes et à mandats similaires est ouvert à la coopération avec tous les partenaires, du Nord comme du Sud. La création d'ECART est un acte de foi dans la mission d'aide que les pays européens se doivent de remplir envers les pays du Sud, en se coordonnant toujours plus étroitement.

Les liens avec la communauté scientifique internationale, en particulier avec les centres internationaux de recherche agricole, fédérés au sein du GCRAI, se renforcent. Le CIRAD coopère avec la plupart de ces centres à travers des accords-cadres, signés aussi par l'INRA et l'ORSTOM. En 1992, de nouveaux accords de ce type ont été passés avec I'INIBAP en mars, I'ADRAO et I'IFDC en juin, I'ILRAD en octobre. Quatre réunions de concertation ont permis d'évaluer les résultats des travaux communs et d'en programmer de nouveaux. Elles ont eu lieu entre le CIRAD, I'INRA, I'ORSTOM d'une part, et le CIMMYT, en février à Mexico, I'IRRI, en mars à Los Baños, le CIP, en avril à Paris, et le CIAT, en novembre à Cali. Près $d^{\prime}$ 'une trentaine de chercheurs des trois organismes français travaillent en coopération dans ces centres internationaux. Une quinzaine d'entre 
eux sont des agents du CIRAD. Une concertation s'est engagée avec I'IITA à Ibadan en juin.

\section{Des recrutements exigeants et une formation permanente renforcée}

Le renforcement des capacités scientifiques du CIRAD repose à la fois sur une politique de recrutement de jeunes chercheurs titulaires d'un doctorat et sur la formation interne.

Une analyse des effectifs des cadres scientifiques montre que le secteur de l'agronomie est fortement représenté ( $36 \%$ ), ceux de l'amélioration des plantes $(14 \%)$ et de la protection des cultures ( $11 \%$ ) bien équilibrés. En revanche, les secteurs de l'économie et de la sociologie (6\%), de la production animale ( $9 \%$ ) et de la technologie $(10 \%)$ doivent être renforcés, compte tenu de leur importance croissante dans la stratégie du CIRAD. La politique de recrutement favorise donc ces trois dernières disciplines.

De même, la formation des allocataires de recherche - dont certains seront à terme recrutés par le CIRAD — va naturellement dans le sens des besoins de l'établissement. En 1992, le CIRAD a encadré 8 boursiers qu'il finance directement, 67 boursiers du ministère de la Recherche et de l'Espace et une vingtaine de boursiers d'autres organismes. En outre, 40 jeunes docteurs mènent une partie de leurs travaux dans les laboratoires du centre.

Le renforcement de la qualification des agents du CIRAD est perçu comme une autre priorité. La proportion de chercheurs titulaires d'un doctorat est encore insuffisante et doit être, dans un délai de cinq à sept ans, nettement accrue. En amélioration des plantes et en protection des cultures, cette proportion est déjà presque satisfaisante ; en agronomie, le faible pourcentage de docteurs s'explique en partie par l'absence de formations doctorales correspondant à l'approche du CIRAD dans ce domaine. Les agronomes ont pourtant accumulé sur le terrain une précieuse expérience du développement; il faut les inciter et les aider à la mettre en valeur en créant les conditions internes propres à la préparation de thèses. 


\section{Une stratégie 2. A de coopération}

Le renforcement scientifique du CIRAD n'a qu'un but : améliorer la contribution de ses agents au développement des régions chaudes. Par tradition, par volonté et en conformité avec son mandat, le CIRAD a choisi la voie de la coopération avec des partenaires multiples : institutions nationales de recherche du Sud, organisations régionales, mais aussi acteurs du développement et producteurs pour mieux comprendre, en se rapprochant du terrain, les dynamiques paysannes et rurales et en déduire les besoins de recherche.

\section{Un partenariat très diversifié}

A la fin de 1992, 365 scientifiques du CIRAD travaillaient dans 51 pays en développement. De nombreux agents participent à des projets de développement, ce qui explique la présence du centre dans un si grand nombre de pays. Mais le dispositif de coopération reste organisé, pour les objectifs de recherche à long terme, autour d'un nombre limité de pays : 12 d'entre eux accueillent plus de $70 \%$ des expatriés du CIRAD.

La présence en Afrique et dans les îles de l'océan Indien reste la plus forte : 27 pays, dont 9 bénéficient d'effectifs supérieurs à la dizaine. Les partenaires sont très nombreux, allant des institutions nationales de recherche à des entreprises privées, en passant par des sociétés de développement et des organisations non gouvernementales.

On trouve aussi des chercheurs du CIRAD dans 13 pays de I'Amérique latine et de la Caraïbe, et 11 pays d'Asie et d'Océanie. Les plus fortes concentrations se rencontrent au Brésil, en Indonésie et au Vanuatu. Le partenariat y est également diversifié.

Dans l'ensemble de ces pays, le CIRAD coopère avec plus d'une centaine de partenaires.

Ce dispositif géographique est resté relativement stable en 1992, par rapport à 1991. Seuls, la Côte-d'Ivoire et, à un degré moindre, le Togo, où le CIRAD s'est désengagé de la gestion des structures nationales, ont vu le retrait d'un nombre significatif d'agents. 


\section{LE CIRAD EN 1992}

En 1992, comme chaque année, le CIRAD a signé des accords-cadres avec des partenaires engagés avec lui sur des programmes à long terme : I'IRAZ, institut régional d'Afrique centrale, I'AFRD (Indonésie), I'ICSB (Malaisie), I'IER (Mali).

\section{De la concertation régulière aux contrats de recherche en coopération}

Définir des objectifs d'intérêt commun et les traduire en projets de recherche conjoints sont des exercices familiers au CIRAD et à ses nouveaux partenaires de la dernière décennie, tel I'EMBRAPA, au Brésil. Le même exercice est plus malaisé avec les anciens partenaires du CIRAD, auxquels nous lie une longue histoire. L'organisation de réunions annuelles de concertation permet de progresser dans cette voie.

En 1992, six d'entre elles se sont tenues avec nos principaux partenaires : le FOFIFA à Madagascar, le MRSTD au Cameroun, I'ISRA au Sénégal, le CNRST au Burkina Faso, I'EMBRAPA au Brésil et I'IDESSA en Côte-d'Ivoire.

Des thèmes d'intérêt commun ont été identifiés. Des projets pluriannuels de recherche en coopération ont souvent été définis. II reste à les contractualiser. Dans certains cas, des structures associatives ont été bâties pour faciliter la gestion partagée de pôles de recherche, comme celui de Garoua pour la diversification des cultures en zone cotonnière et celui de Nyombé pour la banane plantain, tous deux au Cameroun.

Ces projets sont financés de manière multiple : les contributions du CIRAD, I'aide française et aussi les fonds européens (directions générales de la CCE, dont les appels d'offres "Science et technique pour le développement »). II s'agit de projets de recherche, parfois régionaux, associant des laboratoires européens et des institutions du Sud.

Une carte de nos principales implantations se dessine, peu à peu, autour d'une vingtaine de contrats de recherche en coopération, qui devraient être finalisés en 1993.

En revanche, le retrait de la gestion des instituts de recherche du Sud ivoirien, décidé par le CIRAD à la fin de 1991, n'a pas été suivi 
d'une relance de la coopération, malgré la volonté du centre et la tenue d'une réunion en février à Abidjan.

Tout en conservant un effectif minimal afin d'assurer le maintien de recherches d'intérêt stratégique sur l'amélioration génétique du cocotier, de I'hévéa et du palmier à huile en particulier, le CIRAD a tiré les conséquences de cette situation équivoque en poursuivant le rapatriement de ses cadres. De 46 à la fin de 1991, ils n'étaient plus que 26 à la fin de 1992 à travailler au sein de I'IDEFOR, structure ivoirienne en cours de création, qui a repris les activités des instituts du Sud autrefois gérés par le CIRAD. Au contraire, la coopération avec I'IDESSA, dont le siège est à Bouaké, s'est poursuivie dans un esprit de continuité.

\section{L'appui aux organisations régionales}

L'année 1992 a vu la reconnaissance politique de la CORAF, à l'occasion de la réunion, en mars à Dakar, de vingt ministres africains responsables de la recherche agricole. Elle a vu aussi son élargissement à de nouveaux pays, la Gambie, le Burundi et le Rwanda, portant ainsi à vingt et un le nombre des institutions africaines membres.

Le CIRAD est un membre associé actif de la CORAF, aux côtés de I'ORSTOM et de I'INRA. Plusieurs de ses scientifiques participent activement à ses réseaux de recherche (maïs, riz, arachide, coton, résistance à la sécheresse). Les bases-centres qui devaient accompagner ces réseaux n'ont pas toutes vu le jour. Malgré cela, la CORAF s'affirme comme un moyen puissant de collaboration entre les systèmes nationaux de recherche agricole. Grâce à elle, une véritable communauté scientifique a pu émerger ces dernières années en Afrique. Le CIRAD est fier d'y avoir contribué.

Le SPAAR, qui avait défini en 1991 son plan d'action pour le Sahel, s'est attelé en 1992 à celui des zones humides d'Afrique, au cours de réunions à Abidjan et Abuja auxquelles ont participé des experts invités du CIRAD. Par ailleurs, le centre de Montpellier a accueilli, en mars, un atelier de travail du SPAAR consacré à la mise en place d'une base de données des projets de recherche agricole. 


\section{LE CIRAD EN 1992}

\section{Le rôle des DOM-TOM}

Près de 370 agents du CIRAD exercent leur activité dans les départements et territoires d'outre-mer (DOM-TOM), dont 88 cadres scientifiques. Leur situation particulière, entre les expatriés travaillant en coopération à l'étranger et les métropolitains, leur permet d'exercer une double mission.

Membres d'un établissement public de recherche français, ils conduisent des recherches finalisées par les besoins de l'agriculture de ces régions. Les objectifs de ces travaux, leurs modalités d'exécution et les moyens mis en œuvre procèdent d'une concertation approfondie avec les autorités politiques et administratives et les organisations professionnelles locales, qui contribuent à leur financement.

Une rénovation de ces processus de concertation se mettra en place en 1993.

Les établissements de recherche présents dans les DOM-TOM (CIRAD, INRA, ORSTOM, CEMAGREF) doivent eux-mêmes se concerter pour une plus grande efficacité dans leurs actions.

Mieux connaître les besoins de ces agricultures tropicales, qui appartiennent à un ensemble développé, pour pouvoir mieux y répondre, tel est I'un des objectifs du CIRAD. En 1992, à la Réunion, une recherche prospective sur I'agriculture du département a débuté, à I'initiative du Centre. Elle mobilise tous les chercheurs de la Réunion et reçoit un appui méthodologique de plusieurs organismes métropolitains. On attend de ses conclusions la possibilité de mieux définir le dispositif de recherche de ce département pour une meilleure adéquation avec le développement économique.

La seconde mission des agents du CIRAD dans les DOM-TOM est de conduire des recherches intégrées dans les programmes de leur département. Dans plusieurs domaines, comme la défense des cultures, des pôles de recherche en milieu tropical sont irremplaçables. Ils permettent à la fois la formation de jeunes scientifiques et le rayonnement régional des recherches. Deux rôles complémentaires qui devraient se développer à l'avenir, en liaison avec le renforcement des laboratoires. 


\section{Un fonctionnement souple et adaptable}

Le projet d'entreprise du CIRAD inspire ses choix et ses activités. II n'est pas pour autant un document intangible, dont la mise en œuvre servile serait paralysante. II en est de même des schémas pluriannuels de programmation des départements, et il serait absurde de les considérer autrement. Le monde continue à changer, parfois dramatiquement. Cela implique à la fois de poursuivre la réflexion stratégique et d'avoir des règles de fonctionnement claires, acceptées par tous, pour pouvoir s'adapter le plus rapidement possible à la réalité.

\section{Les principes d'organisation}

La mise en pratique des réflexions engagées dans le cadre du projet d'entreprise a permis de dégager des principes simples d'organisation, fondés sur la déconcentration des responsabilités opérationnelles. Garante de l'unicité de l'établissement, la direction générale élabore les grandes orientations du centre, fixe les objectifs des actions des départements, arbitre les moyens qui leur sont consacrés et contrôle l'exécution de ses directives. Unités opérationnelles, les départements disposent d'une véritable délégation de pouvoir pour définir les programmes et engager les moyens humains et financiers nécessaires à leur exécution. Cette responsabilité des opérations, sous-tendue par une gestion déconcentrée, permet aux départements de répondre avec efficacité aux changements qui se produisent dans leur environnement.

$C^{\prime}$ est en conformité avec ces principes que les départements conçoivent leur organisation interne dans le cadre de leur schéma pluriannuel de programmation.

\section{La qualité des ressources humaines}

La qualité des ressources humaines d'un organisme de recherche constitue sa principale richesse. Pour le CIRAD, dont le dispositif géographique est éclaté, cette qualité est primordiale. Le choix de recrutements de haut niveau et l'effort de formation continue en sont deux aspects. Mais une véritable politique des ressources humaines 
ne peut s'y limiter : la connaissance des besoins futurs et des potentiels, l'évaluation individuelle, la carrière et la mobilité des agents, les modalités d'intervention — l'expatriation en particulier -, la communication interne sont, avec le recrutement et la formation, autant de « chantiers » que le centre a décidé d'ouvrir en 1992.

\section{La réflexion stratégique}

La conception du projet d'entreprise a montré la nécessité d'une analyse prospective, qui, répétons-le, doit être conduite en continu. Conscient des changements qui se produisent dans notre environnement - dans les pays en développement comme dans les pays développés et de leur impact sur la stratégie du CIRAD, le centre a lancé, à la fin de 1992, une réflexion prospective. Le groupe de travail qui en est chargé a pour objectif de proposer au comité de direction du CIRAD des axes stratégiques à l'horizon de dix années.

Il est composé d'une quinzaine de chercheurs du CIRAD et fera appel à des experts du centre ou de l'extérieur sur des questions particulières. II remettra son rapport au début de 1994.

\section{Une expression 2. Prache et diversifiée}

Exposer et faire savoir ce que l'on fait est une exigence pour tout organisme de recherche dont les moyens dépendent en grande partie de la notoriété qu'il acquiert. C'est aussi un puissant moyen de cohésion et de dynamisation interne. Une politique globale de communication a été définie à la fin de 1991 et mise en œuvre selon un plan d'action précis.

Ce plan concerne tant la charte graphique et le logo de l'entreprise, conçus afin de lui donner une image forte et homogène, que le secteur crucial des relations avec les médias et la société. Communiqués et réunions de presse, bulletins d'information - CIRAD Information et Horizons Sud en direction du personnel du CIRAD, CIRAD Echos (et sa version anglaise CIRAD News) en direction de l'extérieur -, journées portes ouvertes dans les centres de métropole et des départements d'outre-mer, participation à des expositions sont 


\section{LE CIRAD EN 1992}

I'occasion de faire connaître les compétences et les domaines d'activité du centre. En 1992, le CIRAD a participé à de nombreuses manifestations collectives : citons, en France, le salon international de la machine agricole, Expobois, Terre d'avenir, la fête de la science, Forum Agro et Forum Bio ; à l'étranger, la CNUED et le salon des technologies de l'environnement (Brésil), la semaine franco-cambodgienne de l'agriculture, la conférence de Miami sur les investissements, le commerce et le développement, etc.

Le plan de communication du CIRAD concerne aussi l'expression scientifique proprement dite. Le centre a décidé de réformer profondément ses publications scientifiques. D'une part en encourageant la publication des travaux de recherche originaux dans les revues internationales faisant autorité dans leur domaine. D'autre part en rénovant les périodiques de ses départements en faveur d'un public professionnel et des agents du développement. Enfin, en mettant sur pied de nouvelles collections.

Les colloques sont aussi des lieux d'échange et d'expression. Ils permettent aux chercheurs de faire le point avec la communauté scientifique internationale sur les résultats les plus récents. Le centre de recherche de Montpellier a ainsi été le cadre, en 1992, de rencontres internationales organisées par le CIRAD sur des thèmes aussi divers que l'amélioration génétique du bananier, la transformation des produits vivriers, la sélection du palmier à huile, le secteur agricole et l'économie institutionnelle. A l'étranger, le CIRAD a coorganisé de nombreuses manifestations, comme l'atelier sur les Phytomonas en Colombie, le séminaire sur les Phytophthora des cocotiers en Indonésie, la conférence des institutions de médecine vétérinaire tropicale en Côte-d'Ivoire, le symposium sur l'élevage en fermes en Espagne, et le colloque sur la surveillance de la déforestation en Asie du Sud-Est. 


\section{Département des cultures annuelles}

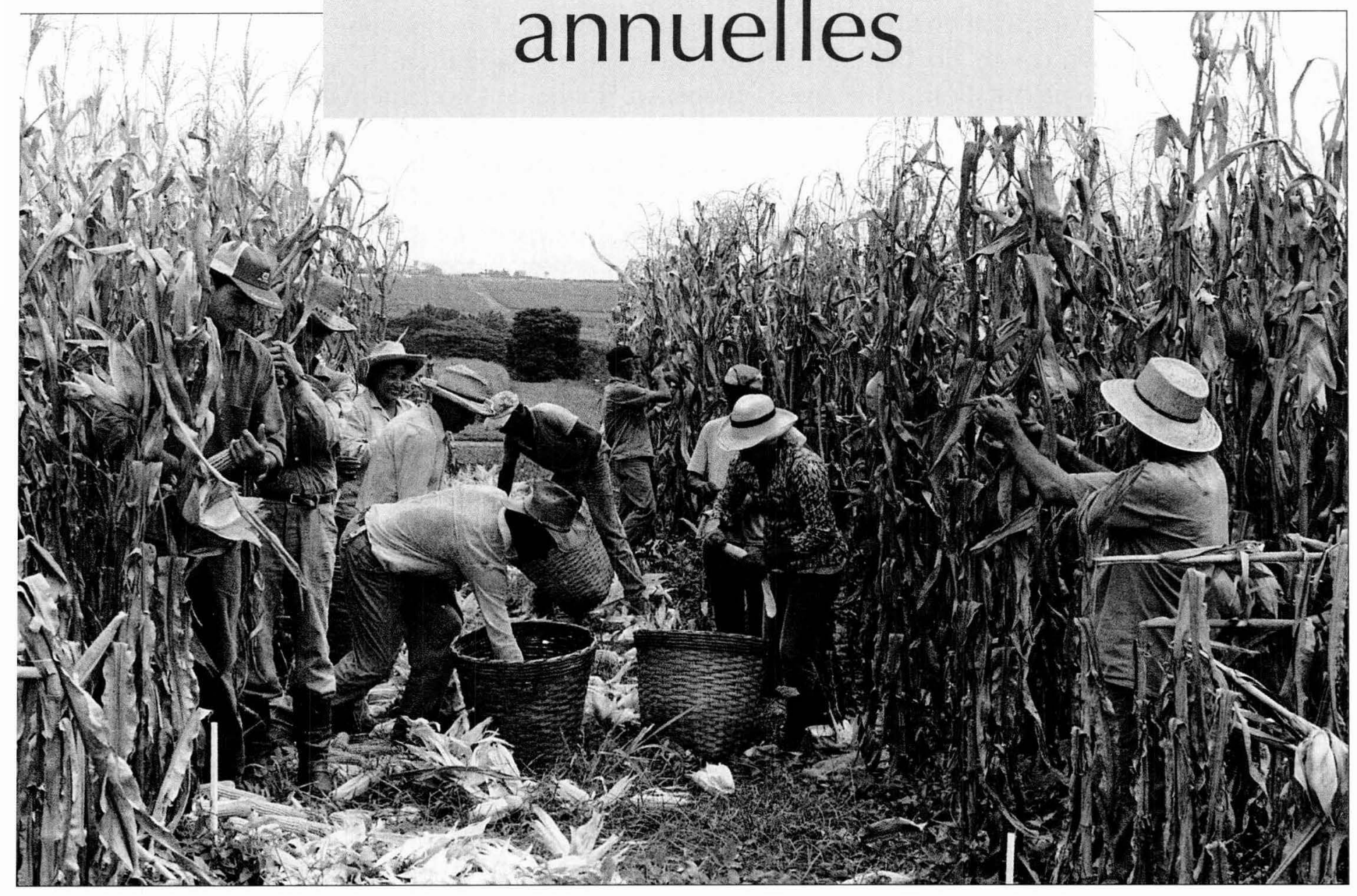

Le développement durable des agricultures fondées sur des plantes annuelles, vivrières et de rente, est inséparable d'une gestion adéquate des ressources naturelles. Les systèmes de culture doivent par conséquent être abordés à l'échelle de successions culturales combinant céréales,

légumineuses, plantes à tubercules et, dans les écologies propices, le coton. L'intensification de la production - exigée par la croissance des populations - est l'autre face du progrès des agricultures du Sud.

Par ses recherches finalisées, le nouveau département des cultures annuelles du CIRAD contribue à relever l'ensemble de ces défis. 


\section{CULTURES ANNUELLES}

e département des cultures annuelles est né en 1992 du regroupement des activités de recherche du CIRAD sur les cultures vivrières et le milieu naturel (IRAT), le cotonnier (IRCT) et les oléagineux annuels (division de I'IRHO), et conserve les mandats de ces départements.

Ce rapprochement favorise les travaux sur les systèmes de culture : il permet de prendre en compte les assolements et successions de l'ensemble des productions vivrières et industrielles annuelles. L'amélioration durable de ces systèmes et la gestion de l'environnement - préoccupations croissantes des agricultures tropicales — peuvent dès lors être considérées dans un cadre global. Ainsi en va-t-il de l'étude de l'évolution à long terme de la fertilité des sols, de la valorisation de l'eau, de la lutte contre l'érosion, de la flore adventice, de l'entomofaune des cultures.

Cinq programmes ont été mis en place par le département pour répondre aux grandes questions soulevées par le développement des différentes formes $d^{\prime}$ agriculture que l'on rencontre en zone tropicale.

Les cultures vivrières paysannes posent des problèmes spécifiques, en grande partie liés à la très faible quantité $d^{\prime}$ intrants utilisables pour assurer la production, la protection des plantes, la conservation de la fertilité des sols, la reproductibilité en termes économiques. L'adaptation aux aléas climatiques pour obtenir une production aussi régulière que possible est un des éléments clés de ces systèmes : elle repose sur la sélection de variétés et la mise au point de techniques de culture appropriées à ces conditions de pénurie.

Dans les zones écologiques où elle est possible, la culture du coton permet, par les revenus qu'elle procure, le recours aux intrants. Cette intensification est souvent associée au développement de la culture attelée ou même motorisée et à la diversification des cultures.

Par ailleurs, la progression rapide de la population oblige à intensifier la production. Lorsque le manque d'eau n'est plus le facteur limitant principal (climat favorable ou irrigation), on peut avoir recours à l'ensemble des facteurs de production - engrais, pesticides, mécanisation - qu'il faut combiner de façon cohérente. Il incombe à la recherche de mettre au point des systèmes de culture adaptés à la diversité des situations.

La consommation des légumes, notamment dans les villes, ne cesse de croître. Une forte demande de recherches sur les productions maraîchères émerge des pays du Sud. Un programme étudie les systèmes de culture dans lesquels elles entrent.

Enfin, la canne à sucre, inscrite dans le mandat de I'IRAT à sa création, fait l'objet d'un programme distinct, cette culture constituant soit un système spécifique dans les grands domaines d'usine, soit un moteur possible du développement agricole lorsqu'elle est produite sur de petites surfaces.

Pour chaque programme, et toujours avec le souci de produire des résultats directement valorisables, l'accent est mis sur l'étude de la diversité des systèmes de culture et de leur environnement. Des méthodes de diagnostic in situ et des modèles d'aide à la décision sont développés.

En effet, un des enjeux majeurs pour la recherche est que ses résultats soient proposés de moins en moins sous forme de conseils normatifs, les " paquets technologiques ", conçus de manière trop générale pour être réellement adaptés à la diversité des situations. Le travail avec les agriculteurs permet d'obtenir les résultats scientifiques qui sont à la base de la conception de systèmes de culture très adaptés à la réalité.

Cette exigence implique d'aller au-delà de l'étude des espèces végétales et des systèmes de culture. Les recherches englobent les produits - grains, fibres et la technologie de leur transformation ainsi que l'étude du fonctionnement économique des filières.

Elles sont conduites en collaboration avec les autres départements du CIRAD et les institutions de recherche françaises et européennes, et en coopération avec les systèmes de recherche agronomique nationaux, régionaux et internationaux. 


\section{Programme} cultures vivrières

\section{paysannes}

Proposer des itinéraires techniques et des systèmes de culture fixés qui permettent une amélioration durable de la productivité des exploitations agricoles

\section{DÉPARTEMENT DES CULTURES ANNUELLES}

\section{CIRAD-CA}

$\begin{aligned} \text { Directeur } & \text { Didier Picard } \\ \text { Directeur scientifique } & \text { Jean-Claude Follin } \\ \text { Directeur des programmes } & \text { Alain Derevier } \\ \text { Directeur délégué } & \\ \text { aux relations internationales } & \text { Harry Palmier } \\ \text { Directeur } & \\ \text { administratif et financier } & \text { Jean-Louis Caminade }\end{aligned}$

\section{Programmes de recherche}

Cultures vivrières paysannes Cultures cotonnières paysannes Canne à sucre Cultures intensifiées Cultures maraîchères

\section{Unités de recherche}

Connaissance et amélioration des plantes annuelles Fonctionnement du peuplement végétal Systèmes de culture Facteurs et conditions du milieu Gestion de l'eau Phytopathologie et malherbologie Entomologie appliquée Biométrie et informatique Technologie cotonnière Technologie des céréales Economie des filières

\section{Services d'appui technique}

Publications, information, documentation Hervé Saint Macary et de la fertilité des sols en limitant le recours aux intrants, faire en sorte que les petits agriculteurs soient en mesure de se les approprier, tels sont les objectifs du programme sur les cultures vivrières paysannes. La place de ces systèmes dans une économie de marché est un autre paramètre pris en compte.

\section{Le riz d'altitude à Madagascar}

Sur 1,3 million d'hectares de rizières à Madagascar, la moitié se situe au-dessus de 1000 mètres d'altitude. Les recherches sur le riz d'altitude conduites en coopération par le CIRAD et le FOFIFA intéressent la riziculture pluviale entre 1200 et 1600 mètres et la riziculture aquatique de 1600 à 2000 mètres.

En riziculture pluviale, trois variétés introduites permettent d'obtenir des rendements en milieu paysan de 2 à 3,5 tonnes à l'hectare. A la fin de la campagne 1992-1993, les premières variétés issues d'une création variétale, bien adaptées au milieu et présentant des potentiels de rendement très élevés (5 à 6 tonnes à l'hectare en essais en station), seront proposées à la vulgarisation.

En riziculture aquatique, les contraintes de la bactériose et du froid commencent à être surmontées. Des lignées en fin de stabilisation présentent une meilleure régularité de rendement que la population locale de référence (Latsidahy). La sélection récurrente vise à obtenir un matériel végétal encore mieux adapté.

Pour améliorer les sols à forte teneur en matière organique, biologiquement peu actifs, différentes techniques culturales sont testées : formes de fertilisation minérale, pratique de la culture de contre-saison, écobuage, techniques de repiquage et semis directs.

Les retombées internationales de ces recherches sont importantes, car elles concernent tous les pays tropicaux, subtropicaux et méditerranéens confrontés aux problèmes du froid (altitude et latitude). Déjà, certaines lignées pluviales testées au Népal ont montré un comportement très satisfaisant. 


\section{Amélioration variétale de l'arachide}

Un programme de sélection pour l'amélioration de la tolérance à la sécheresse de l'arachide, réalisé en collaboration avec I'ISRA au Sénégal et la direction de la recherche agricole au Botswana, a abouti à la diffusion de nouvelles variétés.

Deux stratégies d'amélioration ont été mises en œuvre. La première consiste à rechercher par rétrocroisement et sélection généalogique une précocité extrême, permettant d'éviter la sécheresse. Deux variétés, GC 13 et GC 8-35, sont de dix jours plus précoces que les variétés vulgarisées. En comparaison de la variété sénégalaise 55-437, la variété GC 8-35 atteint un rendement en gousses supérieur de 160 kilos à l'hectare et un poids de 100 graines supérieur de $22 \%$. De nouvelles lignées $\mathrm{F}_{4}$ sont très prometteuses. La seconde stratégie vise à associer des facteurs de résistance au stress hydrique dans une même variété : enracinement, contrôle de la transpiration, résistance membranaire et redistribution des assimilats.

Deux cycles de croisements permettant un brassage génétique à partir de huit variétés ont été réalisés et une extraction de lignées est en cours par sélection généalogique.

Un échange variétal avec la Chine a montré au Sénégal l'intérêt de la variété Fleur 11, qui commence à être vulgarisée. Elle apporte un gain de rendement de $30 \%$ par rapport à la variété 55-437, et la qualité de ses graines est conforme aux normes du marché de l'arachide de confiserie, beaucoup plus rémunérateur que le marché traditionnel de l'huilerie.

\section{Gestion de terroirs en Côte-d'Ivoire}

En Côte-d'Ivoire, la dégradation rapide du milieu naturel est très préoccupante. Dans le Nord, en zone cotonnière, I'érosion est intense et les rendements des cultures sont faibles. Le bois de chauffe devient rare, la fertilité se dégrade rapidement et l'alimentation du bétail est insuffisante en saison sèche. Dans le Sud, en zone forestière, la pratique de l'agriculture itinérante pour les cultures vivrières (riz pluvial surtout) contribue à la disparition rapide des massifs forestiers.
Face à cette situation, le CIRAD et I'IDESSA ont mis en place un dispositif original de recherche chez des agriculteurs, en liaison avec les partenaires du développement agricole.

Le paysage agricole est rapidement transformé : les cordons antiérosifs installés sont fixés par des espèces pérennes (cultures de rente, bois de chauffe, espèces fourragères) et des haies vives forment un véritable bocage protégeant le terroir contre l'érosion et la divagation des animaux. A l'intérieur de ces aménagements, différents systèmes de culture, associés à l'élevage et gérés à plusieurs niveaux d'intensification, offrent une gamme de possibilités nouvelles, parmi lesquelles les producteurs peuvent faire des choix.

En quatre ans, le bénéfice net des exploitations et la productivité du travail sont multipliés par deux pour les systèmes les plus performants.

L'effort porte maintenant sur la suppression du travail du sol et l'installation d'une couverture permanente (mulch ou plante semée en culture dérobée), qui conjuguent économie de main-d'œuvre et lutte contre l'érosion et semblent spécialement appréciées des agriculteurs.

Ces dispositifs de recherche jouent un rôle de "vitrine", support de formation pour les agriculteurs, les chercheurs et les agents du développement. Les techniques et les aménagements proposés se répandent rapidement dans le Nord.

\section{Couverture permanente des sols à la Réunion}

Dans les Hauts de l'ouest de la Réunion, la monoculture du géranium rosat entraîne une baisse de rendement liée à l'appauvrissement des sols et à la prolifération des adventices et des maladies.

Des systèmes très améliorés associant des cultures vivrières et maraîchères au géranium sont mis au point avec les agriculteurs. Ils mettent en jeu des techniques avec travail minimal du sol et couverture végétale permanente. En particulier, trois modes majeurs 


\section{CULTURES ANNUELLES}

de gestion des sols sont comparés depuis 1991 :

sol nu, couverture de kikuyu (Pennisetum clandestinum) ou de lotier velu (Lotus uliginosus).

\section{Des produits pour le développement}

\section{Des produits à base de maïs pour l'Afrique}

La méthode traditionnelle employée au Mexique pour la fabrication des tortillas

repose sur un traitement alcalin du maïs.

En cuisant le maïs dans de l'eau additionnée

de chaux, on supprime le décorticage.

Cette technique est inconnue au Sénégal.

Après étude et mise au point par le laboratoire

de technologie des céréales, elle y a été introduite

et appliquée aux variétés les plus cultivées.

Pour s'adapter aux goûts locaux, le goût de chaux

a été neutralisé par addition de jus de citron et des produits nouveaux ont été mis au point.

Un atelier de production installé à Ziguinchor par des partenaires locaux, dont le Centre régional d'enseignement technique féminin (CRETF), a démontré sa rentabilité.

Une gamme de produits roulés sous forme de petites billes - aklui, yéké-yéké, arraw, couscous - est traditionnellement

fabriquée en Afrique à partir de différentes céréales.

En vue d'une fabrication semi-industrielle,

le laboratoire de technologie des céréales a déterminé les conditions optimales de granulométrie des farines et d'hydratation pour le mil souna et pour dix variétés de maïs du Mali, du Sénégal et du Bénin.

Les conditions de fabrication ont été optimisées et on obtient $90 \%$ de rendement en produits finis. Le premier prototype de rouleur-calibreur conçu par le laboratoire et construit par la société Afrem a été installé à la faculté des sciences agronomiques de Cotonou. Un deuxième rouleur, simplifié, prévu pour une capacité de 40 kilos à l'heure, est actuellement testé par le département des systèmes agroalimentaires et ruraux du CIRAD.
La couverture permet de contrôler l'érosion et améliore l'infiltration de l'eau, les caractéristiques physicochimiques du sol, les restitutions de matière organique et l'activité microbienne.

Des modifications de la faune favorables aux cultures se manifestent : les dégâts causés notamment au géranium par le ver blanc, Hoplochelus marginalis, et par Cratopus humeralis, insecte défoliateur, ainsi que les attaques d'Ophyomia phaseoli sur le haricot, diminuent.

Les couvertures limitent la prolifération des adventices mais peuvent aussi gêner les cultures ou les opérations culturales. Elles doivent donc être maîtrisées par des herbicides très spécifiques (fluazifop-p-butyl pour le kikuyu, bentazone pour le lotier). On peut aussi utiliser des plantes de couverture à port toujours rampant (Arachis pintoi, Axonopus affinis, etc.).

\section{Lutte contre le Striga au Mali}

En zone soudanienne, Striga hermonthica est la plante parasite la plus nuisible, spécialement pour les céréales. Des travaux, réalisés en collaboration avec l'ICRISAT au Mali, portent sur l'étude de techniques simples et peu coûteuses pour les agriculteurs.

Après quatre années d'essais conduits en milieu paysan, trois techniques de lutte peuvent être retenues:

les herbicides, le sarclage, la résistance variétale.

Les essais ont montré que le 2,4-D, le turflon et le triclopyr en pulvérisation foliaire, soit en prélevée soit en postlevée, ont une excellente efficacité contre la levée du Striga (chute jusqu'à 60 \%), avec des conséquences favorables sur les rendements des céréales (augmentation jusqu'à $115 \%$ ).

Le sarclage manuel à 70 jours après semis permet de maîtriser le développement du Striga. Un dispositif à dents sarcleuses adaptable a été mis au point pour les paysans des zones arachidières (traction asine). Cet outil a été apprécié en raison de la rapidité d'intervention et de la qualité du travail.

Les variétés de céréales actuellement vulgarisables ne sont pas encore résistantes ou tolérantes à $S$. hermonthica. En revanche, la résistance de deux 
variétés de niébé à $S$. gesnerioides, APL 1 (Nigeria) et 87-2 (Niger), a pu être confirmée, ainsi que leur bon niveau de tolérance à Alectra vogelii, qui produit les mêmes effets que le Striga.

\section{La gestion du risque hydrique}

Dans le bassin arachidier sénégalais, on constate une variabilité très importante de la productivité des cultures pluviales. Les travaux menés en agroclimatologie avec I'ISRA visent à discerner les parts respectives des conditions climatiques et des pratiques culturales dans cette variabilité.

Les indices climatiques construits à partir des cumuls pluviométriques et de la demande évaporative apparaissent insuffisants pour caractériser l'alimentation hydrique des cultures. Des indicateurs plus pertinents, fondés sur les termes du bilan hydrique, ont été mis au point : évapotranspiration réelle (ETR) pendant le cycle, rapport entre I'ETR et l'évapotranspiration maximale à la floraison et à la maturation. Ils tiennent compte de l'alimentation en eau de la culture aux phases où elle est plus spécialement sensible au stress.

Des mesures de productivité du mil, réalisées dans le cadre d'un projet du FAC sur plus de cent parcelles paysannes réparties dans différents agrosystèmes du bassin arachidier, ont été mises en relation avec ces indicateurs et les itinéraires techniques pratiqués : les rendements sont en général limités par les faibles restitutions d'éléments fertilisants, un mauvais contrôle des adventices, et, dans le sud de la région, par un ruissellement important.

D'autre part, des expérimentations en station ont permis d'étudier les effets directs des pratiques culturales sur l'alimentation hydrique des cultures. Des progrès ont été accomplis dans la modélisation de ces effets. L'application des modèles améliorés permet d'évaluer le risque pris par l'agriculteur en fonction de ses pratiques culturales.

En raisonnant ainsi l'intensification agricole en termes de risque, on peut comprendre l'échec de certaines politiques de développement, ou inversement déterminer le système des prix des produits et des intrants qui pourrait permettre l'intensification dans une région donnée.

\section{Circuits économiques du riz}

Un nouveau terrain d'observation des formes de riziculture et des performances des filières riz a été lancé dans le sud de la Guinée, en région forestière. Les premiers travaux confirment les conclusions antérieures de la Banque mondiale, selon lesquelles la riziculture guinéenne est compétitive par rapport au riz importé. Toutefois, en raison des coûts de transport, cet avantage des riz du Sud sur le marché intérieur n'est réel que dans les zones relativement proches des lieux de production ; ils ne peuvent atteindre à un prix compétitif les grands centres de consommation comme Conakry ou Labé. Par ailleurs, deux types de riziculture sont à promouvoir : la riziculture de bas-fond avec aménagement léger et la riziculture pluviale.

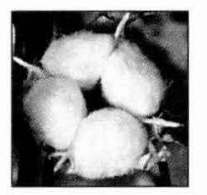

\section{Programme cultures cotonnières paysannes}

Le coton est, pour des millions d'agriculteurs défavorisés, la seule source de revenus monétaires. Par des achats d'engrais et de matériels agricoles, il leur permet d'améliorer globalement leur exploitation et leur niveau de vie. Augmenter la productivité en respectant I'environnement, améliorer la qualité du produit et en diversifier les usages, tels sont les enjeux du développement des régions cotonnières.

Pour y contribuer, le programme des cultures cotonnières tend à proposer des systèmes de culture durables et travaille sur tous les aspects de la filière : création de variétés, techniques culturales, traitement et valorisation du produit — filature, huilerie, trituration -, économie. 


\section{Résistance des insectes aux pesticides}

L'utilisation généralisée des pyréthrinoïdes fait apparaître des phénomènes de résistance chez certains déprédateurs. Cela a été diagnostiqué chez la chenille polyphage Spodoptera littoralis dans des pays producteurs de coton comme l'Egypte, la Turquie, Madagascar, et l'étude des mécanismes régissant ce phénomène a été entreprise.

\section{Des produits pour le développement}

\section{Une nouvelle technique de traitement phytosanitaire}

Les traitements insecticides en ultra-bas volume (UBV) se sont très largement développés en Afrique en raison de leur facilité de mise en œuvre par rapport aux traitements classiques avec des pulvérisateurs à dos, qui nécessitaient 150 à 200 litres d'eau à l'hectare. En contrepartie, leur efficacité n'est assurée que si les conditions de réalisation sont bien respectées. De plus, le faible litrage appliqué ne permet pas toujours de bien traiter des insectes difficiles à atteindre, situés sous ies feuilles, comme Bemisia tabaci, ou les insectes peu sensibles à ce type de traitement, comme les piqueurs-suceurs. C'est pourquoi une nouvelle technique de traitement a été développée, le bas volume (10 litres d'eau à l'hectare), qui permet de pallier ces inconvénients tout en gardant les avantages de l'UBV. Pour cela, on utilise les mêmes appareils, mais on leur a adjoint une nourrice de 5 litres. Cette technique qui améliore les traitements, d'abord expérimentée au Cameroun, connaît actuellement un grand développement. Pour 1993, on estime que, sur un total de 1,2 million d'hectares cultivés en coton, 200000 hectares seront traités de cette façon : 95000 hectares au Tchad, 40000 hectares au Cameroun, 20000 hectares au Mali, la totalité de la culture cotonnière sénégalaise, soit 45000 hectares.
Les tests toxicologiques ont montré que la dose létale de la deltaméthrine pour la souche égyptienne résistante de $S$. littoralis est environ mille fois supérieure à la dose létale pour la souche sensible. II n'y a pas de modification dans la pénétration de l'insecticide à travers la cuticule des larves des deux souches.

La résistance n'est donc pas due à des phénomènes physiques; elle a une origine physiologique. Le métabolisme enzymatique est l'un des mécanismes responsables de la résistance aux pyréthrinoïdes chez ce lépidoptère : les études entreprises ont mis en évidence une activité oxydasique beaucoup plus élevée chez la souche résistante, dont l'activité estérasique semble également plus importante.

L'origine polygénique de la résistance à la deltaméthrine a été démontrée en réalisant des croisements entre souches sensibles et résistantes.

\section{Systèmes de culture cotonnière en Asie du Sud-Est}

En Thaillande, une coopération s'est développée depuis 1991 avec l'université Kasetsart de Bangkok pour remédier à la dégradation de la production cotonnière. Les études sont conduites dans l'ouest du pays, dans la province de Kanjanaburi. L'étude de l'évolution des paysages et des fronts pionniers par télédétection, les enquêtes d'exploitation et les expérimentations avec les agriculteurs ont permis de déterminer les facteurs limitants de la culture et de les hiérarchiser pour entreprendre les recherches nécessaires.

La valeur marchande du produit doit être améliorée par la sélection de variétés à haut rendement à l'égrenage et à fibre de qualité et par l'introduction de variétés sans gossypol.

Le respect de l'environnement doit être mieux pris en compte, en particulier par l'utilisation de pesticides plus spécifiques de ravageurs comme Helicoverpa armigera et par le renforcement des défenses naturelles de la plante contre les insectes piqueurs-suceurs en sélectionnant des cotonniers pileux. 
Les mécanismes physiologiques du cotonnier, en particulier le phénomène d'abscission des capsules, sont étudiés en relation avec la modélisation du fonctionnement du peuplement végétal. Ces travaux s'intègrent à ceux menés à Montpellier et au Cameroun, en collaboration avec l'université du Mississipi.

Autour de cette opération, un réseau régional d'appui à la recherche cotonnière en Asie du Sud-Est péninsulaire se structure. Ses activités sont déjà bien développées au Laos, amorcées avec le Vietnam et pourraient débuter en 1993 avec le Cambodge dans le domaine prioritaire de la formation.

\section{La prévision des rendements en coton}

Chaque année, la CIDT (Côte-d'Ivoire) réalise des prévisions de production en coton-graine afin de gérer au mieux ses usines d'égrenage et son parc de camions et de planifier ses ventes. Ces prévisions sont établies à partir des superficies déclarées par les paysans et des rendements estimés sur la base de données obtenues pour un échantillon de parcelles. Ce système empirique reposant essentiellement sur l'expérience de l'encadrement, la mise au point d'une méthode de prévision de la production devient indispensable.

Le modèle Prevert représente une contribution significative à la prévision des rendements moyens dans les 48 zones actuelles de production encadrées par la CIDT. II prend en compte des variables climatiques (pluie et insolation), des variables agroclimatiques obtenues par interpolation ou simulation (évapotranspiration potentielle et bilans hydriques), et des variables caractérisant le système de culture (fumure, protection et entretien de la culture).

L'analyse multivariable $(\mathrm{ACP})$ des résultats obtenus sur chacune des zones au cours de la période 1983-1991 en fonction de 450 données élémentaires a établi que l'on peut regrouper les 48 zones en trois ensembles correspondant à trois sous-modèles : le Nord, l'Ouest et le Centre. Les simulations réalisées montrent que ce modèle permet d'obtenir des prévisions

\section{Coopération internationale}

\section{Stratégie phytosanitaire pour le coton en Afrique centrale}

La réunion de coordination de la recherche phytosanitaire en culture cotonnière pour la sous-région Afrique centrale s'est tenue du 3 au 5 février 1992 à N'Djamena. Cette conférence, organisée par le département des cultures annuelles du CIRAD, a réuni plus de 90 chercheurs, développeurs et représentants de firmes phytosanitaires. Elle a marqué un tournant dans l'approche des solutions préconisées pour la lutte contre les déprédateurs du cotonnier. Des exposés présentés, trois axes se dégagent: I'accentuation de la prise en compte du respect de l'environnement ; la recherche de techniques de lutte plus économiques; l'élargissement de la stratégie phytosanitaire à d'autres cultures entrant en rotation avec le coton. Les études à caractère biologique sont plus nombreuses, et la lutte biologique seule s'étant révélée insuffisante pour assurer une protection satisfaisante des cultures, le but à atteindre est la lutte intégrée. Mais celle-ci ne pourra être mise en œuvre qu'après un passage par la lutte raisonnée, qui a déjà débuté dans certains pays comme le Cameroun pour le cotonnier, ou le Tchad pour le niébé.

de récolte satisfaisantes, sauf en année climatique vraiment aberrante.

\section{Mesure de la qualité de la fibre}

Les filateurs exigeant un coton d'une qualité de plus en plus grande, la recherche crée des variétés répondant aux nouvelles normes. Les paramètres technologiques de la fibre - longueur, résistance, allongement, maturité et finesse - doivent être mesurés pendant tout le processus de sélection. Or, les analyses classiques 


\section{CULTURES ANNUELLES}

sont longues et coûteuses. De plus, pour améliorer l'efficacité de la sélection, leur nombre doit être multiplié. On a pensé à utiliser les chaînes de mesure à haute capacité, qui permettent actuellement de classer les cotons commercialisés par les Etats-Unis. II a fallu démontrer que ce matériel, conçu pour les besoins du négoce, pouvait être adapté à I'amélioration variétale.

Pour la première chaîne testée, le mode opératoire doit être modifié selon le type d'égrenage (au rouleau ou à la scie) et il faut procéder à dix mesures par échantillon pour obtenir des données suffisamment précises. Dans ces conditions, la chaîne de mesure à haute capacité devrait permettre de réaliser un grand nombre d'analyses pour un coût inférieur aux analyses conventionnelles.

Certains pays du réseau coton de la CORAF commencent à s'équiper pour classer leur production. En liaison avec la Sofitex au Burkina Faso, la CIDT en Côte-d'Ivoire et la CMDT au Mali, les programmes de recherche mettent en place les procédures d'analyse à l'aide de ce matériel.

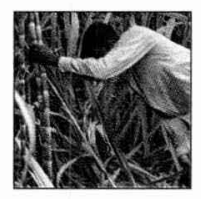

\section{Programme canne à sucre}

L'amélioration des systèmes de culture de canne à sucre fait l'objet de travaux sur des méthodes nouvelles, principalement dans les départements d'outre-mer, où vient d'être créé le Centre français de la canne et du sucre (CFCS).

\section{Biotechnologies et création variétale}

D'origine interspécifique, les variétés de canne à sucre comportent plus de 100 chromosomes, dont une minorité (moins de 20) est issue d'une espèce sauvage. Les marqueurs moléculaires (RFLP) ont permis de montrer que ces chromosomes sont transmis pratiquement entiers dans les descendances. Dès lors, l'analyse des variétés avec quelques sondes (ou marqueurs) suffit pour déterminer les chromosomes issus de l'espèce sauvage. La voie est ouverte aux criblages moléculaires pour manipuler des caractères agronomiques largement influencés par ces chromosomes. Une étude est en cours sur une descendance de la variété phare réunionnaise, $\mathrm{R} 570$.

En aval de la sélection, la conservation, la diffusion et la multiplication des variétés bénéficient des progrès de la culture in vitro. En collaboration avec I'ORSTOM, la cryoconservation a été appliquée avec succès à des cals embryogènes et à des apex de canne à sucre. Ces derniers, prélevés sur des plantes de cinq variétés cultivées in vitro puis encapsulés selon une méthode mise au point par le CNRS, ont été conservés dans l'azote liquide avec des taux de survie de 40 à $90 \%$. L'utilisation d'apex devrait préserver la stabilité génotypique, condition nécessaire à la conservation des variétés. Ces techniques compléteront le dispositif de quarantaine et la collection variétale in vitro de Montpellier.

\section{La résistance à l'échaudure des feuilles}

La culture de variétés résistantes est le meilleur moyen pour lutter contre l'échaudure des feuilles de canne à sucre, causée par Xanthomonas albilineans. L'évaluation des variétés est actuellement fondée sur l'expression des symptômes de la plante après contamination artificielle. On sait cependant que la canne à sucre peut être contaminée sans présenter de symptômes pendant de longues périodes.

Des recherches conduites à la Guadeloupe ont permis d'identifier des marqueurs de résistance plus fiables que la simple observation des symptômes de la maladie. Ainsi, il est montré que le niveau de résistance est directement lié à la densité des populations de l'agent pathogène dans la plante hôte. Ce nouveau critère permet une meilleure différenciation de la résistance variétale, avec ou sans symptômes de la maladie.

Ce mode d'évaluation est maintenant appliqué aux nouvelles variétés de canne à sucre produites par le programme de création variétale du CIRAD à la Guadeloupe. 


\section{La lutte contre le ver blanc}

Détecté en 1981, après son introduction accidentelle à la Réunion, le ver blanc Hoplochelus marginalis a mis en péril la culture de la canne à sucre, notamment sur les exploitations de taille modeste, perturbant ainsi gravement la principale culture d'exportation de l'île. Chargé de la lutte biologique, le CIRAD a importé et étudié une souche de Beauveria originaire de Madagascar. Ce champignon, strictement inféodé au ver blanc, a été introduit en de nombreux sites de l'île à partir de 1987. L'activité immédiate et la progression naturelle ont été remarquables, réduisant, dès 1992, les populations du ravageur en dessous du seuil de nuisibilité. La réussite extrêmement rapide de cette lutte biologique menée en collaboration avec I'INRA, le FOFIFA et les services de développement de la Réunion a suscité l'intérêt des scientifiques et justifie l'étude plus approfondie du prédateur.

\section{Valorisation de l'eau}

Le conseil en irrigation par la simulation du bilan hydrique repose sur une bonne connaissance du fonctionnement du système sol-plante-atmosphère. Le logiciel de gestion de l'irrigation Irricanne est maintenant fonctionnel sur les périmètres irrigués de la Réunion. II sera d'autant plus fiable que les termes du bilan seront connus avec précision.

Des méthodes nouvelles ont été maîtrisées et utilisées pour préciser le fonctionnement hydrique des sols et de la plante. La conductivité hydraulique des sols des périmètres irrigués a été déterminée par perméamétrie à succion contrôlée. Les résultats sont intégrés dans la carte pédologique au 1/10 000 réalisée sur cette zone. La réflectométrie temporelle mesure la vitesse de propagation des ondes électromagnétiques dans le sol, laquelle est proportionnelle à I'humidité. Elle est employée pour suivre l'évolution des bulbes d'humectation sous goutte-à-goutte. On a ainsi pu dimensionner le réseau de surface et définir le mode de conduite de l'irrigation. Les recherches s'orientent vers une appréciation affinée de l'évaporation réelle des cultures par des mesures de débit de sève et une mise en relation de l'intensité d'un déficit hydrique avec le comportement agronomique de la canne à sucre.

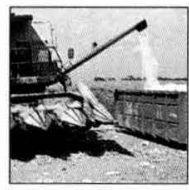

\section{Programme cultures intensifiées}

Les agricultures dites intensifiées ont atteint un niveau technique suffisant pour justifier des investissements et des intrants et sont insérées dans une économie de marché. La dégradation fréquente de la fertilité du sol, I'enherbement, le parasitisme et la rentabilisation des investissements sont les problèmes majeurs qui se posent dans ce contexte.

\section{Création d'hybrides de riz}

La création d'hybrides de riz tropicaux est réalisée en Guyane et au Brésil, en association avec une firme privée. Elle est fondée sur l'utilisation de systèmes de stérilité mâle génocytoplasmique de matériel à dominance indica. Parmi ces systèmes, celui comportant le cytoplasme WA est le plus exploité.

Pour le court terme, un criblage est effectué parmi les variétés déjà présentes en Guyane, qui proviennent en majorité d'Amérique latine. Les rares variétés " mainteneuses » sont stérilisées par rétrocroisement (lignées A). Actuellement, deux d'entre elles ont été retenues pour la création des hybrides. Les variétés " restauratrices » sont, après un cycle de purification, directement testées vis-à-vis des lignées A disponibles. A la fin de 1992, environ 120 lignées restauratrices et 200 nouveaux hybrides sont disponibles pour évaluation en 1993.

Des techniques de production semencière économiquement viables sont développées : repiquage en bandes alternées du mâle stérile et du pollinisateur et, par avion, semis en mélange des deux parents.

Les hybrides de riz pour les régions méditerranéennes sont créés à partir de riz du groupe japonica. 
Trois cytoplasmes de stérilité sont exploités : WA, BT et Gam. Les variétés japonica stérilisées par ces cytoplasmes sont déjà nombreuses, mais très peu de riz japonica sont restaurateurs. Pour faciliter la production de semences hybrides, les grands stigmates de l'espèce allogame Oryza longistaminata sont en cours de transfert dans ces lignées, car l'aptitude naturelle à l'allofécondation des lignées mâles stériles est faible.

\section{Analyse de la stabilité du rendement}

La stabilité du rendement est, de même que la productivité, un objectif essentiel de la sélection. Cette caractéristique peut être évaluée à partir des résultats d'essais multilocaux dans une gamme variée d'environnements. Les méthodes classiques de détermination de cette stabilité sont critiquables. Une nouvelle méthode a été mise au point pour exploiter deux années de données recueillies dans le réseau Amul, essai multilocal d'hybrides de maïs dans I'ensemble de la strate tropicale. Elle a prouvé son efficacité et a permis de repérer IRAT 354, variété de remarquable stabilité. Elle a été également appliquée à un hybride précoce produit par Rhône-Poulenc, Béryl, destiné au marché français.

Cette méthode repose sur un regroupement préalable des essais selon leur signification avant I'analyse de l'interaction entre génotype et environnement. Outre I'analyse classique de la stabilité du rendement, elle fait appel aux techniques d'analyse en composantes principales et de classification automatique pour représenter l'interaction, expliquée par une analyse de covariance.

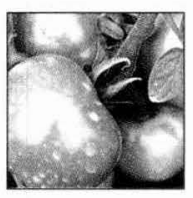

\section{Programme} cultures maraîchères

Le programme cultures maraîchères regroupe différentes productions (légumes, fleurs, plantes aromatiques et à épices) ayant en commun plusieurs caractères originaux : il s'agit de cultures spéculatives réalisées sur de petites surfaces, avec un niveau d'intrants élevé et une forte valeur ajoutée des produits.

En 1992, les résultats portent sur les cultures légumières.

\section{Les filières maraîchères en Afrique}

L'analyse des filières maraîchères au Congo, en République centrafricaine et à Madagascar a révélé la performance du système commercial local qui, malgré les fortes irrégularités de production et les contraintes de transport, parvient à approvisionner les consommateurs urbains sans prix spéculatifs et en limitant les pénuries. La recherche agronomique a pour enjeu stratégique de régulariser l'approvisionnement et de limiter les importations. Ses produits cibles doivent être ceux qui sont les plus consommés, c'est-à-dire les légumes feuilles locaux, I'oignon et la tomate.

\section{Lutte contre Liriomyza trifolii}

Parmi les ravageurs des plantes maraîchères, la mouche mineuse nord-américaine des feuilles (Liriomyza trifolii) est largement répandue sous tous les climats.

Le laboratoire d'entomologie appliquée de Montpellier a travaillé avec les sélectionneurs de l'INRA pour créer des variétés de tomate résistantes à cet insecte. Testées au Sénégal, en collaboration avec I'ISRA, neuf lignées ont présenté, en moyenne, quatre fois moins de mines que le témoin sensible, Flora Dade.

Par ailleurs, d'autres différences de sensibilité variétale ont été observées : la variété Tropimech présente quatre fois moins de larves que la variété Xina, largement cultivée au Sénégal. L'utilisation de variétés tolérantes ou résistantes, associée à une lutte chimique (cyromazine, abamectine) respectant les insectes auxiliaires (Hemiptarsenus varicornis, Opius dissitus), réduit de $60 \%$ les pertes de récolte, estimées à 7,7 tonnes à I'hectare.

\section{Lutte contre la maladie bronzée de la tomate}

La maladie bronzée de la tomate (tomato spotted wilt virus, TSWV), virose transmise par un insecte, 


\section{CULTURES ANNUELLES}

\section{Des produits pour le développement}

\section{Des variétés de légumes pour la culture sous abri}

La culture sous abri en zone tropicale est une solution de plus en plus répandue pour obtenir une production tout au long de l'année. Le choix des variétés reste un facteur essentiel de l'élaboration du rendement dans cette atmosphère confinée. A la Martinique, après quatre années, une liste variétale a été établie : les tomates Capitan, Carmello, Tropic Boy ; les melons Savor, Andès ; les poivrons Narval, Pacific, Drago, Tenno ; les laitues Minetto, Ostinata, Sierra, Laura, Divina ; les concombres Genuine, Victory, Tropi Cuke. Les techniques de fertilisation, d'irrigation et de protection des cultures ont été diffusées auprès des agriculteurs sous forme de fiches techniques.

Frankliniella occidentalis, a été identifiée en septembre 1991 à la Réunion. Le CIRAD a étudié son épidémiologie et la dynamique du vecteur sur deux cultures, la tomate et la reine-marguerite.

L'infection primaire est déclenchée par l'arrivée précoce de thrips portés par les vents dominants. Elle est d'autant plus importante qu'elle a lieu sur des plantes en pépinière. L'infection secondaire se réalise préférentiellement de proche en proche. L'étude de la dynamique des insectes vecteurs démontre que les pullulations d'insectes sont dues à des pics de génération et à des migrations. La destruction précoce et régulière des plantes atteintes par le TSWV permet de réduire de manière significative la vitesse de propagation de la maladie dans la parcelle.

La stratégie préconisée s'oriente vers une prophylaxie rigoureuse en quatre points : protéger les pépinières contre les insectes vecteurs; nettoyer les abords de la parcelle et organiser l'assolement ; maîtriser les populations d'insectes, surtout en début de culture, par la lutte chimique ; supprimer les sources d'inoculum dans la parcelle.

\section{Les thèses soutenues en 1992}

Accueil par le département

Evaluation de la diversité génétique et du comportement en croisement des sorghos (Sorghum bicolor L. Moench) de race guinea au moyen de marqueurs enzymatiques et morphophysiologiques, par Isabelle Degremont (France), université Paris XI, centre d'Orsay.

Biologie et écologie de la mineuse nord-américaine des feuilles, Liriomyza trifolii (Burgess), ravageur des cultures maraîchères au Sénégal : études des possibilités de lutte, par Emile Victor Coly (Sénégal), université Aix-Marseille III.

Biologie et écologie de Cryptophlebia leucotreta en Côte-d'Ivoire : implications agronomiques, par Germain Ochou-Ochou (Côte-d'Ivoire), Ecole nationale supérieure agronomique, Montpellier.

Les relations entre la culture cotonnière et les cultures vivrières au Bénin, par Claude Cossi Chedeme (Bénin), université Montpellier I.

Diversité moléculaire RFLP et cartographie génomique chez la canne à sucre (Saccharum spp.), par Yun Hai-Lu (Chine), université Paris XI, centre d'Orsay. 


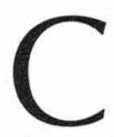

ette année de transition dans les réformes de structure du CIRAD a conduit à la création, le $1^{\mathrm{er}}$ novembre 1992, du département des cultures pérennes, qui intègre trois anciens départements : I'IRCA (plantes à latex), I'IRCC (plantes stimulantes) et l'IRHO (oléagineux pérennes).

Parallèlement à la poursuite des travaux engagés, les trois départements se sont efforcés collectivement de préparer au mieux leur fusion par la définition des objectifs stratégiques, une réflexion sur la programmation scientifique à moyen terme, I'harmonisation et la modernisation des procédures et la concertation entre les personnels. Dès sa création, le nouveau département s'est ainsi doté des principaux outils qui devraient lui permettre de devenir pleinement opérationnel en 1993.

Le département s'est donné la grande ambition de tirer parti de l'ancienneté et de la diversité des expériences des anciens instituts et d'adapter son dispositif de façon à devenir, dans chacun de ses domaines d'activité, une référence incontestée de la recherche au service du développement.

Les cultures pérennes d'exportation se sont développées soit en petites plantations individuelles (caféier, cacaoyer) sur défriche de la forêt, soit en plantations industrielles ou villageoises encadrées (palmier à huile, cocotier, hévéa), généralement sur des terres vierges. Elles commencent à trouver leurs limites. La disparition de la forêt, qui devient une ressource naturelle rare que la communauté internationale entend protéger, en est une cause. La pression foncière, due à la croissance démographique, en est une autre.

Le défi scientifique que la recherche doit relever consiste à créer — tout en protégeant l'environnement — une exploitation agricole économiquement durable en zone humide.

L'objectif est d'abord d'être en mesure de replanter les exploitations existantes avec des rendements et des coûts de production compétitifs par rapport à ceux obtenus sur terres vierges.

L'objectif est aussi, dans une conjoncture internationale où les cours sont bas, de faire baisser les coûts de production et de mieux valoriser les produits, en particulier par une amélioration de leur qualité.

Pour réduire les coûts de production, il faut à la fois augmenter la productivité du travail et diminuer le poids des intrants dans ces coûts, grâce à des itinéraires techniques " économes".

$C^{\prime}$ est en tenant compte de ce contexte qu'ont été définies les priorités du département des cultures pérennes pour les prochaines années.

Un dispositif stable autour de pôles thématiques forts permettra au département d'affermir son travail scientifique près des principales zones de production, de former ses propres chercheurs et ceux de ses partenaires, et de maintenir une liaison aussi étroite que possible avec le développement.

Des synergies entre les différents programmes seront favorisées par des activités communes, qu'elles soient déjà organisées - gestion de la variabilité génétique, culture in vitro, chimie - ou à renforcer - économie, gestion du milieu, agrophysiologie — , et, tant que faire se peut, par une répartition géographique moins dispersée.

Une politique dynamique d'alliances stables est à mettre en œuvre avec des partenaires diversifiés, du Nord et du Sud : organismes de recherche, agences de développement, entreprises privées.

L'adéquation constante de la programmation aux besoins réels du développement doit être maintenue par la mise en place d'une capacité de réflexion prospective faisant une large part à l'économie.

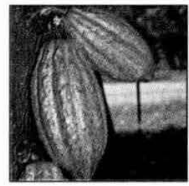

\section{Programme cacao}

Depuis plusieurs années, la production mondiale de cacao est globalement excédentaire, même si la récolte de 1992 semble un peu moins importante que celle des années précédentes. Pour répondre aux enjeux liés à ce contexte de surproduction, les axes 


\section{CULTURES PÉRENNES}

\section{DÉPARTEMENT DES CULTURES PÉRENNES}

\section{CIRAD-CP}

$\begin{aligned} & \text { Directeur } \text { Alain Weil } \\ & \text { Directeur adjoint } \text { Christian Brunin } \\ & \text { Directeur scientifique } \text { Jacques Meunier } \\ & \text { Directeur des programmes } \text { Paul Gener } \\ & \text { Directeur } \\ & \text { administratif et financier } \text { Robert Jouanique } \\ & \text { Programmes de recherche } \\ & \text { Cacao } \text { Denis Despreaux } \\ & \text { Café } \text { Daniel Duris } \\ & \text { Cocotier } \text { François Rognon } \\ & \text { Hévéa } \text { Hubert Omont } \\ & \text { Palmier à huile } \text { Bertrand Tailliez } \\ & \\ & \text { Unités de recherche } \\ & \text { Agronomie } \text { Robert Ochs } \\ & \text { Amélioration des plantes } \text { Dominique Nicolas } \\ & \text { Défense des cultures } \text { Jean-Luc Renard } \\ & \text { Chimie-technologie } \text { François Challot } \\ & \text { Economie des filières } \text { Claude Freud } \\ & \text { Biométrie } \text { François Bonnot } \\ & \text { Services d'appui technique } \\ &\end{aligned}$

Information et communication Christine Nouaille

principaux suivis par le programme cacao ont été l'amélioration de la rentabilité et de la qualité du produit.

\section{Amélioration du rendement}

L'amélioration du rendement par voie génétique doit être poursuivie, dans la mesure où elle permet, pour une même production globale, de diminuer les surfaces consacrées à la culture et l'emploi des intrants.

L'amélioration de la productivité des surfaces exploitées est recherchée, en premier lieu, par la mise en place de variétés à haut potentiel de production. Le deuxième cycle de création variétale est en voie d'achèvement en Côte-d'Ivoire, avec I'IDEFOR. Les hybrides de clones sélectionnés, dont les meilleurs peuvent produire plus de 3 tonnes de cacao marchand à I'hectare, sont sensiblement supérieurs aux hybrides de la première génération, déjà largement utilisés.

L'amélioration de la productivité est aussi abordée par la création de variétés associant un bon niveau de résistance aux maladies (Phytophthora spp.

essentiellement) et aux ravageurs (mirides) à un potentiel de production satisfaisant. C'est l'objectif du nouveau cycle de sélection de type récurrent entrepris en Côte-d'Ivoire depuis 1990, dont l'installation s'est poursuivie avec l'implantation de 250 nouveaux hybrides.

Les recherches sur la résistance au virus du swollen shoot ont été poursuivies au Togo. Parmi les variétés vulgarisées dans ce pays, deux hybrides de clones ont montré un bon niveau de résistance dans des tests d'inoculation précoce des fèves. Par ailleurs, la séquence complète du génome viral a été identifiée dans le cadre d'une collaboration avec I'INRA. De nouvelles. méthodes de diagnostic pourront ainsi être élaborées.

Dans le cadre de recherches plus prospectives, des travaux sur la diversité génétique du cacaoyer avec les marqueurs de I'ADN se poursuivent à Montpellier sur environ 300 clones. Les marqueurs RFLP et RAPD sont maintenant utilisés pour établir une cartographie du génome du cacaoyer. A terme, on espère localiser des gènes de résistance aux maladies et des gènes liés aux qualités organoleptiques du cacao.

En collaboration avec Francereco (groupe Nestlé), les conditions d'obtention d'embryons somatiques à partir de pétales ont été définies pour neuf génotypes. Actuellement, 100 plants issus d'embryogenèse somatique sont en croissance en pots sous serre.

Contre la pourriture brune des cabosses provoquée par Phytophthora spp., des modes de résistance par esquive ont été mis en évidence au Cameroun et au Vanuatu. Les durées de maturation des cabosses et la période de production paraissent jouer des rôles importants dans le développement des épidémies. 


\section{CULTURES PÉRENNES}

Pour développer les échanges de matériel végétal entre la collection internationale localisée à la Trinité et les autres centres de recherche sur le cacaoyer, une coopération nouvelle a été instaurée avec l'université locale (University of the West Indies). Pendant la première année, elle a porté sur la mise au point de traitements thermiques et chimiques contre le balai de sorcière. Cette maladie provoquée par un parasite fongique, Crinipellis perniciosa, n'a jusqu'ici été détectée que sur le continent américain.

\section{Techniques culturales}

Cependant, la lutte génétique n'est pas la seule voie suivie pour réduire l'incidence des maladies et des ravageurs. De nouvelles techniques de lutte chimique contre les Phytophthora et les mirides, qui réduisent de moitié le nombre des applications, ont été vulgarisées à grande échelle au Cameroun. Dans le cas du rose beetle, au Vanuatu, c'est la voie de la lutte biologique qui a été explorée. Plusieurs parasitoïdes de cet insecte ont été identifiés.

Au Vanuatu, un nouveau programme visant à définir les caractéristiques optimales d'une association de cocotiers et de cacaoyers vis-à-vis de l'énergie lumineuse a été engagé en 1992. Il consiste à établir les bilans de photosynthèse dans plusieurs modalités d'association et dans les cultures pures.

\section{Qualité du fruit}

Les itinéraires techniques recommandés par le département ont été définis pour obtenir un cacao de qualité satisfaisante pour les besoins de l'industrie. Cependant, comme pour toutes les denrées alimentaires, il est toujours possible de produire un cacao de qualité supérieure qui serait utilisé pour des produits haut de gamme.

En identifiant les propriétés des cacaos de qualité supérieure et en déterminant à chaque étape de la transformation les différents facteurs qui jouent un rôle dans ce domaine, les chercheurs mettent au point des itinéraires techniques adaptés à ce type de production.
Une meilleure qualité du cacao est d'abord recherchée par une optimisation des opérations de postrécolte : un fermenteur contrôlé, à fonctions automatisées, a été mis au point en collaboration avec la société Gauthier, grâce à des financements de l'ANVAR, du conseil général de I'Hérault et du ministère de la Recherche et de l'Espace.

Au laboratoire, on tente de modéliser la formation de l'arôme du cacao. Les premières études montrent le rôle et la nature des précurseurs de la réaction de Maillard, ainsi que des composés secondaires phénoliques et de la théobromine. La torréfaction en systèmes modèles de quelques précurseurs permet maintenant de préciser, d'une part, l'influence des paramètres de traitement thermique, d'autre part, le rôle des sucres, des acides aminés, des épicatéchines sur le développement des aldéhydes, composés clés de l'arôme de cacao. Cependant, si la torréfaction de modèles simples permet d'interpréter la formation de nombreux composés présents dans l'arôme du cacao, elle ne permet pas encore $d^{\prime}$ interpréter la formation de l'arôme lui-même.

\section{Publication}

\section{L'agronomie du cacaoyer}

L'agronomie du cacaoyer est un condensé des recherches réalisées par les agronomes du département dans les divers terroirs où des expérimentations ont été menées, principalement en Côte-d'Ivoire et au Togo, mais également au Cameroun, à Madagascar, en Ouganda et au Gabon. Ce document comporte quatre parties : multiplication et préparation du matériel végétal, mise en place de la cacaoyère, amélioration des rendements, régénération. Il fait le point sur les techniques disponibles pour intensifier et sécuriser la production et sera utile aux organismes de développement et de vulgarisation. 


\section{CULTURES PÉRENNES}

\section{Programme café}

L'effondrement des cours mondiaux des cafés a provoqué le déficit des filières nationales, qui s'est traduit par une diminution des revenus des agriculteurs. Face à cette situation, les producteurs sont contraints d'améliorer la productivité, de réduire les coûts de production et de proposer un café de bonne qualité. Le programme café conduit des recherches et participe à des actions de développement pour accompagner leur effort.

\section{Qualité du café}

Le café burundais subit une décote de $10 \%$ par rapport à un café arabica moyen, décote liée à la présence d'un goût particulier, le " goût de pomme de terre ", qui est dû à une bactérie propagée par des insectes. Les premières expérimentations réalisées en collaboration avec I'ISABU ont porté sur la désinsectisation des caféières. Les premiers résultats n'ont pas établi de corrélation nette entre les cerises piquées par les insectes et le goût de pomme

\section{Réseaux}

\section{Un réseau de recherche pour les cafés africains}

L'Organisation interafricaine du café (OIAC), inquiète de la baisse de la productivité des caféières africaines et de la dégradation de la qualité des cafés, a sollicité la CCE pour relancer la recherche caféière. Le CIRAD, mandaté pour présenter des solutions, a proposé, à l'issue de plusieurs réunions avec l'OIAC, le CTA et la CCE, la création d'un réseau de recherche sur le café placé sous l'égide de l'OIAC.

Ce réseau, qui comprendra les vingt-trois pays producteurs membres de I'OIAC, sera officiellement créé en mars 1993. de terre. En revanche, l'élimination des cerises flottantes à la réception dans les ateliers de dépulpage apporte une solution à brève échéance, en termes de diminution du risque.

Les études sur le traitement de postrécolte visent à améliorer la qualité pour obtenir un café lavé de type Kenya tout en diminuant les coûts. Les lots de café ayant subi ce traitement sont vendus aux enchères, à des prix toujours supérieurs à ceux du marché à terme.

Le traitement par voie humide du café est très polluant. Au Mexique, une unité pilote de dépollution par fermentation anaérobie des eaux résiduaires de lavage a été installée dans un atelier de dépulpage appartenant à une organisation paysanne. Elle peut également, selon les premiers résultats, assurer une production de méthane suffisante pour terminer le séchage du café.

Dans un cadre plus général, le programme café met en place, avec Francereco, un projet de recherche sur les déterminants de la qualité du café.

\section{Rentabilité de la culture}

En défense des cultures, les études épidémiologiques de la rouille et de l'anthracnose des baies du caféier au Cameroun, au Laos, en Papouasie-Nouvelle-Guinée et en Amérique centrale, ainsi que des essais de fongicides au Cameroun, ont permis d'établir des recommandations pour réduire les coûts des traitements.

En ce qui concerne les principaux insectes ravageurs, un parasitoïde nouveau du scolyte a été identifié au Togo et son élevage est en cours de mise au point. Des essais de lutte biologique contre ce coléoptère ont également commencé au Nicaragua. Enfin, dans le cadre du réseau Promecafé, des études ont été entreprises sur le parasitisme tellurique (cochenilles et nématodes). Dans l'immédiat, le greffage de Coffea arabica sur $C$. canephora Robusta est un moyen de protection contre les nématodes.

En agronomie, les recherches sur la lutte contre l'érosion au Burundi montrent que I'utilisation de Leucaena spp. en lignes alternées permet de stabiliser les sols. 


\section{CULTURES PÉRENNES}

Ce résultat est d'ores et déjà transférable

au développement. La pratique paysanne d'un paillage permanent a entraîné des déséquilibres cationiques qu'il faut corriger. Un réseau d'essais en milieu paysan a été mis en place pour restaurer la fertilité des sols. Au Mexique, les planteurs avaient l'habitude d'utiliser les engrais disponibles sur le marché, dont la composition varie d'une année à l'autre. L'analyse chimique des sols a permis d'établir des formules mieux équilibrées et de réduire les quantités d'engrais nécessaires. Les rendements sont passés en moyenne de 450 à 800 kilos à l'hectare. On a, en outre, observé une diminution des attaques de rouille, probablement liée à l'amélioration de la nutrition du caféier.

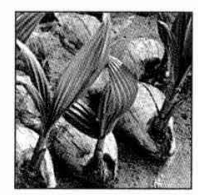

\section{Programme cocotier}

Malgré une augmentation sensible des prix moyens du coprah et de son huile en 1992, le cocotier — qui est souvent la seule culture possible et l'unique ressource financière des petits planteurs — reste une production peu rémunératrice. Les résultats marquants du programme cocotier vont dans le sens d'un meilleur fonctionnement de l'agrosystème et d'une valorisation des produits, conditions nécessaires à I'amélioration de la rentabilité.

\section{Environnement et agronomie}

En 1992, l'étude des facteurs de la production s'est poursuivie en parallèle avec l'élaboration de référentiels techniques adaptés aux milieux très variés où est cultivé le cocotier.

Sur le réseau expérimental de Lampung (Sumatra), une sécheresse exceptionnelle a permis de confirmer la forte réponse des cocotiers hybrides au chlore, qui agit à la fois comme facteur de résistance au stress hydrique et comme facteur de production en conditions de déficit hydrique faible ou nul. En dehors des zones où les apports météoriques sont suffisants - littoraux maritimes par exemple —, la fumure chlorée sera utile.
Le niveau critique en chlore est confirmé à $0,5 \%$ de chlore dans la matière sèche de la feuille 14 .

Les travaux sur le comportement des variétés vis-à-vis de la sécheresse ont mis en évidence l'intérêt de l'étude des acides gras des feuilles. Le bon comportement au champ de I'hybride PB 121 en conditions de stress hydrique pourrait s'expliquer par un bon fonctionnement des membranes cellulaires et chloroplastiques, lié à de faibles teneurs foliaires en acides gras, et par des conductances stomatiques restant élevées, facteurs favorables au maintien d'une certaine productivité. II y a là une nouvelle voie de recherche, qui devra tenir compte de la composition de ces acides gras.

Les mouvements de l'azote dans des cocotiers âgés de quatre ans ont été étudiés avec l'isotope ${ }^{15} \mathrm{~N}$, en collaboration avec I'IDEFOR et I'AIEA. Trois mois et demi après l'application, I'azote s'est réparti dans I'ensemble de la plante. On observe une redistribution des éléments minéraux et des métabolites des vieilles feuilles vers les organes en croissance active. L'azote de l'albumen provient plus de la mobilisation de l'azote de la bourre et de la coque que de l'engrais apporté. Une action de la fumure azotée sur la formation de l'albumen nécessiterait donc huit à dix mois.

Un nouveau projet a pour objectif d'étudier le fonctionnement global de l'agrosystème constitué par une culture associée au cocotier en termes de compétition pour la lumière, l'eau et les éléments nutritifs. Les premiers résultats obtenus avec I'IDEFOR en Côte-d'Ivoire montrent que le pourcentage de lumière transmise au sous-étage par un peuplement de cocotiers est faible, du moins dans la gamme des densités qui autorisent l'expression d'un rendement voisin du rendement maximal pour le cocotier : avec une densité de 115 arbres à l'hectare, $29 \%$ de la lumière parvient au niveau du sol, mais $12 \%$ seulement à une densité de 180 arbres.

\section{Amélioration du cocotier}

Le deuxième cycle de sélection en cours en Côte-d'Ivoire montre que les tests d'aptitude individuelle

à la combinaison sur familles de demi-frères sont fiables et bien adaptés à la biologie de la plante. 


\section{Réseaux}

\section{Ressources génétiques du cocotier}

Le réseau de ressources génétiques du cocotier mis en place par I'IBPGR en 1991 a confié au département des cultures pérennes du CIRAD la réalisation d'une base de données internationale des ressources génétiques du cocotier. Les principes d'établissement et de gestion de cette base ont été discutés par les responsables de collection du réseau, réunis à Montpellier en mai 1992. Le logiciel a été présenté à la première réunion du comité de suivi du réseau, qui s'est tenue à Singapour en décembre.

Ainsi, I'amélioration de l'hybride PB 121 (Nain Jaune de Malaisie x Grand Ouest Africain) permet de proposer en une seule génération un matériel dont la productivité a progressé de $15 \%$ et dans lequel des facteurs de tolérance à Phytophthora katsurae ont été identifiés. Plus de 300 familles de demi-frères sont actuellement étudiées dans ce deuxième cycle. L'évaluation des premières familles plantées s'achève et la diffusion variétale devrait s'accélérer au cours des prochaines années.

En collaboration avec l'ORSTOM, une étape importante a été franchie dans la maîtrise de la multiplication végétative du cocotier avec l'obtention reproductible d'embryons somatiques complets. Des vitroplants appartenant à plusieurs clones de génotypes différents ont été produits à partir d'explants issus de feuilles et d'inflorescences.

\section{Protection des cultures}

Les résultats des études conduites dans le cadre d'un programme sur les Phytophthora financé par la CCE ont été présentés au séminaire organisé par le département sur le centre de recherche de Manado, en Indonésie. Les Phytophthora impliqués dans les symptômes de pourriture du cœur et de chute des noix appartiennent à quatre espèces : $P$. palmivora, $P$. arecae, $P$. nicotianae var. parasitica et $P$. katsurae.
Cette dernière n'a pas été détectée en Asie. L'anaiyse des profils isoenzymatiques révèle l'origine génétique commune de $P$. palmivora et de $P$. arecae. Un programme d'amélioration pour la résistance à la pourriture du cœur pourrait tirer parti du bon comportement au champ de certains cocotiers Grand en Indonésie. De même, il paraît intéressant d'exploiter le caractère de résistance de Nain Vert, détecté dans les tests d'inoculation sur noix détachées. L'effet antagoniste de deux autres champignons, Myrothecium roridum et $M$. verrucaria, envers les Phytophthora a été montré in vitro. Cette activité est confirmée sur de jeunes plants, mais l'application au champ semble difficile.

Sur la plantation Socôco, au Brésil, les maladies foliaires sont en nette régression: deux champignons, Septofusidium elegantulum et Acremonium, ont joué un rôle dans la régulation du développement de Catacauma torrendiella, entraînant une diminution drastique de l'apparition des périthèces. Botryosphaeria sp., agent secondaire qui s'installe à la faveur de la présence de C. torrendiella, s'est ainsi trouvé limité dans son développement. On a observé une disparition quasi totale du dessèchement foliaire et une augmentation du nombre de feuilles vertes de 17 à environ 25.

L'élevage de I'hémiptère Myndus taffini, vecteur du virus du dépérissement foliaire du cocotier au Vanuatu, a été mis au point au laboratoire sur les racines de bourrao (Hibiscus tiliaceus), plante hôte des stades préimaginaux. On peut donc disposer d'une souche de l'insecte indemne de virus pour étudier avec précision la transmission de l'agent pathogène.

\section{Technologie du coprah}

Des résultats préliminaires ont montré qu'une simple souche de collection d'un champignon filamenteux peut augmenter de $50 \%$ la teneur en protéines du tourteau de coprah. Un projet mené en collaboration avec l'INRA, I'ORSTOM et l'université autonome de Mexico va étudier l'enrichissement en protéines et en probiotiques du tourteau de coprah par fermentation en milieu solide pour l'alimentation animale. 


\section{CULTURES PÉRENNES}

\section{Programme hévéa}

Le caoutchouc naturel se situe dans un marché où l'offre et la demande sont équilibrées à environ 5 millions de tonnes par an, ce qui représente $30 \%$ de la consommation mondiale de caoutchouc. Pour maintenir cette place et tenter de l'améliorer, il est nécessaire de rendre le produit encore plus compétitif en abaissant les coûts de production et en l'adaptant mieux aux besoins du marché.

Les résultats les plus marquants du programme hévéa portent sur l'évolution de la fertilité des sols, la connaissance de la plante - qui devrait permettre une meilleure gestion technique des plantations et la mise au point d'une nouvelle forme de caoutchouc.

\section{Agrophysiologie}

Dans le cadre d'un programme financé par le ministère de l'Environnement, un projet intitulé « Evaluation de la relation entre processus biologiques et fertilité dans les plantations d'hévéas " a été conduit en collaboration avec le laboratoire d'écologie de l'Ecole normale supérieure et I'IDEFOR, en Côte-d'Ivoire. Si la mise en place des hévéas ne semble pas sensiblement modifier la fertilité physico-chimique initiale, elle a une grande influence sur la faune du sol. Le sol de forêt contient une faune variée, dominée par les vers de terre.

La plantation des hévéas bouleverse sa composition : les populations de termites, profitant des résidus ligneux d'abattage, prolifèrent aux dépens des autres espèces. Au bout de cinq ans, le développement des hévéas correspond à un retour à l'équilibre avec des populations nombreuses de vers de terre. Cette faune participe de façon essentielle au maintien des paramètres physiques de la fertilité du sol.

La modélisation du fonctionnement du système laticifère se poursuit dans différentes voies. L'électrophysiologie a précisé les mécanismes de transfert des sucres à travers les membranes cellulaires des laticifères. L'étude de l'action de l'éthylène, agent majeur de la stimulation de la production, a montré son influence sur l'activité de certaines enzymes clés du métabolisme isoprénique. L'analyse de systèmes antisénescents tels que les thiols est en cours.

Le diagnostic latex est un outil d'évaluation de l'état physiologique des hévéas qui permet d'optimiser les systèmes de récolte. II est dorénavant développé en appui aux expérimentations et dans les plantations industrielles, avec un suivi de plus de 50000 hectares, en Indonésie, en Côte-d'Ivoire et au Cameroun.

\section{Matériel végétal}

Grâce à des expérimentations à long terme et à grande échelle, on est maintenant en mesure de recommander des clones d'hévéa bien adaptés aux conditions agroécologiques variées de sept pays : Cameroun, Côte-d'Ivoire, Gabon, Guinée, Guatemala, Vietnam et Cambodge.

La multiplication végétative des hévéas par greffage suppose une rigueur extrême de la gestion des jardins à bois de greffe, car toute erreur a une incidence de type exponentiel. La méthode de contrôle de la conformité clonale des hévéas par la technique des marqueurs enzymatiques est dorénavant opérationnelle.

Le laboratoire portable mis au point en 1991 a permis d'effectuer les analyses in situ et de contrôler la composition des jardins à bois de greffe de plusieurs pays.

Il est maintenant possible de produire des vitroplants de plusieurs clones par microbouturage, mais certaines difficultés restent à surmonter pour une exploitation à grande échelle.

En embryogenèse somatique, l'étude des caractéristiques biochimiques et histologiques des cals d'hévéa et celle des jeunes embryons formés ont permis de passer d'un phénomène aléatoire à une réussite systématique pour la plupart des clones étudiés. Cette connaissance du matériel végétal rend possible une meilleure maîtrise du passage des embryons aux plantules et une stabilisation de la capacité embryogène. 


\section{Des produits pour le développement}

\section{Nouveaux procédés de fabrication pour le caoutchouc}

Le projet de développement du caoutchouc naturel liquide financé par l'ONUDI dans le cadre de I'IRRDB a pris fin en 1992. Les derniers travaux effectués avec I'IDEFOR en Côte-d'Ivoire - en liaison étroite avec I'université du Maine et I'IRAP — ont abouti à la mise au point d'un procédé de fabrication pour trois produits : le caoutchouc liquide non modifié, de masse moléculaire comprise entre 8000 et 16000 , stable au stockage; le caoutchouc liquide époxydé, avec des taux d'époxydation de 10 et de $25 \%$; le coupage de caoutchouc liquide, modifié ou non, avec des latex d'hévéa courant à des taux de 5 et $10 \%$ de polymère liquide.

Des contacts ont été pris avec l'industrie des pneumatiques pour utiliser ce caoutchouc liquide dans la mise en œuvre de mélanges de qualité plus homogène. D'ores et déjà, certaines utilisations industrielles sont au stade des tests à grande échelle.

Dans le domaine de la lutte contre Microcyclus ulei, une synthèse de plusieurs années de recherche en Guyane a été effectuée. Elle a abouti à la mise au point d'une méthode d'identification et d'évaluation des composantes de la résistance au champignon, au champ et en conditions contrôlées. Ces travaux sont destinés à soutenir un programme d'amélioration de I'hévéa en Amérique latine, dont la première phase a débuté en 1992 au Brésil en association avec une grande société de plantation.

\section{Economie de l'hévéaculture paysanne}

Les recherches en agroéconomie ont été principalement orientées vers le secteur hévéicole paysan. Les résultats de ces recherches de terrain sur les stratégies paysannes ont débouché sur des recommandations novatrices de politiques sectorielles. Par exemple, en Indonésie, I'analyse des stratégies de replantation des paysans hors des structures d'encadrement a conduit les autorités indonésiennes à élaborer un programme de soutien au développement et à mettre en place plusieurs réseaux expérimentaux en milieu paysan.

En Thaïlande, les rapports entre secteur public et secteur privé ont été étudiés dans le cadre d'une opération de développement portant sur la diffusion de variétés sélectionnées d'hévéa. La multiplication du matériel végétal est une fonction technique délicate,

qui détermine à long terme le rendement en caoutchouc. Cette fonction a été confiée à des entreprises privées spécialisées (jardins à bois, pépinières, revendeurs), qui répondent rapidement à la demande des planteurs. Le contrôle de l'origine génétique et de la qualité des plants est exercé par les établissements chargés de la recherche (RRIT) et du développement (ORRAF). Cette organisation, très satisfaisante, est à l'origine du succès du programme de replantation clonale conduit par I'ORRAF.

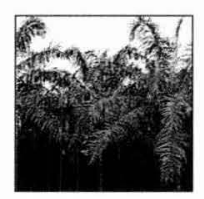

\section{Programme palmier à huile}

L'huile de palme, qui représente près de $20 \%$ de la production mondiale d'huile d'origine végétale, est classée en deuxième position derrière l'huile de soja. Pour progresser encore, l'augmentation de la productivité est possible grâce à un matériel végétal à haut potentiel, tolérant aux principales maladies à épidémiologie connue (fusariose) ou inconnue (pourriture du cœeur). Elle l'est aussi par le choix d'itinéraires techniques respectueux de l'environnement incluant la lutte contre la compaction des sols et contre l'érosion, et une fertilisation raisonnée. La valorisation des produits et sous-produits du palmier à huile fait également partie des priorités du programme palmier. 


\section{CULTURES PÉRENNES}

\section{Les itinéraires techniques}

En 1992, le programme palmier s'est attaché à poursuivre la mise au point d'itinéraires techniques adaptés à l'environnement afin de répondre à la demande des plantations, en particulier Palmindustrie en Côte-d'Ivoire, Socapalm et autres plantations au Cameroun, Socfindo en Indonésie, Palmas del Espino au Pérou.

En Indonésie, par exemple, on a pu mesurer l'arrière-effet des engrais phosphatés apportés depuis de nombreuses années aux doses optimales estimées par l'expérimentation. L'arrêt de cette fumure ne se répercute que quatre ans plus tard sur la nutrition, et six ans plus tard sur la production. Cela confère une très grande souplesse de gestion au producteur.

Au Cameroun, il a été possible de mieux définir l'équilibre optimal entre le potassium et le magnésium dans les sols ferrallitiques sableux très désaturés caractérisés par cette double déficience.

\section{Le fonctionnement de l'agrosystème}

L'étude du fonctionnement de l'agrosystème du palmier à huile permet de mieux comprendre les mécanismes de limitation de la production provoqués par les facteurs du milieu et de s'acheminer, par une modélisation, vers des outils plus précis de diagnostic à l'usage des plantations.

Le suivi des profils hydriques montre que, en phase de bonne alimentation en eau, l'évapotranspiration du couvert s'établit à $80 \%$ de l'évapotranspiration potentielle. En saison sèche, la fraction d'eau disponible dans la zone d'influence racinaire (soit cinq mètres de profondeur) reste supérieure à $40 \%$ en raison de la fermeture précoce des stomates. Les échanges gazeux, alors extrêmement ralentis, assurent la survie végétative du palmier mais réduisent à néant la production de régimes.

En Afrique de l'Ouest, le rayonnement solaire, insuffisant du fait de l'important couvert nuageux, ne permet pas de dépasser un rendement de 20 à 23 tonnes de régimes à l'hectare en l'absence de déficit hydrique. Le même matériel végétal atteint 30 tonnes et plus en Asie du Sud-Est, où le rayonnement solaire est supérieur de $30 \%$.

\section{La qualité du matériel végétal}

En Côte-d'Ivoire, un diagnostic de l'état des 130000 hectares de palmeraies réalisé à la demande de Palmindustrie a montré en particulier que les replantations industrielles produisent, en moyenne, près de $25 \%$ de plus que la première génération au même âge. Ce gain s'explique essentiellement par les progrès du matériel végétal sélectionné au cours de ces vingt dernières années.

Dans le nord de Sumatra, où les conditions climatiques sont particulièrement favorables, un essai comparant diverses origines de matériel végétal démontre

\section{Des produits pour le développement}

\section{Une coopération exemplaire au Pérou}

Au Pérou, la société Palmas del Espino exploite 4600 hectares de plantations de palmier à huile créées entre 1982 et 1987. Le respect des techniques culturales recommandées depuis dix ans par le CIRAD a permis d'obtenir 18,5 tonnes de régimes à quatre ans puis une moyenne annuelle de 24 tonnes à l'hectare, avec un taux d'extraction d'huile de $24 \%$. Ces performances, favorisées par un excellent matériel végétal, sont tout à fait satisfaisantes compte tenu des températures peu élevées enregistrées deux mois par an (minimas moyens inférieurs à $18^{\circ} \mathrm{C}$ ) et de l'insolation annuelle relativement faible ( 1700 heures). La pollinisation assistée, par pulvérisation de pollen sur les fleurs matures, et l'introduction de l'insecte pollinisateur Elaeidobius kamerunicus ont contribué à cette réussite. 


\section{CULTURES PÉRENNES}

\section{Rencontres internationales}

\section{Vers une coopération sur les Phytomonas}

Avec la collaboration de Cenipalma, le CIRAD a organisé le deuxième atelier international sur les Phytomonas, qui s'est tenu à Santa Marta, en Colombie, du 5 au 8 février 1992. La vingtaine de communications présentées a fait le point des recherches menées sur les trypanosomes de plantes et sur deux maladies qu'ils provoquent, la marchitez du palmier à huile et le hartrot du cocotier. Depuis le premier atelier, qui s'était tenu cinq ans auparavant, des progrès importants ont été enregistrés. Les chercheurs disposent maintenant de cultures de Phytomonas et de techniques biotechnologiques de caractérisation des souches. Plusieurs espèces d'insectes vecteurs sont identifiées. Ces résultats font espérer un aboutissement rapide à une lutte intégrée contre les maladies causées par les Phytomonas.

\section{Le point sur la sélection du palmier à huile}

Du $7^{\text {er }}$ au 3 juillet 1992 à Montpellier, le symposium de I'International Society of Oil Palm Breeders (ISOPB), organisé par le PORIM, institut de recherche malais, et le CIRAD, a réuni de nombreux spécialistes mondiaux de la sélection du palmier à huile. L'objectif était d'établir un bilan des travaux sur les grands thèmes de l'amélioration du palmier tant du point de vue de la productivité que de la résistance aux maladies.

que les hybrides Deli x La Mé atteignent une production annuelle de 6,6 tonnes d'huile à I'hectare entre dix et seize ans, contre 5,4 à 6 tonnes pour les autres sources. La baisse de rendement après huit ans, due à la compétition entre les arbres, est également beaucoup moins accusée et plus lente à s'installer chez ce matériel, moins encombrant et de croissance en hauteur plus faible.
Toujours dans cette région, les meilleurs croisements de deuxième cycle de sélection récurrente réciproque dépassent largement 8 tonnes d'huile à l'hectare, ce qui laisse espérer un potentiel de plus de 10 tonnes avec les clones sélectionnés à partir des arbres les plus performants.

On a montré que les meilleurs clones de palmier à huile peuvent produire 25 à $30 \%$ de plus que la moyenne de la descendance hybride dont ils sont issus.

Plus de 2500 hectares de vitroplants provenant du procédé d'embryogenèse somatique mis au point en collaboration avec l'ORSTOM ont été plantés dans le monde. Cette expérimentation en vraie grandeur permet de comprendre les difficultés de passage de la technique du laboratoire à l'échelle du développement, et de les surmonter. Par des dosages de phytohormones endogènes, on a expliqué le dérèglement provoquant l'anomalie de la morphogenèse florale. La recherche de marqueurs moléculaires permettrait d'éliminer précocement les cals atteints potentiellement de cette anomalie.

La réduction des coûts de production des plantules devient un objectif prioritaire. Le procédé de suspensions embryogènes en milieu liquide devrait être au point d'ici à quelques années : ses avantages résident dans les économies substantielles de maind'œuvre et d'espace de laboratoire.

\section{La protection des palmeraies}

En Equateur, la responsabilité d'insectes piqueurs du genre Molomea (Cicadellidae) dans la transmission d'une maladie à pourriture du cœur du palmier semble de plus en plus certaine. Après confirmation, il restera à mettre au point la méthode de lutte contre les vecteurs et à déterminer la nature du pathogène.

Grâce à un financement de la CCE, les travaux sur l'épidémiologie de la marchitez du palmier et du hartrot (pourriture du cœur) du cocotier, maladies dont on suspecte qu'elles sont dues à des trypanosomes, ont permis de dégager deux résultats importants. 


\section{CULTURES PÉRENNES}

D’une part, la maîtrise de l'élevage des punaises vectrices (Lincus spp.) est acquise, avec l'obtention de plusieurs cycles complets. Les punaises en élevage permettront d'inoculer les plantes dans le but de confirmer la pathogénicité des trypanosomes. On a, d'autre part, montré que les trypanosomes hébergés par les plantes herbacées adventices des palmeraies et des cocoteraies sont différents de ceux des deux palmacées.

La lutte biologique contre Chromolaena odorata, plante très envahissante en Extrême-Orient et en Afrique, a été entreprise en Côte-d'Ivoire et en Indonésie sur un financement de la CCE. Une chenille défoliatrice, Pareuchaetes pseudoinsulata, a été introduite et semble bien s'acclimater.

\section{Les thèses soutenues en 1992}

Chercheurs du département

La maladie sud-américaine des feuilles de l'hévéa : étude en conditions naturelles et contrôlées des composantes de la résistance partielle à Microcyclus ulei (P. Henn.) V. Arx, par Frank Rivano, université Paris XI, centre d'Orsay.

\section{Accueil par le département}

Les composés phénoliques foliaires de l'hévéa et leur implication dans la résistance à Colletotrichum gloeosporioides Penz. et Microcyclus ulei Henn., par Pascale Berger (France), université des sciences et techniques du Languedoc, Montpellier II.

Mécanisme du brunissement en culture in vitro : facteurs d'influence et potentiel embryogène des cals chez Hevea brasiliensis, par Fatima Housti (Maroc), université des sciences et techniques du Languedoc, Montpellier II.

Approche par enquête et expérimentation de l'effet de l'état structural du sol sur la nutrition azotée et l'élaboration du rendement, par Gede Wibawa (Indonésie), Institut national agronomique, Paris-Grignon.

Bioraffinage : désacidification enzymatique des huiles hyperacides, par Amélie Ducret (France), Institut national polytechnique de Toulouse.
Recherche du déterminisme hormonal de l'anomalie de la morphogenèse florale liée à l'embryogenèse somatique chez le palmier à huile (Elaeis guineensis Jacq.), par Isabelle Besse (France), université Paris VI.

Utilisation de la culture in vitro d'embryons zygotiques pour la collecte et la conservation des ressources génétiques du cocotier (Cocos nucifera L.), par Béatrice Assy-Bah (Côte-d'Ivoire), université Paris VI. 


\section{Département des fruits}

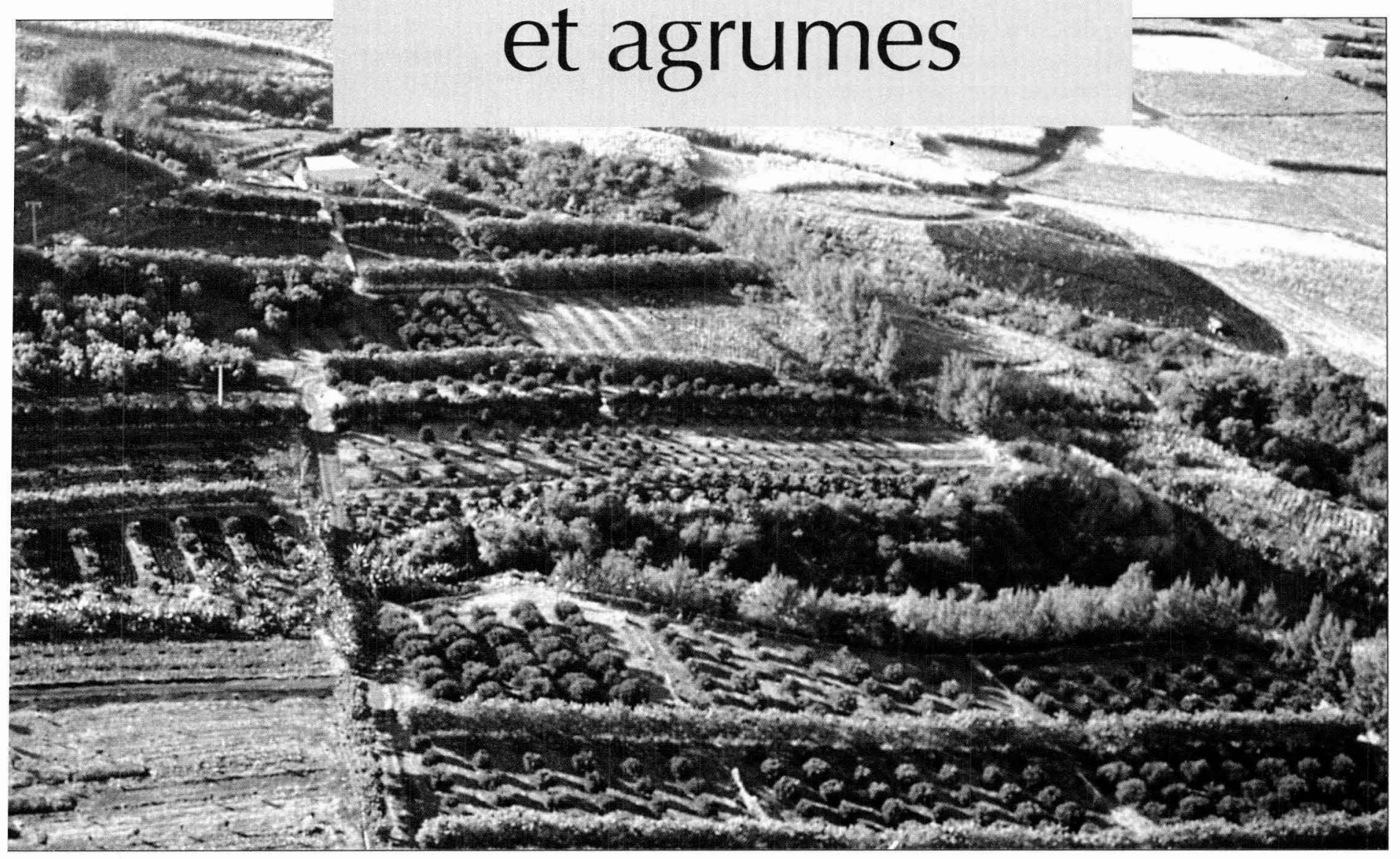

Avec une production de 200 millions de tonnes, les fruits contribuent à la sécurité alimentaire et à l'équilibre nutritionnel des populations des régions intertropicales et méditerranéennes. Ils constituent souvent une part importante du revenu des agriculteurs, et la diversification fruitière ouvre des perspectives aux marchés intérieurs et à l'exportation. Dans les régions forestières, les fruitiers occupent une place déterminante dans les combats pour la protection de l'environnement.

Par ses recherches et son implication dans le développement, le département des fruits et agrumes du CIRAD aborde tous les aspects de la filière, de l'amélioration de la plante et de la culture à l'insertion du produit frais ou transformé dans l'économie. 
'intérêt accru pour les productions fruitières tropicales - l'un des rares secteurs

où le commerce international enregistre des taux de croissance élevés - se traduit au sein de I'IRFA, département des fruits et agrumes du CIRAD, par un approfondissement des thématiques scientifiques, un renforcement des bases implantées sur le terrain et un redéploiement géographique des équipes.

La mise en place, au Cameroun, du Centre régional bananiers et plantains (CRBP) est soutenue par la Communauté européenne. Elle se poursuit avec la volonté d'aboutir à une coopération régionale plus forte. En Afrique de l'Est, les relations avec les pays de la Communauté économique des pays des Grands Lacs (CEPGL) se concrétisent par l'émergence de deux projets porteurs, I'un sur les bananiers d'altitude dans les pays de la CEPGL, I'autre sur les fruits et légumes au Burundi.

En Amérique latine, deux pôles de recherche sont confortés. Au Costa Rica, dans le cadre du CATIE, le projet de recherche sur les plantains est renforcé dans le domaine de la phytopathologie. En Colombie, le projet fruitier de la Valle del Cauca et le projet sur le bananier plantain dans la zone caféière centrale obtiennent des résultats qui rayonnent déjà dans les pays andins.

Dans le Pacifique, la coopération régionale se noue à partir de la Nouvelle-Calédonie, où la station de recherche de Pocquereux est désormais bien établie.

A la Réunion, le dialogue établi avec les assemblées régionales et départementales permet de mener des recherches répondant bien aux besoins de l'île. Les actions de développement réalisées en collaboration avec la chambre d'agriculture contribuent à une progression sensible de la production fruitière. La coopération dans l'océan Indien - en particulier avec l'île Maurice — prend de I'ampleur.

A la Guadeloupe et à la Martinique, I'année a été marquée par l'instabilité de l'économie bananière, due à la mise en place prochaine de l'Organisation commune de marché (OCM). Avec le souci $d^{\prime}$ 'une meilleure compétitivité et d'une protection — à long terme - de l'environnement, la profession exprime une forte demande d'innovation technique. Cette évolution implique des capacités de recherche accrues, une adaptation aux exigences de la coopération régionale et internationale, et un renforcement des échanges avec les acteurs de la filière.

Le symposium sur l'amélioration génétique des bananiers pour les résistances aux maladies et aux ravageurs, organisé en collaboration avec I'INIBAP du 7 au 9 septembre 1992 à Montpellier, illustre bien le rôle et l'ouverture du département. A l'occasion de cette manifestation, la coopération internationale sous forme de réseau, déjà fortement structurée par I'INIBAP, s'est encore accrue.

Le début de l'année 1993 marque une étape importante dans I'histoire de I'IRFA. Son mandat est significativement élargi : il devient le département des productions fruitières et horticoles du CIRAD et adopte un nouveau sigle, CIRAD-FLHOR. Son champ de compétence est ainsi étendu aux filières des légumes, des plantes ornementales, aromatiques et médicinales. Il a pour mission de contribuer à un meilleur approvisionnement des centres urbains et des marchés d'exportation en produits frais et transformés issus de l'arboriculture fruitière, du maraîchage et des cultures florales.

Les nouvelles responsabilités du département le placent au sein du dispositif que le CIRAD construit pour mieux répondre aux demandes de ses partenaires en accroissant son offre dans le domaine horticole. Il exercera son activité en concertation et en complémentarité avec le département des cultures annuelles et le département des systèmes agroalimentaires et ruraux.

Enfin, son nouveau mandat devrait permettre au département des productions fruitières et horticoles de procéder à un redéploiement géostratégique dans le cadre des coopérations régionales. 


\title{
Programme
} agrumes

Pour promouvoir de nouveaux types de vergers, mieux adaptés aux situations agroéconomiques des pays de la zone tropicale et subtropicale, des techniques agrumicoles sont créées, améliorées, expérimentées. Les thèmes retenus pour le programme agrumes sont

\section{DÉPARTEMENT DES PRODUCTIONS FRUITIÈRES ET HORTICOLES}

\author{
CIRAD-FLHOR* \\ Directeur \\ Directeur adjoint \\ et directeur des programmes \\ Directeur scientifique \\ Responsable \\ administratif et financier \\ Jean-Louis Rastoin \\ Jean-Pierre Gaillard \\ Jacky Ganry \\ Catherine Pacherie-Simeral
}

\section{Programmes de recherche}

Agrumes

Ananas

Bananiers et plantains

Diversification fruitière
Bernard Aubert

Pierre Martin-Prevel

Hugues Tézenas du Montcel

Bernard Aubert

\section{Unités de recherche}

Ressources génétiques et amélioration des plantes

Biologie et contrôle des parasites et ravageurs Agronomie et systèmes de production Economie et gestion Technologie

et maîtrise de la qualité Biométrie et informatique

\section{Services d'appui technique}

Publications, documentation Chantal Loison la gestion et la valorisation des ressources génétiques, I'amélioration génétique et les biotechnologies, la lutte contre les maladies et les ravageurs, l'écophysiologie et l'élaboration du rendement, la technologie alimentaire et les huiles essentielles.

\section{Gestion et valorisation des ressources génétiques}

Un système de gestion informatisé des collections d'agrumes a été mis au point à la Martinique. Il peut être exploité en vue du criblage variétal. Outre la position de l'arbre dans la parcelle, le système prend en compte son origine génétique, son historique et ses performances agronomiques. Ce système a retenu l'attention des spécialistes en arboriculture fruitière de I'INRA, qui souhaitent l'élargir à d'autres espèces fruitières ligneuses.

La publication du catalogue des espèces et cultivars de la collection de Corse devrait permettre d'élargir la clientèle s'approvisionnant en greffons et graines de porte-greffe d'élite. Un important travail de dépistage a été entrepris par le service de virologie afin de préserver la qualité sanitaire exceptionnelle du matériel végétal corse, qui, à la demande des instances locales, alimente des pépinières aux Antilles, en Nouvelle-Calédonie et à la Réunion.

Par ailleurs, pour créer des clôtures impénétrables autour de sites à protéger, une étude sur les haies défensives d'épineux composées de diverses espèces, dont la plus importante est Poncirus trifoliata, a été lancée.

\section{Amélioration génétique et biotechnologies}

L'évaluation génétique des agrumes grâce aux techniques de marquage moléculaire a apporté un éclairage nouveau sur la taxonomie et l'évolution des agrumes.

Trois taxons ancestraux des Citrus cultivés ont été clairement identifiés. Les génomes nucléaires et cytoplasmiques des mandariniers, cédratiers et pamplemoussiers sont en effet fortement différenciés tant au niveau allélique que structurel. La cytométrie en flux a mis en évidence que la variation des tailles des génomes nucléaires du genre Citrus est de l'ordre 
de $10 \%$. Les plus petits sont ceux des mandariniers, les plus grands ceux des cédratiers. Les structures génotypiques complexes observées pour la majorité des cultivars d'importance économique indiquent clairement que seules des stratégies de modification ponctuelle du génome permettront d'améliorer efficacement les cultivars, en particulier leur résistance aux pathogènes.

A cette fin, une carte de moyenne résolution du génome des agrumes a été obtenue. Elle associe plus de 100 marqueurs RAPD, RFLP et isozymes. La descendance de l'hybridation intergénérique Citrus x Poncirus ayant servi à l'établir devrait également permettre, dans les années à venir, la localisation de plusieurs gènes de résistance à la tristeza, à Phytophthora et aux nématodes présents dans le génome des Poncirus.

Les techniques d'embryogenèse somatique ont été développées à partir des tissus nucellaires de l'ovule. Une collection d'une douzaine de cultivars est aujourd'hui conservée sous forme de cals embryogènes. Les premiers résultats obtenus pour la cryoconservation des suspensions cellulaires devraient aboutir à l'établissement d'une banque cryoconservée des principaux cultivars en vue de leur amélioration par transgénose. La régénération des plantules à partir des cals et des suspensions cellulaires est bien maîtrisée. Les techniques d'isolement et de régénération des protoplastes ont été mises au point en collaboration avec I'université de Floride, à Lake Alfred. Les premiers travaux de transgénose avec le gène marqueur Gus ont été réalisés. Parallèlement, des hybrides somatiques ont été obtenus et sont en phase de régénération et d'acclimatation.

\section{Lutte contre les maladies et les ravageurs}

Une technique de diagnostic du chancre citrique (forme asiatique) a été récemment développée par l'équipe de la Réunion en collaboration avec des chercheurs de I'USDA de Beltsville. Un fragment d'ADN

plasmidique associé à ce chancre (PFL 62.42) a été cloné dans Escherichia coli. Une méthode de détection fine, par amplification génique (PCR), va être utilisée pour la réalisation d'études épidémiologiques et pour la certification de la qualité sanitaire des plants.

Cette technique de pointe prend toute sa valeur alors que l'on redéfinit les modalités d'importation des agrumes dans la Communauté européenne, notamment en provenance de l'Amérique du Sud.

Dans la Caraïbe, la progression de la tristeza est d'autant plus surveillée que son principal vecteur, le puceron Toxoptera citricidus, a atteint la République dominicaine.

La technique d'électrophorèses successives en gel de polyacrylamide a été adaptée pour la détection du complexe de douze viroïdes affectant les agrumes.

A la Réunion, les mouches des fruits s'attaquent à une trentaine d'espèces fruitières et sont à l'origine de pertes évaluées à 7 millions de francs par an. Les recherches se concentrent sur la mouche du Natal, Ceratitis rosa, qui cause les plus gros dégâts.

L'étude des facteurs d'attractivité des fruits a montré que, contrairement à la majorité des autres espèces, le comportement de cette mouche est dominé

\section{Des produits pour le développement}

\section{Mouche des fruits : un succès d'éradication à la Réunion}

Une nouvelle mouche des fruits, Bactrocera zonata, originaire d'Asie et particulièrement active, s'était propagée à Maurice depuis 1986. Les chercheurs, la chambre d'agriculture et les services de la protection des végétaux de la Réunion, conscients de cette proche menace, ont mené en 1991 et 1992 une campagne de piégeage précoce dans les zones les plus directement exposées. La mouche a été éradiquée dans les mois suivant son apparition dans I'île. La surveillance est maintenue. 


\section{FRUITS ET AGRUMES}

\section{Rencontres internationales}

\section{Agrumiculture pour la Caraïbe}

La conférence régionale IICA-CIRAD

sur l'agrumiculture dans la Caraïbe s'est déroulée à Fort-de-France les 18 et 19 février 1992. Organisée par le département des fruits et agrumes du CIRAD et financée par le Fonds interministériel français pour la Caraïbe (FIC), que représentait le projet fruitier régional de I'IICA, cette conférence a rassemblé une vingtaine de représentants de la Martinique et de la Guadeloupe, et une trentaine de délégués venus de Trinité-et-Tobago, de la République dominicaine, de Dominique, de Sainte-Lucie et de Guyana. Des itinéraires techniques comportant des innovations ayant trait au travail du sol, au choix des porte-greffe et des cultivars, au dépistage des maladies à virus et de leurs vecteurs, résultats des travaux sur les agrumes engagés à la Martinique au cours des dix dernières années, ont été présentés. Au terme de cette conférence, une motion a été adoptée à l'unanimité pour le renforcement de la collaboration scientifique agrumicole entre les pays de la Caraibe.

\section{Le réseau international ananas}

Les chercheurs du département des fruits et agrumes du CIRAD ont présenté huit communications au premier symposium international sur l'ananas, organisé à Honolulu du 2 au 6 novembre 1992. Le CIRAD et l'université d'Hawaii ont animé le groupe de travail constitué au sein de la commission tropicale de la société internationale de la science horticole (ISHS). L'ouverture géographique et institutionnelle qui se dessine sera un facteur favorable aux recherches internationales sur l'ananas. Le département est chargé d'organiser le deuxième symposium, qui aura lieu en 1995. par le parfum. Ce résultat devrait déboucher sur des applications pratiques. Avec deux hyménoptères, Biosteres arisanus, parasite des œufs, et B. vandenboschi, parasite des jeunes asticots, des techniques de lutte biologique sont en cours de mise au point.

Des traitements par appâts empoisonnés se révèlent aussi efficaces que la lutte chimique classique mais beaucoup moins coûteux et respectent l'environnement. Le piégeage sexuel de la mouche sert de système d'avertissement pour commencer les traitements. Ces techniques sont déjà appliquées par les agriculteurs.

L'expérience de l'équipe de la Réunion sur la mouche des fruits est mise à contribution dans le cadre d'un partenariat avec la Grèce, soutenu par la CCE, auquel contribuent l'université de Thessalonique et I'IMBB.

Pour un autre projet de la CCE sur le diagnostic et la prévention d'organismes nuisibles susceptibles d'atteindre les vergers d'agrumes européens, le département des fruits et agrumes est partenaire de I'IVIA (Espagne).

\section{Ecophysiologie et élaboration du rendement}

Des mesures micrométriques en continu d'organes

— branches ou fruits - de clémentinier

ont été effectuées en Corse pour évaluer l'intensité des stress hydriques. Ces informations sont précieuses pour l'élaboration de systèmes de rationnement en eau qui n'affectent ni le rendement ni la qualité.

Par ailleurs, une étude préliminaire a été entreprise sur la formation et l'utilisation des réserves en sucres et en amidon dans les parties aériennes du clémentinier sous le climat corse.

Une synthèse des résultats d'un essai de porte-greffe de clémentinier conduit en Corse pendant vingt ans a été réalisée. Le citrange et le Poncirus confèrent une meilleure productivité que le bigaradier. Le Poncirus présente le meilleur comportement en sol à tendance hydromorphe.

A la Martinique, le porte-greffe Flying Dragon a été testé avec succès en verger de comportement. Ce porte-greffe, 


\section{FRUITS ET AGRUMES}

qui fournit des arbres nains à compacts, va permettre de moderniser la conception du verger tropical.

\section{Technologie alimentaire}

Des travaux sont en cours sur la désamérisation des jus d'agrumes par voie enzymatique ou biophysique. Un contrat industriel a été signé avec la société Marie Brizard pour engager des travaux sur la détection des adultérations de jus d'agrumes.

\section{Programme} ananas

Les activités du programme ananas sont axées sur la diversification des variétés commercialisées, avec un important volet de création variétale, et sur l'étude des mécanismes régissant l'élaboration du rendement et de la qualité. Des recherches $d^{\prime}$ accompagnement sont destinées à optimiser les systèmes de production de l'ananas en Amérique andine, dans la Caraïbe, en Afrique et aux Mascareignes.

\section{Amélioration variétale}

La sélection se poursuit sur les descendances d'hybridations antérieures, mais elle se diversifie selon les demandes des marchés. On ne recherche plus un modèle de fruit unique, mais un idéotype adapté à la production de tranches en boîtes, un autre (légèrement multiforme) pour la relance des courants d'exportation en frais, un troisième pour la fabrication de jus, sans oublier les préférences du marché interne. $S^{\prime} y$ ajoutent, comme produits accessoires, les ananas floraux.

En vue de cette diversification, une nouvelle série de grandes prospections financée par la CCE a été entreprise dans le bassin amazonien par des équipes franco-brésiliennes. Cinq cents accessions nouvelles ont été récoltées dans I'Amapa,

\section{Publication}

\begin{abstract}
Ananas : critères de qualité
Le COLEACP, association internationale des importateurs européens et des exportateurs des pays $A C P$, et le CIRAD ont collaboré pour éditer un ouvrage de référence, Ananas : critères de qualité. Cet ouvrage présente les caractéristiques optimales de qualité du fruit, les facteurs susceptibles d'affecter cette qualité, les anomalies et les critères d'évaluation à chaque stade de la culture et de la commercialisation. Des photographies commentées permettront aux différents intervenants de la filière, du producteur au commerçant, de définir sans ambiguité les défauts constatés, d'en déterminer les causes et les remèdes.
\end{abstract}

I'Acre et le Mato Grosso. La méthode d'évaluation de ces accessions a été affinée en combinant trois techniques d'analyse multifactorielle appliquées à un ensemble de 45 critères quantitatifs et qualitatifs.

En collaboration avec l'université de Louvain-la-Neuve, dans le cadre du même financement, les conditions de viabilité du pollen et des ovules ont été partiellement élucidées, ainsi que les mécanismes d'incompatibilité.

Cependant, pour les hybridations, la graine est un premier stade nécessaire. Jusqu'à présent, le degré de compatibilité des géniteurs ne pouvait pas être évalué. La possibilité de lever temporairement les incompatibilités accroîtra le spectre des hybridations réalisables. Ces études ont permis de préciser la position taxonomique de certains groupes encore mal définis.

\section{Elaboration du rendement et de la qualité}

Des travaux réalisés en Côte-d'Ivoire ont abouti à la modélisation de la croissance pondérale et du rendement de l'ananas en fonction des paramètres 


\section{FRUITS ET AGRUMES}

climatiques. Cette modélisation, destinée à faciliter les décisions des agriculteurs, est testée dans les conditions d'Hawaii, où un autre modèle a été élaboré par I'Université. La collaboration engagée devrait aboutir à l'optimisation de ces modèles.

D'autre part, pour adapter la culture de l'ananas aux différentes écologies, le système expert Diana permet d'établir, sur le terrain, un diagnostic de l'état des parcelles. II prend en compte les caractéristiques du sol, la fertilisation, le climat et la pression parasitaire.

\section{Systèmes de culture}

Les travaux se sont poursuivis en Amérique latine et en Asie pour conforter les contacts qui s'établissent dans les zones de production intensive.

Par des expérimentations multilocales, une meilleure connaissance des cycles a permis de préciser les programmes de fertilisation en Colombie. Une collecte du germplasm colombien a été suivie d'une évaluation comparative des variétés Manzana et Cayenne. Les activités de conseil et d'expertise s'exercent en Equateur et dans plusieurs pays d'Amérique centrale (Costa Rica, Honduras, Nicaragua). Un programme d'amélioration de la culture de l'ananas financé par la CCE se poursuit en Amazonie péruvienne, en collaboration avec la structure nationale de recherche agronomique, I'INIAA. Une nouvelle action de ce type est prévue en Bolivie.

Au Vietnam, I'ananas, une des rares plantes cultivables dans les sols sulfatés acides du delta du Mékong, se prête aux études de fond sur la résistance à différentes agressions et sur des techniques originales d'aménagement et de conduite des cultures.

Aux Philippines, une étude sur l'association de cocotiers et d'ananas devrait permettre aux paysans de tirer le meilleur profit de chacune de ces deux cultures, I'une industrielle, l'autre familiale. L'ananas préserve la couverture du sol et participe à la lutte contre I'érosion.

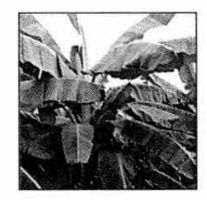

\section{Programme bananiers et plantains}

Des variétés de bananes plus tolérantes et des méthodes de lutte intégrée pour faire face aux ravageurs et aux maladies, des techniques et des systèmes de culture rentables et qui préservent l'environnement, une adaptation de la production aux besoins locaux, tels sont les principaux objectifs du programme bananiers et plantains.

\section{Amélioration génétique et phytopathologie}

Les études de classification associent des techniques de marquage moléculaire, comme l'électrophorèse d'isozymes et I'analyse du polymorphisme de restriction (RFLP), et des descriptions morphologiques - par fiches descriptives standardisées couplées à un logiciel informatique de détermination variétale, Musaid. Ces études apportent des informations essentielles pour le sélectionneur.

Par l'analyse de descendances en ségrégation et la maîtrise de la polyploïdisation, on est en mesure d'appréhender les mécanismes génétiques gouvernant la transmission de caractères agronomiques ou de résistance aux pathogènes. En association avec les études de cytogénétique, les relations inter et intra-spécifiques ainsi que les composantes de la stérilité sont maintenant mieux comprises.

La construction d'une carte génétique par les techniques de marquage moléculaire (RFLP) est en bonne voie de réalisation et rendra possible la localisation génomique de caractères à sélectionner.

Les résultats obtenus dans le domaine des biotechnologies constituent un appui précieux à une stratégie d'amélioration conventionnelle par hybridation : mise au point des techniques de sauvetage d'embryon zygotique, confirmation de la possibilité d'utiliser l'androgenèse et la parthénogenèse induite. L'évolution des techniques 


\section{FRUITS ET AGRUMES}

d'embryogenèse somatique et de régénération de protoplastes permet d'envisager la création variétale par transformation génétique des cultivars triploïdes ou des parents potentiels diploïdes. Les premiers essais de transformation par bombardement de particules montrent que cette méthode est applicable sur le bananier.

Les progrès dans la connaissance des mécanismes de résistance aux cercosporioses ouvrent la voie à une meilleure stratégie de l'amélioration génétique.

La recherche de systèmes de production plus respectueux de l'environnement passe par l'utilisation d'un matériel végétal indemne de maladies, comme le vitroplant, dans un environnement sain. En ce sens, les travaux conduits sur le complexe souterrain ont une importance de tout premier plan. Ils aboutissent à une meilleure connaissance des populations des champignons pathogènes : leur cycle, leur pathogénie, les interactions avec les nématodes. Ils permettent d'envisager une amélioration des méthodes de diagnostic et des techniques de contrôle du parasitisme tellurique. Une endomycorhization a été clairement mise en évidence chez le bananier.

\section{Qualité du fruit}

Le critère de qualité est un déterminant majeur de la compétitivité commerciale pour l'exportation des bananes. Après l'analyse des composantes strictement physiologiques, l'accent est mis sur les composantes pathologiques. Un piège à spores a été adapté sur le bananier afin d'étudier les sources et les variations d'inoculum de Colletotrichum musae et de Fusarium sp. sur les fruits. Cet outil permettra de tester diverses techniques destinées à réduire l'inoculum et donc à améliorer la qualité sanitaire des bananes.

\section{Enquêtes agronomiques et économiques}

Les compétences acquises en agronomie des bananiers sont utilisées pour la réalisation d'enquêtes agronomiques multifactorielles dans différentes conditions de production. Par ces enquêtes, les principaux facteurs limitants, de sol et de fertilité, sont identifiés et hiérarchisés. Les résultats obtenus, directement traduits en conseils aux producteurs, orientent également le choix des recherches thématiques à entreprendre pour améliorer la production à plus long terme. Après le Cameroun, la Martinique, la Guadeloupe et le Rwanda, la dernière enquête, faite en Colombie, a confirmé l'intérêt de cette approche.

Des enquêtes conduites dans le sud-ouest du Cameroun ont abouti à un repérage et à une analyse dynamique des systèmes de production de la banane plantain. Elles mettent en évidence l'essor du plantain comme production de rapport ainsi que l'influence agroécologique déterminante des ravageurs. Le charançon, en particulier, impose un déplacement de la culture, au détriment de la forêt. L'éradication de cet insecte est un objectif prioritaire pour parvenir à la sédentarisation de la culture.

\section{Rencontres internationales}

\section{Amélioration génétique du bananier}

Un symposium sur l'amélioration génétique des bananiers pour les résistances aux maladies et aux ravageurs s'est tenu à Montpellier du 7 au 9 septembre 1992. Ce symposium a mobilisé 151 personnes représentant 37 pays. Trois sessions, consacrées aux contraintes liées à la plante, aux pathogènes et aux stratégies d'amélioration, ont permis de faire un large tour d'horizon des problèmes actuels et des moyens d'action mis en œuvre dans le monde. Les partenaires scientifiques du projet européen Sciences et technologies du vivant pour les pays en développement - université de Louvain-la-Neuve, NRI, WINBAN, CRBP, CIRAD - ont exposé, en 30 communications, les résultats de recherches qu'ils conduisent en concertation depuis huit ans. D'autres équipes ont également présenté leurs travaux et apporté une ouverture vers d'autres approches, d'autres objectifs. 


\section{FRUITS ET AGRUMES}

La filière de commercialisation de la banane plantain au Cameroun présente certaines similitudes avec celles d'autres régions productrices en Afrique. Malgré une organisation remarquable, les coûts de transaction sont importants et pourraient être diminués. Les pertes de postrécolte, inférieures à $5 \%$, sont faibles. Des innovations techniques en matière de conditionnement ne semblent pas présenter d'intérêt car les circuits de commercialisation sont courts. Pourtant, elles pourraient devenir intéressantes avec l'essor d'un marché interrégional.

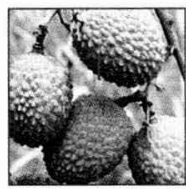

\section{Programme diversification fruitière}

L'extension des cultures de fruits tropicaux autres que les bananes, les ananas et les agrumes a un double objectif : élargir les disponibilités en fruits frais pour la consommation locale des pays producteurs et développer des activités exportatrices, tant en produits frais qu'en produits transformés à haute valeur ajoutée. Pour y contribuer, le programme de diversification fruitière a pour priorités la défense des cultures, l'écophysiologie et les technologies de transformation et de conservation. La mise au point de techniques fournit des solutions à court terme, tandis que les recherches en amélioration variétale apportent des réponses de fond.

\section{Amélioration génétique}

De nouvelles accessions ont enrichi les collections de manguiers, litchis et passiflores. Les travaux sur ces collections permettent de sélectionner certaines variétés en fonction de caractéristiques précises : papayers tolérants à la bactériose aux Antilles, porte-greffe de passiflores tolérants à Fusarium oxysporum, litchis plus précoces, manguiers tolérants à l'anthracnose et à la bactériose.

Les garanties sanitaires des collections permettent de multiplier et de diffuser un matériel végétal d'élite. Ainsi, plus de 100000 plants greffés ont été fournis

\section{Des produits pour le développement}

\author{
Un appareil de désinsectisation des dattes \\ Les fruits secs, notamment les dattes, \\ dont la production est d'environ 2 millions de tonnes \\ par an, doivent être protégés par des traitements \\ chimiques appliqués après la récolte. Une technique \\ de traitement physique contre les insectes des fruits \\ secs a été élaborée par le département des fruits \\ et agrumes du CIRAD. Les premiers résultats \\ établissent que l'on obtient une mortalité de $100 \%$ \\ des œufs et des larves $d^{\prime}$ Ectomyelois ceratoniae, \\ principal responsable des pertes après la récolte \\ des dattes. Ce procédé pourrait remplacer les produits \\ chimiques, en particulier le bromure de méthyle, \\ dont l'utilisation va être interdite par la législation \\ européenne. La mise au point d'un appareil adapté \\ aux petites et moyennes productions est en cours.
}

à des producteurs d'une vingtaine de pays.

Une opération de multiplication d'espèces fruitières rares en voie de disparition est en cours à la Réunion.

\section{Défense des cultures}

$L^{\prime}$ inventaire des ravageurs des espèces fruitières en Nouvelle-Calédonie a défini les menaces les plus fortes - mouches des fruits, papillons piqueurs pour l'implantation de nouvelles cultures.

Le rôle des bourgeons du manguier dans la conservation et la dissémination de la bactérie Xanthomonas campestris mangiferae a été prouvé, et les conditions d'utilisation des greffons ont ainsi pu être précisées.

\section{Technologie}

La mise au point, en Colombie, de l'extraction des pectines des peaux et des pépins de passiflores est à l'origine de nouveaux produits complémentaires 


\section{FRUITS ET AGRUMES}

des jus et concentrés. D'autres opérations ponctuelles, comme la mise au point d'un procédé de fabrication de vinaigre de papaye au Burundi ou la désinsectisation des dattes par voie physique pour la Tunisie, illustrent les apports de la recherche technologique selon les situations locales.

\section{Agronomie et écophysiologie}

Des études fines en physiologie de la croissance et du développement ont permis de mieux comprendre le comportement du pêcher et de la vigne en l'absence de froid, ainsi que les phénomènes de réitération chez le goyavier. La connaissance de ces processus de croissance et de développement conduit à la mise au point de techniques de taille mieux raisonnées influençant l'élaboration du rendement.

Les travaux conduits à la Réunion et en Côte-d'Ivoire ont abouti à de nouveaux itinéraires techniques pour le litchi, le pêcher et le manguier.

A la Réunion, la culture de la fraise s'est considérablement développée, et la consommation locale a quintuplé en moins de dix ans. L'itinéraire technique est mis en œuvre avec l'appui des groupements professionnels locaux depuis la production du matériel végétal. II assure la maîtrise complète de cette culture en zone tropicale et suscite des demandes d'expertise en régions chaudes.

\section{Les thèses soutenues en 1992}

\section{Chercheurs du département}

Etude dynamique de la croissance et du développement des bourgeons de quelques cultivars de pêchers cultivés à diverses altitudes sous le climat tropical de la Réunion, par Philippe Balandier, université Blaise Pascal, Clermont-Ferrand.

Etude des interactions hôte-parasite chez des bananiers sensibles et résistants inoculés par Cercospora fijiensis, responsable de la maladie des raies noires, par André Beveraggi, université des sciences et techniques du Languedoc, Montpellier II.

Etude architecturale du goyavier, par Jean-Yves Rey, université des sciences et techniques du Languedoc, Montpellier II.
Accueil par le département

Régénération chez Musa sp. : recherche des conditions d'établissement de suspensions cellulaires d'espèces diploïdes et triploïdes, par Cécile Chatelet (France), université Paris XI, centre d'Orsay.

Contribution à l'étude des ressources génétiques des passiflores forestières de Guyane française pour I'amélioration de la culture des fruits de la passion, par Olivia Delanoe (France), université des sciences et techniques du Languedoc, Montpellier II.

Le chancre bactérien des agrumes (Xanthomonas campestris pv. citri) : étude épidémiologique et écologique dans le cadre de l'île de la Réunion, par Christian Vernière (France), université Paris XI, centre d'Orsay. 


\section{ÉLEVAGE ET MÉDECINE VÉTÉRINAIRE}

A méliorer les élevages de diverses espèces et races animales des pays chauds, intégrer des animaux dans les systèmes de production agricoles, assurer la protection sanitaire du bétail sont les priorités du département d'élevage et de médecine vétérinaire du CIRAD. Pour cela, les recherches favorisant une meilleure alimentation ont été renforcées : exploitation des parcours, pâturages améliorés, valorisation des sous-produits des cultures, constitution de réserves fourragères. L'importance économique des maladies dans les divers systèmes de production, les mesures prophylactiques, l'adaptation aux difficiles conditions du terrain de certains outils de diagnostic et de vaccins sont les points forts des programmes de médecine vétérinaire. Des progrès ont été réalisés dans la lutte contre les trypanosomoses et certaines maladies transmises par les tiques, fréquentes dans les élevages des régions tropicales humides.

Le département conduit une grande part de ses recherches avec les pays de l'Afrique francophone, Madagascar et les départements et territoires d'outre-mer (Réunion, Nouvelle-Calédonie, Guadeloupe, Guyane). II travaille aussi en Afrique de I'Est (Ethiopie, Zimbabwe, Soudan), en Asie (Thaïlande, Malaisie) et en Amérique tropicale (Colombie, Brésil).

En Afrique, des équipes de recherche se forment, qui ont une vocation internationale, comme le Centre international de recherche-développement sur l'élevage en zone subhumide (CIRDES) au Burkina Faso, ou régionale, comme le projet de recherche sur les petits ruminants, qui intéresse le Tchad, le Cameroun et le Niger. Beaucoup d'actions restent bilatérales, car la demande de coopération de la part des organismes nationaux de recherche demeure importante.

En Amérique, la base des Caraïbes et les antennes de Guyane et du Brésil travaillent surtout dans le domaine de la pathologie, sur les trypanosomoses, les tiques et les maladies à tiques. Des recherches sur les ressources pastorales et les systèmes de production s'amorcent en Guyane et au Brésil.
En Asie du Sud-Est et en Océanie, des accords ont été établis à partir de la Nouvelle-Calédonie (par exemple pour l'élevage des cerfs en Malaisie), tant en secteur public qu'en secteur privé.

Une stratégie d'alliances s'amplifie, non seulement avec les principales institutions françaises, comme I'INRA, I'ORSTOM, I'Institut Pasteur, le Muséum national $\mathrm{d}^{\prime}$ histoire naturelle, diverses universités, mais aussi avec les centres internationaux de recherche agricole, comme I'ILRAD, le CIPEA, le CIAT.

Trois projets dans le domaine de la nutrition animale et quatre projets dans le domaine de la santé, en partie financés par la CCE, impliquent plusieurs pays africains ou tropicaux et des laboratoires européens.

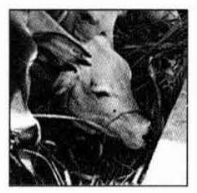

\section{Programme ressources alimentaires}

Pour permettre aux éleveurs de fournir toute l'année des rations de fourrage ou d'aliments suffisamment abondantes et nutritives à leurs animaux, des techniques sont élaborées, la gestion de l'espace pastoral améliorée, la connaissance de la nutrition des animaux approfondie.

\section{Surveillance des ressources pastorales}

Des dispositifs d'observation de la végétation ont été élaborés en Afrique de l'Ouest dans le but de limiter les conséquences des sécheresses pour les éleveurs et d'organiser au mieux les mesures d'urgence dans les régions sahéliennes. L'évaluation précoce de la production herbacée permet d'orienter rapidement les troupeaux vers les régions les plus favorisées et de prévoir les besoins en compléments alimentaires de secours. La méthode, élaborée en collaboration avec AGRHYMET, se fonde sur l'exploitation des données à haute résolution des satellites NOAA traitées en indices de végétation. Les valeurs de biomasse végétale correspondant aux classes d'indice sont obtenues au sol sur un réseau de sites échantillons. Des cartes de la biomasse végétale sont ainsi réalisées chaque année. 


\section{ÉLEVAGE ET MÉDECINE VÉTÉRINAIRE}

\section{DÉPARTEMENT \\ D'ÉLEVAGE ET DE MÉDECINE VÉTÉRINAIRE}

\section{CIRAD-EMVT}

\author{
Directeur Georges Tacher \\ Directeur scientifique \\ (productions animales) \\ Directeur scientifique \\ (santé animale) \\ Directeur \\ administratif et financier \\ Gérard Matheron \\ Gerrit Uilenberg \\ Jean-Vital Decloquement
}

\section{Programmes de recherche}

Ressources alimentaires Ressources animales Systèmes de production animale Aquaculture et pêche Pathologie infectieuse Pathologie parasitaire Ecopathologie

Bernard Toutain Dominique Planchenault Philippe Lhoste Jérôme Lazard Pierre-Charles Lefèvre Gerrit Uilenberg Pierre-Charles Lefèvre

\section{Services d'appui technique}

$\begin{aligned} \text { Documentation } & \text { Geneviève Thierry } \\ \text { Publications } & \text { Dominique Lasserre } \\ \text { Enseignement } & \text { Jean Gruvel }\end{aligned}$

Des structures nationales utilisent cette méthode au Tchad et au Burkina Faso.

Un groupe de chercheurs de I'ORSTOM, du CNRS et du CIRAD a réalisé la première cartographie de la biomasse végétale du nord du Sénégal à partir d'un modèle climatique. Les pluviométries ont été évaluées d'après les températures des sommets de nuages fournies par le satellite Météosat ; les bases de données quantitatives de la végétation recueillies sur le terrain ont permis de préciser la valeur des coefficients du modèle.

En zone de savane, la pratique de l'élevage dépend de la répartition de l'espace pastoral et des surfaces cultivées. Une synthèse cartographique régionale de l'occupation des sols, s'appuyant sur des travaux de terrain antérieurs, a été réalisée grâce à une base de données statistiques obtenue par sondage systématique et interprétation d'images satellitaires. Elle concerne une large zone couvrant en partie trois pays, le Burkina Faso, la Côte-d'Ivoire et le Mali. Des informations chiffrées peuvent être extraites, indépendamment de l'échelle.

\section{Production de fourrage}

En Afrique tropicale humide, I'envahissement par l'herbe du Laos (Chromolaena odorata) des savanes surexploitées a rendu inaccessibles au bétail de larges zones traditionnellement ouvertes à l'élevage. L'extension de cette plante est devenue contrôlable grâce à la mise au point, en République centrafricaine, d'une lutte intégrée. Elle fait appel à des pulvérisations d'herbicides, déterminées en fonction du stade phénologique de la plante, associées à des moyens physiques, comme le feu, et à d'autres techniques culturales.

Dans le nord du Sénégal, I'ISRA, avec I'appui du CIRAD, a expérimenté quelques espèces de graminées fourragères tolérantes à la salinité. Dans les casiers irrigués stérilisés par la salinisation, Echinochloa pyramidalis, Diplachne fusca, Chloris gayana et Sporobolus robustus se sont bien développées. La production de fourrage dans les périmètres rizicoles permet la pratique de l'élevage sur des terres inaptes à l'agriculture vivrière.

L'ensilage d'herbe est désormais envisageable en milieu tropical. En Nouvelle-Calédonie, la mesure du pouvoir tampon de diverses espèces de graminées a permis de choisir celles qui s'acidifient rapidement, comme Panicum maximum et Brachiaria decumbens. A la Réunion, la technologie de I'ensilage en balles rondes sous film plastique a été mise au point avec le département des systèmes agroalimentaires et ruraux. Pour les graminées tempérées (ray-grass), un conservateur, comme l'acide formique, doit être ajouté. Les espèces tropicales récoltées au printemps ne nécessitent pas d'additif.

Une banque de semences a été créée à Montpellier pour permettre aux stations expérimentales de diversifier I'usage des plantes fourragères. Elle débute 


\section{ÉLEVAGE ET MÉDECINE VÉTÉRINAIRE}

avec une vingtaine d'espèces et de variétés tropicales d'origines diverses.

\section{Alimentation des animaux}

En 1992, le CIRAD a adhéré à une base de données sur les valeurs alimentaires associant divers professionnels de l'alimentation animale. Ainsi, la composition des sous-produits tropicaux a été intégrée dans cette base, et, en retour, les interlocuteurs en régions chaudes peuvent bénéficier d'informations actualisées en provenance des pays industrialisés.

Une étude de la valeur nutritive et de l'ingestibilité des graminées fourragères cultivées en NouvelleCalédonie, en Afrique de l'Ouest et à la Guadeloupe, ainsi que des tourteaux de coprah et de palmiste, a été menée en collaboration avec I'INRA. Des tables, fondées sur des modèles de prévision des valeurs alimentaires, ont été publiées.

Un programme européen impliquant cinq institutions africaines et quatre laboratoires européens étudie le rôle des arbres et arbustes fourragers d'Afrique dans les systèmes d'élevage. La prévision de l'énergie métabolisable, calculée à partir de plus de 700 échantillons, a été plus précise par les mesures de dégradabilité enzymatique que par l'analyse chimique, ce qui avait été observé pour les fourrages herbacés. Le calcul prévisionnel de la dégradabilité de l'azote par la méthode de la pronase est affiné si l'on dose aussi l'azote insoluble dans les détergents acides. Les teneurs en tanins ont été évaluées sur 350 échantillons afin de mettre en évidence leur action sur la digestibilité, celle de l'azote en particulier.

Les performances animales, jusqu'alors étudiées essentiellement par rapport à la qualité de la ration alimentaire, sont à présent abordées en fonction des relations de l'animal avec son terroir. Dans le sud du Sénégal, des animaux ont été suivis de façon à noter les déplacements des troupeaux dans les différents types de végétation, les prélèvements de fourrage, les restitutions d'éléments fertilisants et les productions animales. Les écarts de résultats entre différents

\section{Publication}

\section{Atlas de l'élevage et des potentialités pastorales sahéliennes}

Cet ouvrage regroupe les acquis scientifiques de quarante années, souvent peu ou mal diffusés. Les principaux thèmes de l'élevage, exposés par pays, sont traités : ressources végétales (botanique, agropastoralisme, nutrition animale, ressources en eau et utilisation des parcours) ; ressources et santé animales (zootechnie, parasitologie et infrastructure vétérinaire). Le Tchad, le Niger, le Burkina Faso, le Mali, le Sénégal et la Mauritanie, en tout plus de 1300000 kilomètres carrés, ont été couverts dans le cadre de cette publication. La cartographie agropastorale, résultat de l'inventaire du tapis végétal sahélien, comprend 34 feuilles polychromes au 1/500 000. Les autres thèmes sont illustrés par des cartes à plus petites échelles. Les textes ont été rédigés en collaboration avec des spécialistes $d^{\prime}$ autres institutions africaines et françaises. Un atlas du nord du Cameroun, réalisé selon la même conception, est venu s'ajouter à cette série.

troupeaux mettent en évidence l'influence des pratiques des bergers sur les performances de leurs animaux.

La consommation de viandes blanches et d'œufs $s^{\prime}$ accroît rapidement dans les régions chaudes. Dans le domaine de l'élevage des monogastriques, le CIRAD a fourni des prestations de conseil et de diagnostic pour des filières, des projets de développement ou des programmes de recherche dans plusieurs pays d'Afrique et de la Caraïbe. En aviculture, les recherches ont porté sur l'alimentation séparée et sur les possibilités d'incorporation de tourteau de coton riche en gossypol.

Les volailles des élevages intensifs reçoivent habituellement des aliments complets de fabrication industrielle, qui ne leur permettent pas de choisir le type 
d'aliment qui leur convient au cours de la journée. En régions chaudes, l'alimentation libre, offrant séparément des aliments énergétiques (céréales) et un concentré complémentaire de haute qualité favorise la thermorégulation des oiseaux et fait appel aux produits locaux. Les avantages techniques et économiques de cette méthode ont été testés en collaboration avec I'INRA et l'IDESSA (Côte-d'Ivoire).

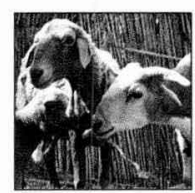

\section{Programme} ressources animales

Le programme contribue à la mise en place d'un système fiable de caractérisation et d'évaluation de la diversité d'espèces animales telles que les bovins, les petits ruminants, les dromadaires et certains animaux sauvages en régions tropicales.

\section{Enquêtes sur le bétail}

Dans les provinces camerounaises de l'Extrême-Nord, du Nord, de l'Adamaoua, de l'Ouest et du Nord-Ouest, le potentiel de production du bétail a été évalué sur la base d'un large inventaire. La région couvre près de 200000 kilomètres carrés et l'on y dénombre, pour 6 millions d'habitants, plus de 3 millions de bovins, 1,5 million de moutons et autant de chèvres. L'enquête, menée par quarante-deux enquêteurs spécialement formés, a duré dix semaines et a produit 38000 feuilles de réponses. Au total, 2035 troupeaux ont été étudiés, ce qui représente un effectif de 73000 bovins (soit un échantillonnage de 2,4\%), 9000 ovins et 7000 caprins. Cette évaluation, réalisée en moins d'un an, a révélé l'efficacité de la technique d'enquête mise au point et sa puissance de diagnostic sur la productivité des troupeaux.

Les éleveurs ont été répartis en dix catégories, depuis le pasteur vivant exclusivement de ses bovins jusqu'à l'agriculteur possédant quelques chèvres.

Dans chaque catégorie, et pour chaque espèce animale, les paramètres démographiques et zootechniques ont été établis. Ainsi, deux cents données nouvelles ont permis, en fin d'étude, de simuler le développement des troupeaux sur dix ans. L'enquête a été l'occasion de relever un " accident » en 1990-1991, qui se traduit actuellement par un manque d'effectif d'animaux de un à deux ans pour toutes les espèces. On s'attache à vérifier l'hypothèse d'une mortalité accrue des jeunes et d'une chute importante des naissances. Néanmoins, ce phénomène reste bénin, puisque ses effets devraient avoir totalement disparu en 1995. En revanche, pour toutes les espèces, les premières mises bas sont tardives. Ainsi, chez les vaches, elles ne se produisent pas à l'âge de quatre ans, mais vers six ans.

A partir d'études similaires réalisées au Tchad, en Guinée, au Niger, aux Comores, au Burkina Faso, une base de données a été conçue pour permettre d'effectuer des études comparatives sur des troupeaux d'origines différentes. Ce travail a commencé, en 1992, par la recherche de critères comparatifs pertinents à partir des enquêtes réalisées selon la méthode Kalao. La procédure de saisie a été améliorée, et on cherche à simplifier et à accélérer les enquêtes en ajoutant une base de données réduite propre à chaque nouvelle zone d'étude.

\section{Critères d'aspect et biodiversité}

Les critères d'aspect extérieur des animaux, les mensurations corporelles et les données phénotypiques diverses, regroupés dans des bases de données, permettent de s'interroger sur la réalité d'une différence intrapopulation, parfois plus importante que celle constatée entre plusieurs populations. L'idée qui est défendue est celle de la nécessité de caractériser les diverses races animales non plus intrinsèquement mais par rapport à un milieu spécifique ou à une utilisation particulière. Grâce à un ensemble complet et fonctionnel d'outils de suivi et d'évaluation remis à jour en 1992, les données collectées ont permis de porter un jugement objectif sur les productions animales. En Afrique, une grande variabilité subsiste, variabilité déjà fortement réduite sur d'autres continents. 


\section{ÉLEVAGE ET MÉDECINE VÉTÉRINAIRE}

L'étude de la faune sauvage a pour finalité la préservation de la biodiversité et la diversification des productions animales. C'est ainsi que les connaissances acquises en Nouvelle-Calédonie sur l'élevage du cerf rusa sont utilisées pour promouvoir le développement de cette production à la Réunion et en Asie du Sud-Est (Malaisie principalement). Le département participe aussi au développement de l'exploitation de la faune sauvage au Zimbabwe. Ces opérations ont conduit à la mise au point du logiciel Milan, spécifique du suivi de production des animaux sauvages.

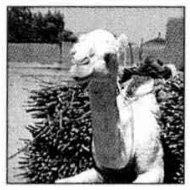

\section{Programme} systèmes de production animale

La pérennisation des systèmes de production et la préservation des ressources renouvelables contribuent au maintien des populations rurales dans leur milieu. Une meilleure connaissance des élevages par des méthodes de terrain permet de proposer des améliorations aux éleveurs.

\section{Amélioration de la production animale chez les éleveurs}

En Nouvelle-Calédonie, dans la province Nord, la typologie des systèmes d'élevage établie en 1991 a été la base d'un réseau de fermes de référence mis en place pour l'établissement d'un référentiel technique, support d'expérimentations chez les éleveurs. Une relation particulièrement active s'est établie avec les services provinciaux de développement rural au cours de cette opération.

Les troupeaux camelins du Soudan et du Niger sont soumis à des enquêtes très détaillées pour identifier les difficultés liées à cet élevage, expérimenter des solutions en milieu réel et les proposer à la vulgarisation. Comme au Soudan en 1990, six cents animaux ont été identifiés au Niger et suivis mensuellement à l'aide du logiciel Pikbeu. Au Kenya, la survie des chamelons jusqu'au sevrage est mise en relation avec la quantité de lait prélevée par l'éleveur. La collaboration avec I'ACSAD s'est concrétisée par l'édition d'un bulletin de liaison, Camel Newsletter, et par des protocoles expérimentaux sur l'alimentation des dromadaires et la technologie de la viande et du lait au Maroc et en Tunisie.

Au Cameroun, au Niger et au Tchad, le programme régional de recherche sur les petits ruminants comporte seize expérimentations touchant tant à la caractérisation des animaux et des systèmes de production locaux qu'aux situations pathologiques dans chacun de ces pays. Au Cameroun, le suivi zootechnique des bovins de la région de Garoua a montré que les coûts consentis pour l'alimentation sont largement compensés par les performances de reproduction.

En Guyane, le plan sectoriel de développement de l'élevage bovin a été mis en place avec l'ensemble de la profession.

\section{Rencontres internationales}

\section{La production cunicole en Afrique}

Pour la première fois, un congrès régional sur le lapin a été organisé en Afrique par le CIRAD, I'INRA et le Centre cunicole de recherche et d'information du Bénin (CECURI). Cette rencontre, qui a eu lieu à Cotonou du 16 au 20 mars 1992, a permis de montrer l'importance croissante de la production cunicole dans les sept pays représentés.

\section{Systèmes d'élevage}

A l'initiative du CIHEAM, de I'INRA et du CIRAD, le deuxième symposium international sur les systèmes d'élevage en ferme a eu lieu à Saragosse (Espagne), du 23 novembre au 4 décembre 1992. Il a rassemblé 126 participants de 33 pays. A cette occasion, une convergence, récente, a été relevée entre les démarches des zootechniciens d'Europe et celles de certains pays du Sud. 


\section{ÉLEVAGE ET MÉDECINE VÉTÉRINAIRE}

\section{Relations entre l'élevage et l'agriculture}

A Garoua, au Cameroun, les recherches sur la traction animale se concentrent sur l'efficacité de l'effort en relation avec l'espèce, l'état corporel et l'intensité du travail. Elles s'élargissent à l'ensemble animalharnachement-outil et abordent l'efficacité du travail du sol.

Au Burkina Faso, dans le cadre du CIRDES, deux axes de recherche sont développés. Une étude

de la productivité des troupeaux

et de la trypanotolérance est engagée grâce

à un dispositif de suivi pluridisciplinaire

chez les éleveurs. D'autre part, agriculture et élevage

sont associés à travers des expérimentations de cultures

fourragères. L'amélioration fourragère fondée

sur l'association de Panicum maximum cv. C1

et de Stylosanthes hamata, qui a donné des résultats

satisfaisants en station, est en cours d'adaptation

en milieu paysan. Les essais de fabrication de fumier

en étables à partir de tiges de cotonnier sont poursuivis.

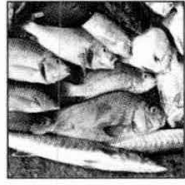

\section{Programme}

\section{aquaculture et pêche}

Le programme aquaculture et pêche poursuit ses activités sur la biologie des espèces aquacoles et sur les systèmes de production au centre de recherches piscicoles de I'IDESSA, à Bouaké (Côte-d'Ivoire). Il est par ailleurs chargé de la mise en œuvre de la troisième phase du projet de développement de l'aquaculture au Niger.

\section{Biologie des espèces aquacoles}

Les tilapias, dont la production mondiale est évaluée

à 500000 tonnes, constituent le troisième

groupe de poissons, après les carpes (cyprinidés)

et les salmonidés.

Un travail portant sur l'étude du déterminisme de la supériorité de croissance des mâles sur les femelles chez Oreochromis niloticus a été entrepris, en collaboration avec I'INRA, I'ORSTOM et l'université de Bordeaux. L'objectif est de préciser les facteurs indissociables de la masculinisation. Les premiers résultats font apparaître un effet des facteurs d'élevage sur la précocité d'apparition du dimorphisme, qui pourrait donc être lié à l'ontogenèse gonadique et aux modifications endocriniennes qui l'accompagnent.

Parallèlement, des travaux menés sur l'effet du stress causé aux populations aquacoles, notamment par des pêches répétées, montrent une augmentation des niveaux hormonaux de cortisol et de prolactine et un ralentissement de la croissance.

Il est donc nécessaire de mettre au point des techniques d'élevage qui réduisent au minimum la manipulation des poissons.

L'étude de la différenciation sexuelle chez Oreochromis par la thermosensibilité, mise en évidence en 1991, conduit à proposer une technique " propre » et économique de production de descendances à fortes proportions de mâles. Elle a porté sur la détermination de la période thermosensible, qui, à une température de traitement de $36{ }^{\circ} \mathrm{C}$, semble de dix jours au plus à compter du dixième jour après la fécondation.

Dans le but d'obtenir un tilapia à la fois résistant aux eaux saumâtres et de croissance optimale, des hybrides viables intergénériques Oreochromis niloticus $\times$ Sarotherodon melanotheron ont été obtenus à Bouaké : le premier, mâle, confère le potentiel de croissance, le second, femelle, la résistance au milieu lagunaire.

L'étude du polymorphisme enzymatique s'est poursuivie, en collaboration avec le laboratoire de génétique des poissons de I'INRA. L'analyse porte actuellement sur 34 populations appartenant à 9 espèces de tilapias. Aucune différence $\mathrm{n}^{\prime}$ a été diagnostiquée entre les populations d'O. niloticus. A Bouaké, le fort taux $d$ 'hétérozygotie et la présence d'allèles spécifiques des deux groupes sont à mettre en relation avec la double origine de l'élevage. Il s'agit d'un mélange de deux populations, I'une originaire de la Volta, I'autre du Nil. 


\section{ÉLEVAGE ET MÉDECINE VÉTÉRINAIRE}

Les techniques de PCR et de séquençage de I'ADN mitochondrial ont été mises au point sur du matériel congelé ou conservé dans l'alcool. Dans la majorité des cas, l'étude d'une partie du gène codant pour le cytochrome b permet de distinguer les différentes espèces et populations.

\section{Développement de l'aquaculture au Niger}

L'action pour le développement de l'aquaculture au Niger mise en œuvre pour le compte du ministère nigérien de l'hydraulique et de l'environnement, sur financement du ministère français de la coopération et du développement, fait suite à l'opération menée depuis 1981. L'Association des aquaculteurs du Niger (ADAN), cheville ouvrière des activités, poursuivra ses travaux à l'issue du projet.

La production d'alevins sur la station d'alevinage de Sona a repris en 1992, ainsi que celle de poissons de taille marchande en cages flottantes sur les trois sites des aquaculteurs artisans situés le long du fleuve Niger. Les estimations de production sont de 40 tonnes pour 1993 et de 120 tonnes pour 1994.

Les priorités sont l'abaissement des coûts pour les producteurs et le développement d'un marché fragilisé par la détérioration du pouvoir d'achat des Nigériens. Les recherches visent à réduire les charges les plus lourdes dans le compte d'exploitation d'une cage flottante, l'alevinage (production de monosexes mâles) et l'alimentation.

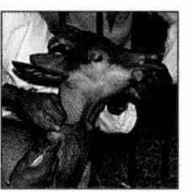

\section{Programme} pathologie infectieuse

Les maladies infectieuses des bovins et des petits ruminants sont à l'origine de pertes souvent importantes pour les éleveurs. Les recherches se concentrent sur la conception de techniques de diagnostic précoce ou utilisables sur le terrain et de vaccins stables en climat tropical.

\section{Des produits pour le développement}

\section{Diagnostics et vaccins}

Dans le cadre de ses activités de laboratoire de référence de la FAO pour les mycoplasmoses des ruminants, le département d'élevage et de médecine vétérinaire du CIRAD est dépositaire pour l'Afrique de la souche-mère vaccinale T1-SR contre la péripneumonie contagieuse bovine. Il en assure le contrôle et la distribution auprès des laboratoires africains et garantit l'homogénéité de la qualité des vaccins.

La trousse Elisa pour le diagnostic sérologique de la péripneumonie contagieuse bovine est en cours de validation par des laboratoires africains et européens, sous la supervision de l'OIE et de l'AIEA. Cette phase d'évaluation par des organismes étrangers est indispensable avant toute distribution par les organisations internationales.

\section{Nouvelles techniques de diagnostic}

Le clonage et le séquençage des gènes des protéines $N$, $\mathrm{H}$ et $\mathrm{F}$ des virus de la peste bovine et de la peste des petits ruminants, entrepris il y a quelques années en collaboration avec l'institut de santé animale de Pirbright (Grande-Bretagne), ont abouti à la mise au point d'une sonde froide pour le diagnostic de la peste bovine. Elle est constituée d'un oligonucléotide sur lequel on a fixé une molécule de biotine et dont la séquence a été choisie dans la fraction variable du gène de la protéine $N$. Cette sonde est spécifique et permet le diagnostic précoce de la peste bovine lorsqu'elle est appliquée sur des lymphocytes circulants. Toutefois, le bruit de fond doit être réduit avant qu'elle puisse être utilisée sur d'autres prélèvements.

Un baculovirus recombinant, utilisé comme vecteur d'expression des protéines $\mathrm{N}$ et $\mathrm{H}$, a également été obtenu. Ces protéines entrent dans la mise au point de tests de diagnostic par la sensibilisation 


\section{ÉLEVAGE ET MÉDECINE VÉTÉRINAIRE}

de microplaques pour la technique Elisa ou de billes de latex pour les tests d'agglutination sur lame.

Les essais préliminaires ont démontré la spécificité et la fiabilité du test d'agglutination sur lame, qui permettra le dépistage sur le terrain des animaux vaccinés et servira au suivi sérologique des campagnes de vaccination. Ce test sera finalisé en 1993.

Des travaux similaires sont menés pour la mise au point de sondes nucléiques ainsi que d'amorces pour

\section{Rencontres internationales}

\section{Médecine vétérinaire tropicale}

La septième conférence de l'Association internationale des institutions de médecine vétérinaire tropicale (AIMVT), coorganisée par le comité national de Côte-d'Ivoire et le CIRAD, s'est déroulée à Yamoussoukro, du 14 au 19 septembre 1992. Elle a regroupé 250 participants de 54 pays. Sous le titre général "L'élevage, facteur essentiel d'une agriculture durable", les interventions ont fait apparaître la priorité des thèmes consacrés à l'élevage et à la préservation de l'environnement (la faune sauvage en particulier), à la production laitière, à la privatisation des services vétérinaires et à la réorganisation de la santé animale dans les pays d'Afrique.

\section{Epidémiologie vétérinaire, diagnostic, résistance aux maladies}

Le CIRAD a organisé en Crète, du 2 au 6 novembre 1992, un atelier de travail sur l'épidémiologie vétérinaire et les méthodes du diagnostic. Il a été suivi d'un second atelier, animé par l'université de Bruxelles, sur la résistance des animaux aux maladies. Ces ateliers ont réuni 48 participants engagés dans des projets européens financés par la CCE.
I'amplification de I'ADN in vitro (PCR), utilisables dans le diagnostic de diverses espèces de mycoplasmes: Mycoplasma mycoides mycoides SC, agent de la péripneumonie contagieuse bovine, M. capricolum et $M$. putrefaciens, responsables, parmi d'autres espèces, de I'agalaxie contagieuse et de pleuropneumonies chez les petits ruminants.

En dépit de leur sophistication, sondes et PCR sont des techniques intéressantes pour la mise en évidence de pathogènes qu'il n'est pas possible d'isoler dans des échantillons biologiques mal conservés.

Par ailleurs, grâce à la production d'anticorps monoclonaux, deux tests ont été développés : un test Elisa de compétition destiné au diagnostic sérologique de la peste bovine et un test d'immunocapture pour la mise en évidence et la différenciation des virus de la peste bovine et de la peste des petits ruminants.

De même, un ensemble d'anticorps monoclonaux spécifiques de $M$. mycoides mycoides SC a été obtenu et devrait permettre l'élaboration de nouveaux tests de diagnostic (tests Elisa de compétition et d'immunocapture).

Enfin, le diagnostic de la pleuropneumonie contagieuse caprine à M. mycoides sp. F38 a fait l'objet de plusieurs améliorations. La composition du milieu de culture a été modifiée de façon à accélérer la croissance de ce mycoplasme particulièrement difficile à cultiver.

De plus, un test d'immunoperoxydase sur bandelettes a été mis au point. Le liquide pleural est déposé sur des bandelettes de nitrocellulose qui, une fois séchées, peuvent être envoyées aisément au laboratoire. La présence des mycoplasmes est révélée grâce à un sérum spécifique, un conjugué anti-lgG marqué à la peroxydase et un substrat.

\section{Vaccins : transfert de technologie}

Le vaccin thermostable contre la peste bovine a été produit dans des laboratoires africains et testé sur le terrain, notamment dans des zones difficiles comme le sud du Soudan. Ce transfert de technologie 
est réalisé en collaboration avec la Tufts University (Etats-Unis), dans le cadre d'un programme financé par la CCE.

Le vaccin homologue contre la peste des petits ruminants a été testé en vraie grandeur avec des partenaires africains. Au total, plus de 20000 petits ruminants ont été vaccinés en Côte-d'Ivoire, en Mauritanie et au Tchad, et un suivi sérologique est assuré pour 2000 d'entre eux en Mauritanie. Un mois après la vaccination, $95 \%$ des animaux sont positifs, et $75 \%$ deux ans plus tard. Le vaccin n'a aucun effet abortif sur les femelles en gestation.

\section{Programme pathologie parasitaire}

Le programme de pathologie parasitaire évalue les effets des parasites des ruminants et recherche des solutions de lutte économiques et peu agressives pour l'environnement. Dans les pays chauds, plusieurs maladies parasitaires entravent l'élevage des ruminants ou interdisent I'amélioration génétique des races locales, souvent peu productives, par des géniteurs de races importées, très sensibles à ces maladies. Le programme se concentre sur deux grands thèmes, les tiques et les maladies transmises par les tiques ou associées aux tiques, et les trypanosomoses et leurs vecteurs, notamment les glossines.

\section{La cowdriose et ses vecteurs}

Le réseau de recherche sur la cowdriose et ses vecteurs a été conforté par la CCE. Ses objectifs principaux sont le diagnostic, I'immunologie de la maladie, la vaccination, la résistance génétique et la lutte contre les vecteurs. Le département, coordonnateur du réseau, réalise certaines des recherches sur la cowdriose et la tique Amblyomma variegatum à la Guadeloupe et à Maisons-Alfort.

L'étude de la génétique de la résistance à la cowdriose chez les chèvres créoles a été entreprise à la Guadeloupe. On a constaté que, si la résistance naturelle progresse avec l'ancienneté du contact, elle est également variable selon les géniteurs mâles. Un troupeau a été constitué avec des géniteurs résistants, un autre avec des géniteurs sensibles, un troisième avec les produits des croisements de géniteurs résistants et sensibles. Les descendants sont testés pour déterminer I'héritabilité de la résistance ou de la sensibilité, et pour chercher des marqueurs génétiques de résistance ou de sensibilité qui permettraient une sélection rapide.

Les espoirs d'aboutir à un vaccin synthétique contre la cowdriose ont été confirmés : on a démontré que l'inoculation de Cowdria tuées protège les chèvres de l'infection.

\section{La dermatophilose}

Le réseau sur la dermatophilose, auquel participe le CIRAD, notamment à la Guadeloupe, est coordonné par le Royal Veterinary College de Londres. II a aussi bénéficié d'un financement de la CCE. Ses objectifs sont d'étudier l'immunologie et l'influence de divers facteurs sur la réponse immunitaire, la pathogénie de la dermatophilose, le rôle $\mathrm{d}^{\prime} A$. variegatum, la résistance génétique à la maladie.

Au Cameroun, certains animaux se révèlent peu attractifs pour les tiques, tandis que d'autres sont rapidement infestés. Les différences d'intensité de l'infestation sont de l'ordre de un à dix. A l'occasion de l'étude de la transmissibilité génétique de ce caractère, on a observé que les veaux opérent un important détiquage de la mamelle de leurs mères, qui se traduit par une infestation nettement plus faible des femelles allaitantes. L'objectif est de sélectionner des animaux attirant peu les tiques.

\section{Les trypanosomoses}

L'élevage de glossines a été transféré à Montpellier pour devenir un élevage conjoint de l'ORSTOM et du CIRAD. Les recherches sur les trypanosomes et leurs vecteurs, les glossines, sont menées en collaboration avec le CIRDES au Burkina Faso, I'ORSTOM et I'ANDE en République centrafricaine. 
L'étude de pièges à glossines pour les espèces d'intérêt médical ou vétérinaire d'Afrique occidentale et centrale se poursuit. Les essais sur le système de collecte des glossines en haut du piège, sur l'emplacement du système diffuseur d'odeurs, sur l'efficacité vis-à-vis d'autres insectes piqueurs ont permis d'identifier les meilleurs modèles de pièges. Le piège bipyramidal en matière plastique apparaît rentable pour les éleveurs centrafricains.

Par rapport au piège classique en tissu, il assure un gain de 35000 francs CFA pour cent têtes.

Il est employé dans le foyer de la maladie du sommeil de Nola.

Pour améliorer encore les techniques de piégeage, on étudie les systèmes sensoriels des glossines. Les recherches sur les soies chimioréceptrices des ailes, réalisées par microscopie électronique et électrophysiologie fine, indiquent qu'elles sont le siège d'une fonction de gustation plutôt que d'olfaction.

Au Burkina Faso, les applications épicutanées de pyréthrinoïdes (méthode pour on) apparaissent très efficaces contre les glossines et les tiques. Des essais sont en cours en République centrafricaine.

La technique Elisa-Ag de I'ILRAD a permis d'évaluer la situation épidémiologique dans deux zones de République centrafricaine. Elle a révélé la vaste circulation des parasites et l'importance des infections mixtes ou multiples. Elle indique 70 à $80 \%$ d'animaux positifs, alors que les techniques parasitologiques classiques n'en donnaient que 10 à $15 \%$.

La détection des biotopes à glossines en Adamaoua (Cameroun) par I'analyse de données satellitaires Spot a été conduite par le laboratoire de télédétection du CIRAD, en collaboration avec la mission spéciale d'éradication des glossines de Ngaoundéré.

Les résultats se sont traduits par une cartographie au 1/100 000 des systèmes forestiers (savane boisée et galeries forestières), qui sont des gîtes potentiels à Glossina morsitans submorsitans.

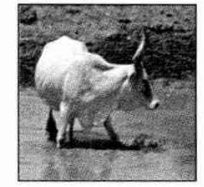

\section{Programme écopathologie}

Les enquêtes d'écopathologie abordent des thèmes essentiels à la mise en place des programmes de développement. L'écopathologie, fondée sur une approche globale des aspects de la santé animale, est complémentaire de la démarche systémique aujourd'hui classique. L'écopathologie est une discipline éminemment appliquée, dans la mesure où elle apporte des solutions directement et facilement utilisables. Des enquêtes écopathologiques sont conduites dans plusieurs pays partenaires.

Au Brésil, dans le Nordeste, la collecte de données sur le terrain, réalisée dans le cadre de l'étude écopathologique des avortements caprins en milieu traditionnel, s'est achevée en 1992. Elle s'appuie sur une enquête rétrospective par questionnaires et sur le suivi mensuel de 1300 chèvres réparties en 34 élevages.

Le traitement des données est en cours. Les principaux paramètres zootechniques, tels que l'âge à la première mise bas (626 jours), l'intervalle entre mises bas (404 jours), les taux d'avortement (13\%) et de mortalité avant six mois ( $24 \%$ ), ont été précisés. Les résultats sont présentés sous forme de fiches techniques et de tableaux directement utilisables par les services de l'élevage et les éleveurs.

Au Sénégal, les enquêtes d'écopathologie sont menées dans le cadre du programme pathologie et production des petits ruminants. La démographie du troupeau et certains paramètres de santé animale sont suivis par le logiciel Panurge. Le traitement des données sur les pneumopathies des petits ruminants sera terminé en 1993.

La plupart de ces enquêtes sont conduites avec le laboratoire d'écopathologie de I'INRA, qui, comme le centre d'écopathologie Rhône-Alpes, participe au Comité d'écopathologie tropicale, créé en 1992. 


\section{ÉLEVAGE ET MÉDECINE VÉTÉRINAIRE}

\section{Formation}

\section{Des formations en élevage et médecine vétérinaire}

En 1991-1992, le DESS de productions animales en régions chaudes a été organisé en collaboration avec I'INA-PG, I'ENVA et le Muséum national $d^{\prime}$ histoire natureile. La promotion était composée de 21 étudiants, dont 7 étrangers. Trois spécialisations étaient proposées : aviculture, petits ruminants, grands ruminants. Le certificat de pathologie animale tropicale, réservé aux vétérinaires, a été suivi par 20 étudiants, et le cours international de pathologie et de production des ovins et caprins a réuni 21 participants, originaires de 13 pays. Le cours d'épidémiologie et d'économie vétérinaire est organisé à Rabat en collaboration avec I'Institut agronomique et vétérinaire Hassan II et I'université du Minnesota.

\section{Les thèses soutenues en 1992}

Chercheurs du département

Etude de la variation phénotypique dans le groupe Sporobolus indicus (L.) R. Br et incidence sur le plan systématique, par Gilles Mandret, Muséum national d'histoire naturelle, Paris.

Recherches sur les carences en oligo-éléments affectant le cheptel domestique ruminant dans la Rift Valley éthiopienne et les régions afro-montagnardes limitrophes; influence de quelques facteurs de I'environnement, par Pierre-Luc Puglièse, université Paris XII.

Accueil par le département

Production d'anticorps monoclonaux spécifiques de Mycoplasma capricolum ; application potentielle à un test de diagnostic rapide sur des laits suspects, par Baya Belaid (Algérie), université Paris XI, centre d'Orsay.

Situation et conditions de développement du secteur productif au sein d'une filière laitière en milieu tropical insulaire : le cas des Antilles françaises, par Annick Jordan (France), Institut national agronomique, Paris-Grignon. Accueil : INRA-CRAAG et CIRAD-EMVT. 


\section{Département des}

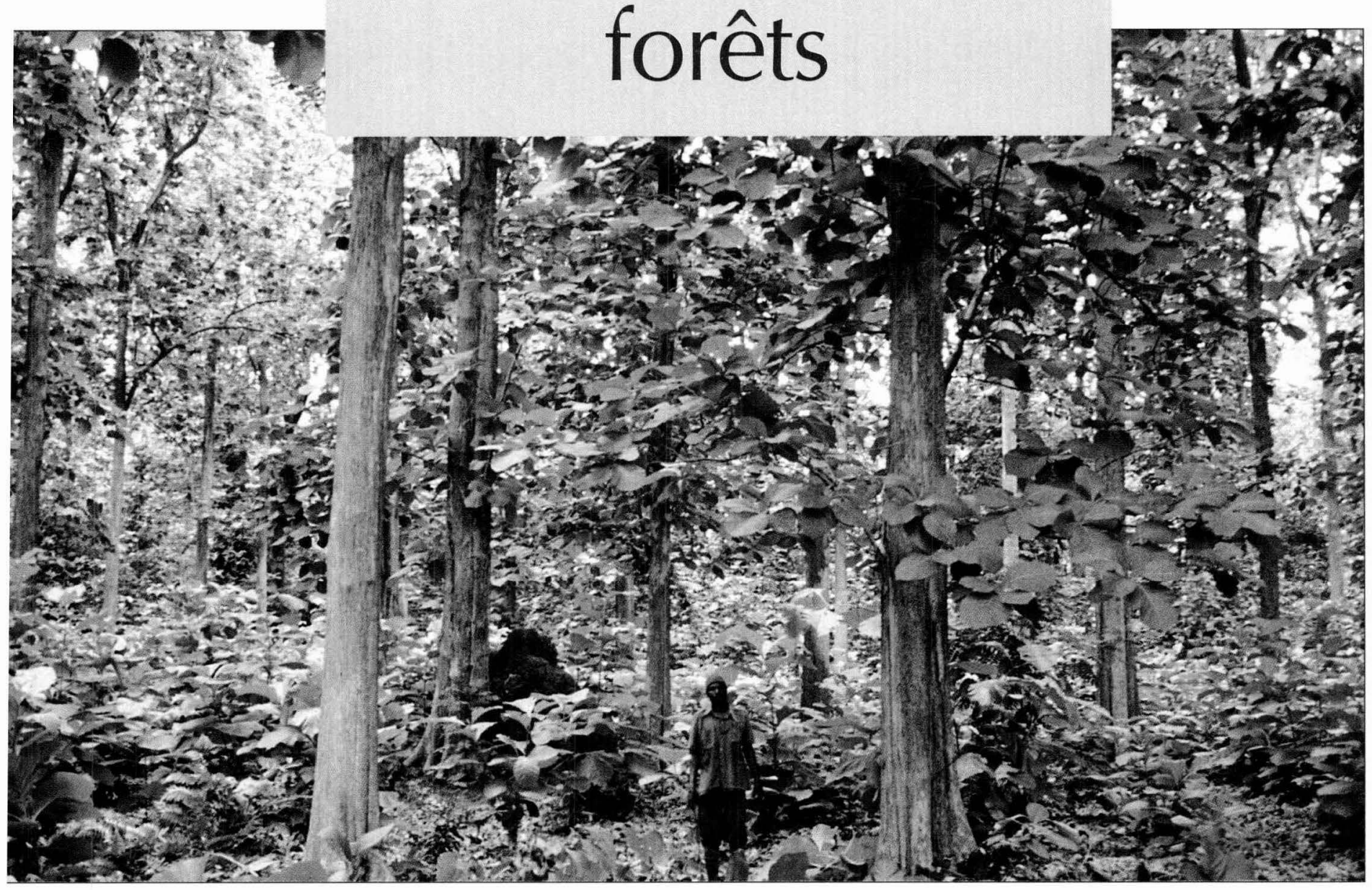

Le dernier congrès forestier mondial et le Sommet de la Terre ont réveillé la conscience collective sur les périls qui menacent la forêt. Si l'exploitation de la forêt répond à un besoin vital pour les sociétés humaines, elle doit se faire dans des conditions assurant une bonne reproduction naturelle ou un repeuplement rapide. Développement et environnement sont liés. Par la protection de la diversité des espèces et la création de nouveaux arbres, par des méthodes d'aménagement forestier et d'intégration de l'arbre à l'agriculture, par la valorisation des bois tropicaux, le département forestier du CIRAD témoigne de cette certitude. 
A près le dixième congrès forestier mondial réuni à Paris en septembre 1991, le Sommet de la Terre a eu lieu à Rio de Janeiro en juin 1992.

Il a été un temps fort de la concertation internationale sur des thèmes restés très en vogue toute l'année : conservation des forêts tropicales, biodiversité, environnement et développement. La préparation du CIFOR, dernier-né des centres relevant du GCRAI, exprime par la voie la plus officielle l'intérêt des milieux scientifiques et économiques internationaux pour la gestion et la conservation des forêts tropicales.

De nombreux contacts avec la presse destinée au grand public, la participation à la conférence Forest 92 à Rio juste avant le Sommet de la Terre, et la préparation du programme d'amélioration des arbres du CIFOR attestent de la contribution du département forestier du CIRAD au débat international.

L'Europe est également un terrain d'action pour le département, qui anime le point focal France du réseau européen de recherche forestière tropicale lancé en 1992 à l'initiative de la CCE.

La signature de la convention Silvolab, groupement d'intérêt scientifique constitué par le CIRAD, I'INRA, I'ENGREF, I'ORSTOM et I'ONF, crée en Guyane les conditions d'un développement coordonné des activités de recherche forestière. A partir de 1993, le CNRS doit s'associer à Silvolab, qui regroupera ainsi la plus grande partie des recherches menées en Guyane sur les écosystèmes forestiers. D'utiles coopérations pourront ensuite se mettre en place, notamment le programme interrégional de recherche forestière Amazonie-Guyane (PIRFAG), auquel la Guyane pourra être associée.

La forêt, patrimoine de l'avenir, tel était le leitmotiv du congrès forestier mondial. Les grands enjeux sont désormais clairement perçus : enjeu écologique, qu'il s'agisse des grands équilibres ou de l'environnement local, mais aussi enjeu économique pour tous les utilisateurs des produits des forêts. Il est de plus en plus clair que la seule manière réaliste de préparer I'avenir est d'apprendre à conjuguer environnement et développement. Cela ressort bien de la Déclaration sur les forêts adoptée à Rio.

Cette évolution confirme l'orientation des recherches, qui ont pour finalité la mise au point des outils et des méthodes nécessaires à la gestion des forêts tropicales; que ce soit pour la sylviculture des forêts naturelles ou la création de plantations, pour la production de matériel végétal amélioré ou la valorisation des bois. L'arbre est aussi étudié dans son insertion au milieu agricole, où il joue un double rôle, à la fois protecteur et producteur.

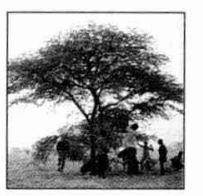

\section{Programme agroforesterie, conservation des eaux et du sol}

Pour contribuer à une meilleure intégration de l'arbre dans les systèmes agraires, protéger l'environnement et conserver la biodiversité animale et végétale, des solutions techniques et institutionnelles sont proposées par des équipes d'agroforestiers et de socio-économistes.

\section{Marchés ruraux de bois}

Au Niger, le projet Energie II, financé par la Banque mondiale, a clairement évalué les besoins en bois des cinq plus grandes villes (par enquêtes), ainsi que la quantité de bois sur pied dans les savanes du pays (par inventaires et télédétection). En 1992, les disponibilités dans les espaces cultivés tels que les jachères et les parcs arborés ont également été estimées. Par exemple, la production annuelle de bois de feu d'une jachère de Guiera senegalensis peut atteindre 300 kilos à I'hectare, qui couvrent les besoins d'un habitant.

Les premiers marchés ruraux de bois ont été organisés dans la région de Say avec le ministère de l'Hydraulique et de l'Environnement et le ministère des Mines et de l'Energie. Les communautés des villages concernés se sont engagées à gérer de façon conservatoire leurs espaces sylvopastoraux en y pratiquant une rotation 


\section{DÉPARTEMENT DES FORÊTS}

\section{CIRAD-FORÊT}

\author{
Directeur Jean-Marc Dubois \\ Directeur scientifique Jean-Claude Bergonzini \\ Directeur \\ administratif et financier Claude Thevin

\section{Programmes de recherche} \\ Agroforesterie, \\ conservation des eaux et du sol \\ Aménagement forestier \\ Amélioration du matériel végétal \\ Technologie du bois \\ Régis Peltier \\ Henri-Félix Maitre \\ Hélène Joly \\ Bernard Parant

\section{Unités et services} \\ Biométrie et informatique \\ Biotechnologie des symbioses \\ forestières tropicales* \\ Documentation \\ Publications \\ Formation \\ Valorisation \\ Jean-Claude Bergonzini \\ Emile Duhoux \\ Lucien Trong \\ France Lavaux \\ Hélène Laforge \\ Jean Estève \\ * Unité commune CIRAD-ORSTOM.
}

des coupes et des pâturages compatible

avec la régénération du milieu. L'Etat a avalisé

ces aménagements et a consenti des réductions de taxes

sur les chargements de bois commercialisés

par ces groupements. II s'agit d'un exemple concret

de cession aux communautés villageoises d'anciennes

prérogatives de I'Etat sur la gestion des forêts.

A moyen terme, la coupe et la vente du bois doivent devenir le moteur d'une gestion de terroir incluant les composantes forêt-élevage et agriculture, qui pourrait s'étendre à tout le pays. Ce schéma d'évolution adopté par les populations rurales est un cas intéressant d'utilisation des études réalisées par une équipe associant économistes, sociologues, experts en inventaire forestier et en télédétection, aménagistes pastoraux et spécialistes de la législation et de la taxation. La Banque mondiale, très intéressée par les résultats obtenus, compte étendre l'expérience à d'autres pays sahéliens, comme le Mali et le Sénégal.

\section{Fronts pionniers et reboisement}

Au Cameroun, dans le cadre du projet Nord-Est Bénoué financé par le FED, une étude de télédétection a montré les mécanismes de progression des fronts pionniers, par lesquels les agriculteurs migrants défrichent la savane arborée pour la mettre en culture. En I'espace d'une dizaine d'années, environ 100000 habitants se sont installés dans la région. La surface cultivée est évaluée à 100000 hectares, ce qui représente $10 \%$ des terres. Les cultures sont installées après brûlis et défrichement de la savane, en étoile autour de la ville de Garoua, le long des axes routiers.

Le constat établi en relation avec I'IRA et les structures de développement est clair : c'est uniquement lorsque les besoins en terre et en bois deviennent graves que les populations adoptent les méthodes de plantation et d'utilisation de l'arbre mises au point par la recherche pour lutter contre l'érosion, produire des perches et du bois de feu, régénérer ou maintenir la fertilité des sols.

En 1992, les agriculteurs de la région ont acheté environ 50000 arbres forestiers et fruitiers aux pépinières rurales encadrées par le projet. Ces plantations, ainsi que les savanes arborées aménagées, devraient progressivement couvrir les besoins en bois de Garoua, estimés à 100000 tonnes par an, soit un revenu de 1,5 milliard de francs CFA.

\section{Techniques d'exploitation des arbres en savane}

Dans la zone soudanienne du Burkina Faso, on a montré, avec I'IRBET, qu'une formation naturelle de savane arborée totalement coupée en taillis tous les cinq ans pouvait produire près de 3 mètres cubes de bois à l'hectare chaque année. Ce type de coupe n'est cependant pas compatible avec le maintien de la biodiversité et ne satisfait pas les besoins des paysans. A moyen terme, en effet, il entraîne 
la disparition de nombreuses espèces utiles, comme le karité.

Il faut donc envisager des types de gestion différents, adaptés aux besoins essentiels des populations, à la vitesse de croissance et à la résistance à la coupe de trois ou quatre grands groupes d'espèces. Ces résultats devraient bouleverser les méthodes d'exploitation forestière actuellement préconisées par de nombreux projets.

\section{Enrichissement des jachères en zone forestière}

Dans la région forestière du sud de la Côte-d'Ivoire, une équipe financée par la CCE réunissant I'IDEFOR, I'IDESSA, trois départements du CIRAD et l'université de Bayreuth a mis au point des méthodes, facilement utilisables par les paysans, pour constituer une jachère nettement plus productive que la jachère spontanée. Cette jachère arborée associe Acacia mangium ou $A$. auriculiformis à des souches de rhizobium fixatrices d'azote. Huit ans après la plantation, des productions de 70 à 140 tonnes de bois de feu à l'hectare sont possibles. L'application de ces techniques de jachère enrichie en milieu rural contribuerait à réduire le défrichement des forêts denses humides et à fixer les systèmes de culture.

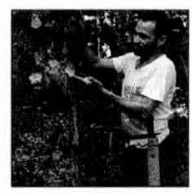

\section{Programme aménagement forestier}

Il s'agit avant tout pour le programme d'aménagement forestier d'acquérir une meilleure connaissance de l'étendue et de la dynamique des peuplements forestiers naturels et artificiels pour les valoriser : des méthodes de création, de protection et d'exploitation des formations ligneuses tropicales sont mises au point, en vue d'une production pérenne de bois d'œuvre, de bois de service et d'énergie répondant aux demandes locales.

\section{Des produits pour le développement}

\section{Le reboisement pour lutter contre l'érosion}

A Madagascar, une équipe associant le FOFIFA, le CIRAD et le BDPA mène une recherche-action avec les populations concernées par les conséquences de l'érosion dans la région du lac Alaotra.

Ces dernières années, ce sont près de 500 hectares de rizières qui ont été définitivement enfouis sous le sable provenant des collines environnantes. Le volume de curage annuel des canaux d'irrigation est évalué à 650000 mètres cubes. Le reboisement des collines est l'une des solutions les plus efficaces pour lutter contre l'érosion. A l'instigation de la recherche et des structures de développement, les groupements paysans réalisent les travaux de reboisement autrefois traités en régie par l'Etat, concrétisant, à leur modeste échelle, l'évolution souhaitée par le pays. En 1992, ils ont planté environ 100000 arbres, issus de leurs propres pépinières, sur les collines et dans les lavaka, vastes cônes d'érosion. L'effet des reboisements est encore amélioré par la mise en place de boutures de bambous sous forme de fascines et par la protection de la flore naturelle.

\section{Les peuplements naturels d'okoumé}

Une étude sur l'évolution des peuplements naturels semi-purs d'okoumé, Aucoumea klaineana, a été réalisée dans la zone côtière du Gabon. Grâce à l'analyse de tiges (dénombrement anatomique des cernes d'accroissement) et à une série d'observations et de mesures limitée dans le temps (1987-1992), on a réussi à prévoir l'évolution et la production des peuplements en fonction de la fertilité des sols. On a aussi pu reconstituer leur évolution passée et déterminer leur âge. Ainsi, sur un pas de temps très court, les modèles de croissance ont été élaborés. Les modalités et le rythme d'intervention en éclaircie 


\section{FORÊTS}

\section{Coopération internationale}

\section{Surveillance de la déforestation en Asie du Sud-Est}

Organisé par le département forestier du CIRAD et Scot Conseil, le séminaire final du projet SEAMEO - qui a pour objet la surveillance de la déforestation dans six pays d'Asie du Sud-Est - s'est tenu à Manille en octobre 1992. Les résultats techniques et les conclusions du programme de coopération multilatérale, lancé en 1989 et financé en grande partie par la France, ont été présentés. L'importance de l'adoption d'une nomenclature commune, dérivée de celle de la FAO, a été soulignée, de même que la nécessité d'équiper les pays touchés par la déforestation de systèmes permanents utilisant des données satellitaires. L'effort de formation et de transfert de savoir-faire sur les méthodes de suivi de la déforestation doit être prolongé. Une seconde phase du projet devrait l'étendre à l'ensemble de la péninsule indochinoise et s'attacher à développer de nouveaux outils, en particulier les systèmes d'information géographique et l'imagerie radar.

ont été définis pour le futur plan d'aménagement des forêts de l'estuaire du Gabon.

\section{Les incendies en forêt dense humide}

L'étude de l'effet du feu sur la forêt naturelle dense humide a été parachevée en 1992 en Côte-d'Ivoire, à partir d'un incendie accidentel au sein du dispositif expérimental de dynamique du peuplement.

Il est apparu que les forêts ouvertes par l'exploitation pour le bois d'œuvre sont plus vulnérables que les forêts fermées. Le degré de destruction est bien traduit par les types majeurs d'évolution du peuplement dans les premières années : blocage de la régénération, apparition progressive de peuplements arbustifs, évolution vers une forêt secondaire. Selon le diagnostic, les forestiers et les agronomes sont à même de prendre des décisions d'aménagement des territoires brûlés : récupération agricole, reboisement ou protection intégrale.

\section{L'éclaircie en forêt guyanaise}

En Guyane, on a défini, en utilisant plusieurs modèles, la validité des différentes modalités et intensités d'éclaircie au sein des forêts déjà exploitées. Ce travail, mené sur la station de Paracou, a bénéficié de l'apport scientifique du réseau expérimental du programme sur les écosystèmes forestiers en Amérique latine, en Afrique et en Asie. II a permis de mieux ajuster les opérations d'aménagement entreprises par l'Office national des eaux et forêts agissant dans les massifs guyanais.

\section{Plantations forestières au Vietnam}

Une opération de recherche-développement en partenariat a été menée dans la province de Song Be, au nord-ouest d'Hô Chi Minh-Ville, pour développer les plantations d'essences à croissance rapide (eucalyptus et acacias) destinées à la production papetière.

Les objectifs majeurs ont été la diversification génétique des espèces, l'estimation de la production des plantations et I'amélioration sylvicole. Pour ce faire, 150 hectares d'essais ont été mis en place en 1990 et 1991.

Dans un premier temps, le matériel végétal le mieux adapté a été défini, et les techniques de préparation du terrain, de conduite de pépinières et de création de peuplements ont été précisées.

Par ailleurs, de larges perspectives dans le domaine de la multiplication clonale, de la création variétale et de I'amélioration de la fertilité ayant été identifiées, un programme complémentaire sera engagé en 1993 sur un financement interministériel français. Cette action devrait permettre le lancement d'un projet industriel de grande envergure. 


\section{FORÊTS}

\section{Le plan directeur forestier de la Guinée Bissau}

Le plan directeur forestier de la Guinée Bissau a été parachevé dans le cadre du Plan d'action forestier tropical, soutenu par la CCE, la Banque mondiale, la coopération japonaise et la FAO.

L'ensemble du travail a été présenté au cours de la deuxième table ronde nationale, en novembre 1992. Une nouvelle politique d'aménagement du territoire a été établie sur la base de quatorze projets prioritaires, dans les domaines suivants : maîtrise foncière, développement d'une foresterie communautaire, agroforesterie, gestion durable des forêts, formation forestière et pastorale, dispositions fiscales et douanières, conservation de la biodiversité.

La préparation de ce plan par le département forestier du CIRAD répond à son souci de s'impliquer dans l'élaboration de politiques forestières nationales, établies avec l'aide des agences de financement internationales.

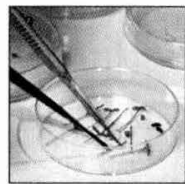

\section{Programme amélioration du matériel végétal}

Pour répondre aux besoins du développement forestier, les programmes d'amélioration génétique de l'arbre portent sur des espèces à croissance rapide (eucalyptus, Acacia mangium, pins), des essences de bois d'œuvre (teck, Terminalia, Gmelina, Cedrela, Swietenia) et sur certaines espèces à usages multiples comme Acacia albida et $A$. senegal. Le programme d'amélioration du matériel végétal a aussi une autre mission essentielle pour l'avenir des forêts : participer à la conservation des ressources génétiques. Pour cela, une collection de semences rassemble 7000 lots de graines, et des parcelles conservatoires sont implantées dans plusieurs pays. L'évaluation de la diversité génétique se fait par des essais comparatifs de provenances et de descendances et par l'utilisation de marqueurs génétiques.

\section{Diversité génétique des acacias sahéliens}

Les recherches sur l'évaluation de la diversité génétique et les critères de sélection des espèces à usages multiples sont menées en coopération avec l'ISRA, au Sénégal, et I'IRBET, au Burkina Faso.

Dès 1984, des essais de comparaison de provenances d'Acacia albida ont été installés au Burkina Faso ; cette collection représente actuellement 35 provenances de 9 pays répartis dans l'ensemble de l'aire de distribution de l'espèce. Des essais de comparaison de provenances ont aussi été mis en place pour $A$. albida et $A$. senegal au Sénégal, et pour $A$. nilotica au Burkina Faso.

Les travaux menés en collaboration avec l'ORSTOM semblent montrer qu' $A$. senegal est une espèce peu variable au Sénégal. La diversité génétique $\mathrm{d}^{\prime} A$. albida a également été étudiée, avec I'ENGREF, I'IRBET, I'ISRA et I'OFI, dans le cadre d'un financement de la CCE. Or, l'électrophorèse enzymatique a mis en évidence la grande diversité génétique de cette espèce. L'étude de l'organisation de cette diversité montre une large séparation entre les populations d'Afrique de l'Est et celles d'Afrique de l'Ouest. Ces résultats sont confirmés par les essais de terrain, qui ont établi que les provenances d'Afrique de l'Est sont très mal adaptées aux faibles pluviosités d'Afrique de l'Ouest. Elles ne survivent pas à deux saisons sèches, malgré une bonne croissance initiale. Par ailleurs, le taux d'allofécondation a été évalué à plus de $95 \%$ pour cinq populations d'A. albida.

Cette espèce est donc largement allogame et possède vraisemblablement un niveau élevé d'auto-incompatibilité.

\section{Amélioration génétique de l'eucalyptus}

En collaboration avec la recherche forestière congolaise et I'UAIC, le programme d'amélioration des eucalyptus du Congo se poursuit. Le schéma de sélection récurrente réciproque, défini depuis plusieurs années, est fondé sur des hybrides interspécifiques, Eucalyptus urophylla $\times$ E. grandis et $E$. urophylla $\times$ E. pellita. 


\section{FORÊTS}

La structure génétique des populations parentales et celle des populations hybrides sont maintenant mieux connues : la variabilité observée dans les populations hybrides est surtout due à E. urophylla, et son expression à un stade juvénile est plus importante pour les hybrides avec $E$. grandis que pour ceux avec E. pellita. L'héritabilité des principaux caractères mesurés à deux ans est surtout additive. Trois essais ont été mis en place

\section{Coopération internationale}

\section{Un laboratoire de biotechnologies en Malaisie}

Dans le cadre de l'extension de ses activités en Asie, le département forestier du CIRAD développe depuis 1989 une coopération avec la Yayasan Sabah Foundation. Cette entreprise, qui s'implique dans le développement du Sabah (Malaisie), réalise des plantations forestières. Le programme d'amélioration du matériel végétal apporte son savoirfaire pour l'amélioration génétique et la production de semences de rotins, d'acacias à croissance rapide (Acacia mangium et $\mathrm{A}$. auriculiformis) et d'espèces de bois d'œuvre, comme le teck et le Swietenia.

Afin de mettre en œuvre les outils utiles à une amélioration efficace et rapide, un laboratoire commun de biotechnologies a été créé à Tawau. La conception du laboratoire a bénéficié de l'expérience du CIRAD dans ce domaine. Les programmes de multiplication végétative portent sur la multiplication conforme des rotins (Calamus manan en particulier) et sur le rajeunissement de Tectona grandis et d'Acacia mangium.

La capacité de production est de 250000 vitroplants par an.

Le laboratoire a aussi été équipé pour l'électrophorèse enzymatique afin d'évaluer la diversité génétique et d'analyser les systèmes de reproduction de plusieurs espèces de rotins. afin d'estimer les corrélations entre le stade juvénile et le stade adulte.

Pour améliorer la maîtrise de la production de graines, plusieurs essais d'induction florale sont en cours au Congo et dans les collections conservatoires d'eucalyptus installées ces dernières années en Guyane. Dans le cadre d'une collaboration avec I'INRA, des recherches ont été entreprises à Bordeaux pour établir une carte génétique des eucalyptus grâce aux marqueurs moléculaires (RAPD, RFLP).

\section{Vergers à graines pour les espèces de bois d'œuvre}

L'importance des plantations de teck à travers le monde et leur suprématie en Côte-d'Ivoire justifient la priorité accordée à cette essence dans les programmes d'amélioration des bois d'œuvre menés avec I'IDEFOR. Depuis 1970, 24 provenances ont été introduites grâce à des essais internationaux. Après mobilisation de ces clones par greffage, un verger à graines a été installé à Sangoué. Les premières fructifications importantes du verger ont eu lieu en 1990.

Elles ont permis I'installation de tests de descendances des clones, en vue d'une éclaircie sélective sur la base des qualités génétiques des descendants.

Toutes les plantations de teck de Côte-d'lvoire se font maintenant à partir du matériel amélioré issu du verger à graines.

Pour Gmelina arborea, on dispose actuellement d'une variété multiclonale obtenue par bouturage. Deux vergers à graines constitués de 115 clones de G. arborea ont été mis en place à Anguédédou et à Sangoué pour créer la prochaine génération de sélection.

Un parc multiplicatif de Cedrela odorata a été installé avec 100 arbres sélectionnés. Cette première étape sera suivie de la mise en place d'un verger à graines clonal et de l'installation de tests clonaux.

\section{Symbioses fixatrices d'azote}

Les arbres fixateurs d'azote tirent parti de l'azote de l'air qu'ils fixent par leurs racines grâce à une bactérie 


\section{FORÊTS}

associée. Ils sont particulièrement indiqués pour les repeuplements de sols peu fertiles ou dégradés par l'érosion. Le laboratoire de biologie des symbioses forestières tropicales (ORSTOM-CIRAD) étudie deux associations modèles, I'association du filao (Casuarina) avec Frankia et celle de certains acacias avec des rhizobiums, afin de mieux comprendre comment ces symbioses s'établissent et se développent.

Il apparaît que les caractéristiques physico-chimiques des sols - en particulier leur teneur en fer - ont une influence importante sur l'établissement de la symbiose Acacia mangium-rhizobium. Les méthodes de transformation génétique sont utilisées pour une étude plus fine du fonctionnement de la symbiose : les gènes de Casuarina et d'Acacia impliqués dans la fixation de l'azote sont étudiés dans le but de les modifier pour accroître l'efficacité de la symbiose.

En 1992, un bilan de l'ensemble des essais d'A. mangium inoculé par différentes souches de rhizobium en Côte-d'Ivoire, au Bénin et aux îles Cook a été réalisé. A deux ans, les arbres inoculés ont, en moyenne, une hauteur et une circonférence supérieures de 10 à $15 \%$ à celles des térnoins. Une étude fondée sur des techniques immunologiques a permis de confirmer que cette croissance est bien due à la souche sélectionnée, toujours présente dans tous les nodules racinaires après deux ans. Les techniques moléculaires utilisées (PCR, RFLP) permettront également d'observer s'il y a concurrence avec les souches natives.

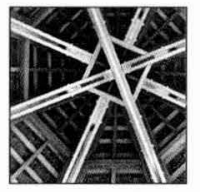

\section{Programme technologie du bois}

Les propriétés des bois tropicaux de forêt naturelle sont, dans l'ensemble, encore mal connues. Leur anatomie, leur durabilité, leurs qualités physiques, mécaniques et énergétiques sont étudiées. Les travaux sur les bois de plantation concernent tous les aspects de leur mise en œuvre - sciage, séchage, collage, imprégnation. Le bois et les déchets industriels sont aussi considérés dans leurs aspects énergétiques. Par ces recherches, le programme de technologie est en mesure de conseiller les producteurs et les utilisateurs de la filière bois.

\section{Les espèces forestières de Madagascar}

Sur un territoire grand comme la France, il y a à Madagacar plus de 1000 espèces d'arbres, dont 880, appartenant à 363 genres de 95 familles botaniques, ont été étudiées.

La description de la structure anatomique de chaque essence permet en particulier de résoudre des problèmes d'identification, d'autant plus difficiles que de nombreux genres n'existent qu'à Madagascar. Pour les familles très importantes dont les bois se ressemblent beaucoup, des clés dichotomiques sont données. Chaque genre est illustré par trois photos, du plan transversal, du plan tangentiel et du plan radial, prises au microscope.

Ce travail peut aider les botanistes à classer certaines espèces, mais il a également des applications pratiques. Ainsi, le laboratoire d'anatomie peut répondre à toutes les questions qui se posent dans le cadre de prospections et $d^{\prime}$ inventaires forestiers.

\section{Panneaux de bois massif}

Le panneau de bois massif reconstitué (composé de lattes collées), dont le procédé a été mis au point par le département, est particulièrement intéressant du fait de sa stabilité aux variations d'humidité, de son coût assez bas et de ses possibilités d'emploi pour l'ameublement, la menuiserie extérieure

et la construction. Proposé aux industriels et aux artisans, il est directement prêt à l'emploi. II ne nécessite ni séchage ni corroyage.

Depuis cinq ans, l'utilisation des panneaux de bois massif reconstitué s'est développée en Guyane dans le cadre des programmes de construction de maisons de bois. Jusqu'à ces derniers temps, les panneaux étaient fabriqués de façon artisanale, à partir des chutes de scieries ou de bois secondaires. La demande de plus en plus importante a conduit une entreprise locale à passer du stade artisanal 


\section{Des produits pour le développement}

\section{Valorisation des déchets agro-industriels pour la production de chaleur}

Les industries du bois et les agro-industries sont confrontées à des problèmes de séchage de leurs produits (bois, caoutchouc, coprah, etc.) et d'élimination de leurs déchets. La gazéification de ces déchets permet d'alimenter des brûleurs industriels et d'éviter l'emploi de produits pétroliers.

En association avec trois industriels français spécialistes des équipements concernés (gazogènes, brûleurs, séchoirs), une opération pilote a été réalisée en 1992. Elle a mis en évidence la parfaite possibilité de maîtriser l'ensemble de la chaîne à l'échelle industrielle. Elle a aussi fourni les éléments techniques permettant le dimensionnement des brûleurs à gaz pauvres.

La première application concerne le séchage industriel du caoutchouc en Côte-d'Ivoire, où un séchoir d'une capacité de 4500 tonnes de caoutchouc par an est en cours d'équipement à la SAPH. Ce procédé, qui se substitue au séchage au fuel, permettra d'en économiser 250 tonnes par an, soit 35 millions de francs CFA pour un seul séchoir.

Les analyses technico-économiques mettent en évidence une récupération de l'investissement très rapide, en une année environ, ce qui devrait faciliter la diffusion du procédé. Les garanties industrielles et les possibilités de construction locale confortent ces perspectives de diffusion.

au stade industriel. Pour cela, elle a acquis une abouteuse automatique, matériel issu de la collaboration entre le fabricant de panneaux, le fabricant de matériel et le département. L'implantation de cette chaîne industrielle améliore la qualité des panneaux et permet d'envisager leur exportation.
Après l'introduction du procédé en Guyane, I'entreprise locale a donc été accompagnée pour les essais, les premières réalisations en série et la commercialisation du produit. Une expérience similaire de transfert de technologie est en cours au Cameroun, en collaboration avec l'ONADEF, une exploitation forestière, une scierie et une fabrique de meubles.

\section{Valorisation du bois de cocotier}

Alors que les îles du Pacifique importent du bois, le potentiel ligneux important que représentent les cocotiers en fin de production reste pratiquement inexploité. Or, on a montré que la quasi-totalité de la masse ligneuse du cocotier, y compris la partie tendre, pouvait être mise en valeur, à condition de respecter certaines techniques de sciage et $d^{\prime}$ utiliser la technologie du bois massif reconstitué. $C^{\prime}$ est pourquoi la CFD et le ministère des Affaires étrangères ont confié au département forestier du CIRAD une opération de valorisation du cocotier dans le Pacifique.

Des démonstrations de sciage et des actions de formation ont été menées en 1991 à Tahiti, Makemo, Rarotonga, Tonga et Fidji. Les troncs, de faible diamètre, peuvent être sciés sans investissement important de matériel (la scie mobile conçue par le département est parfaitement adaptée). En 1992, les démonstrations ont porté sur les utilisations du bois de cocotier.

Elles se sont concrétisées par la production de panneaux de bois massif reconstitué et de poutres lamellées collées, à partir desquels des menuiseries, des portes et des meubles ont été fabriqués.

En outre, des essais de trempage dans l'eau de mer ont montré que les planches pouvaient être conservées pendant plus d'un an à l'abri des pourritures, sans traitement chimique, en attendant leur mise en œuvre. Cette méthode non polluante intéresse particulièrement les îles, dont les lagons ont un équilibre biologique fragile qu'il faut protéger.

Les responsables locaux de toute la région ont été convaincus de l'intérêt de l'exploitation du bois de cocotier, à la fois pour réduire les importations 
de bois brut et de produits élaborés et pour créer des emplois. Trois coopératives ouvrières de sciage et de fabrication de meubles doivent être installées à Makemo, Hao et Rangiroa. Une opération similaire de valorisation des cocotiers et des pins de plantation est lancée en Nouvelle-Calédonie sur un financement de la Région et de la CORDET.

\section{L'amélioration de la carbonisation traditionnelle}

Le charbon de bois est le combustible privilégié des grandes agglomérations des pays en développement et de certaines industries. Dakar en brûle 200000 tonnes par an, Abidjan 300000 et la sidérurgie brésilienne 10 millions de tonnes. Or, la carbonisation du bois par les procédés traditionnels se traduit par des pertes supérieures à $50 \%$ de l'énergie initiale, sous forme de composés qui contribuent fortement à l'accroissement de l'effet de serre. Un programme de recherche visant à récupérer l'énergie contenue dans les fumées et à les dépolluer a été entrepris.

Le premier travail a consisté à analyser les paramètres de la carbonisation. On a montré la très forte incidence de la température finale de la carbonisation sur la perte énergétique et sur la contribution à l'effet de serre : les émissions de composés non recyclables (hors $\mathrm{CO}_{2}$ ) doublent entre 450 et $700{ }^{\circ} \mathrm{C}$. Il faut par conséquent privilégier la carbonisation à basse température.

Sur un financement de l'ADEME, le traitement par incinération des fumées de carbonisation a été étudié en laboratoire, sur des unités pilotes et sur des unités artisanales. L'analyse systématique des fumées, avant et après incinération, a mis en évidence une réduction de la contribution à l'effet de serre de l'ordre de $75 \%$, et la possibilité de n'obtenir, après incinération, que du $\mathrm{CO}_{2}$ recyclable.

La comparaison des techniques de dépollution par condensation et par incinération a montré l'intérêt de la seconde, qui génère une énergie facilement utilisable, alors que les condensats résultant de la première n'ont plus aujourd'hui de valeur économique.
On peut considérer que la carbonisation commence à être bien analysée ; une expérimentation sur l'utilisation domestique du charbon de bois et de sous-produits agro-industriels est engagée.

\section{Les thèses soutenues en 1992}

\section{Chercheurs du département}

Evolution d'un taillis de formation naturelle en zone soudanienne du Burkina Faso, par Yves Nouvellet, université Paris VI.

Etude de l'effet du feu en forêt semi-décidue de Côte-d'Ivoire au sein d'un dispositif expérimental sylvicole, par Jean-Guy Bertault, université Nancy I.

Etude de l'évolution des peuplements naturels d'okoumé, Aucoumea klaineana, dans le Sud-Estuaire du Gabon, par Laurent Rivière, université Paris VI.

Optimisation de la fixation d'azote chez la symbiose Acacia mangiumBradyrhizobium : relations de la plante hôte et de la bactérie symbiote avec l'acidité et les oligoéléments, par Didier Lesueur, université Paris VI.

\section{Accueil par le département}

Approche moléculaire du rôle de la plante hôte dans la symbiose Casuarinaceae-Frankia, par Michèle Phelep (France), Ecole nationale du génie rural, des eaux et des forêts. 


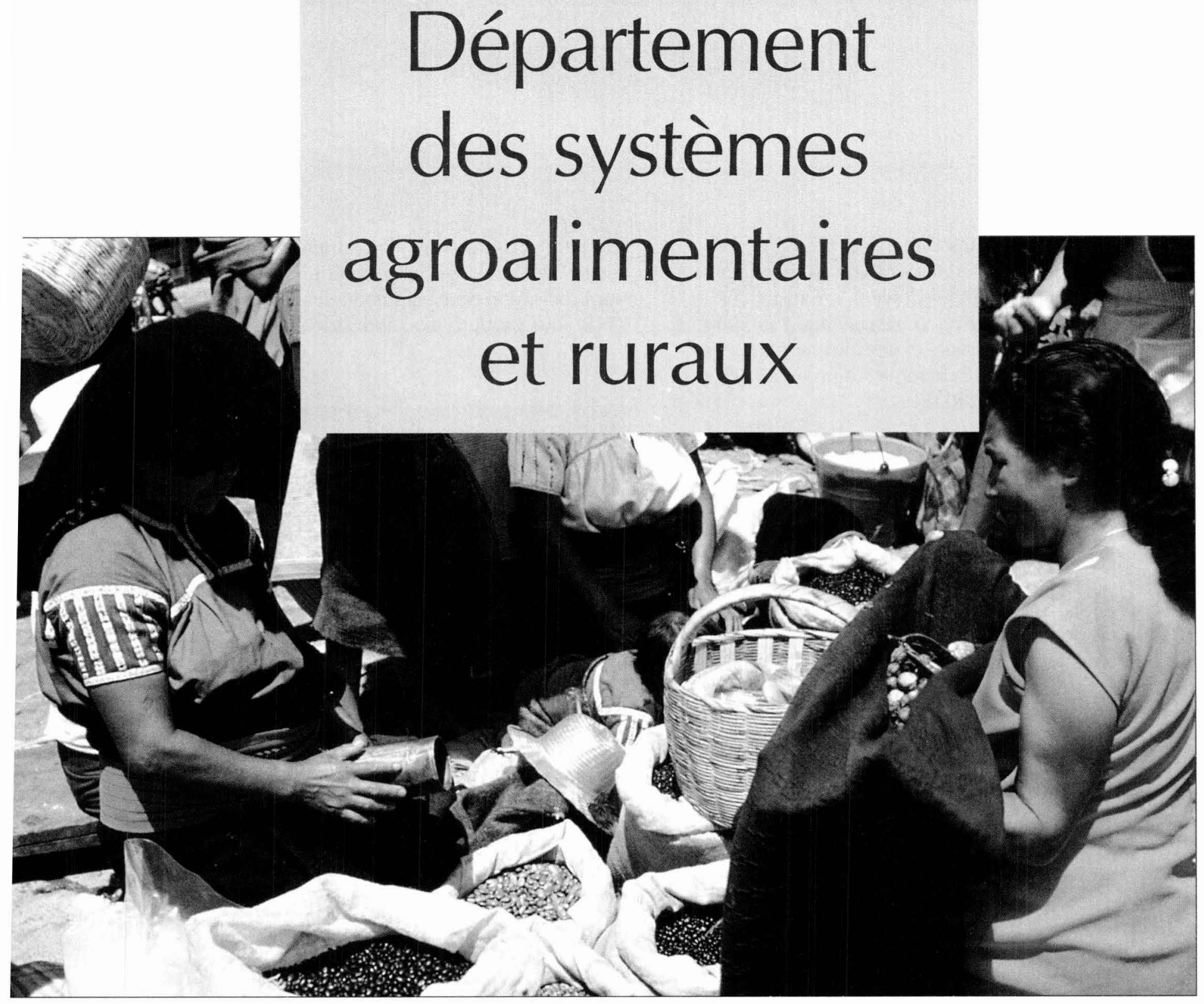

La crise de l'agriculture et l'explosion urbaine montrent l'ampleur des changements sociaux que vivent les sociétés rurales.

Réussir l'intégration au marché mondial impose au producteur, à l'industriel et au politique des décisions rapides, exigeant une connaissance approfondie des dynamiques agraires. L'aide à la décision devient une priorité de la recherche. Elle concerne I'appropriation des ressources naturelles, la gestion des moyens de production, la transformation des produits, l'ouverture sur un nouvel espace économique, la ville. 
$\mathrm{L}$ a nécessité d'appréhender globalement la production agricole, la gestion du milieu naturel et les dynamiques agraires, les marchés et débouchés, la transformation des produits, la diversification des activités rurales, a conduit le CIRAD à réunir au sein d'un département des systèmes agroalimentaires et ruraux les activités du CEEMAT (mécanisation agricole et technologie alimentaire) et du DSA (systèmes agraires).

L'évolution démographique et la diminution des réserves de terres cultivables obligent à sécuriser, à intensifier les systèmes de production. Les choix techniques dépendront d'abord du degré de fragilité des milieux naturels, des conditions climatiques, de la densité de la population. Ils sont également liés aux groupes sociaux et à leur capacité d'innovation. Entrent ici en jeu I'accès à l'information, au capital et aux marchés.

Ces marchés sont en pleine transformation. Les politiques d'ajustement structurel et de libéralisation des échanges accélèrent l'intégration à l'économie mondiale. Le problème de la compétitivité des produits d'exportation et des produits vivriers destinés à des marchés locaux en pleine croissance est brutalement posé. De la production à la consommation, les coûts doivent diminuer, et cela concerne toutes les filières. Le critère de qualité devient déterminant pour les industries agroalimentaires.

Ces mutations se reflètent dans l'émergence d'initiatives économiques nouvelles - individuelles ou communautaires - pour la mise au point ou la diffusion d'innovations, la gestion solidaire de l'épargne et du crédit, la commercialisation et la transformation des produits alimentaires. Ces initiatives sont souvent freinées par des cadres institutionnels inadaptés, que la recherche peut contribuer à faire évoluer.

Ces enjeux définissent les priorités de recherche du département : sécurisation des systèmes de production face aux risques climatiques; pérennisation des systèmes techniques et des exploitations agricoles ; adaptation à l'économie de marché ; alimentation des villes; structuration du monde rural et évolutions institutionnelles.

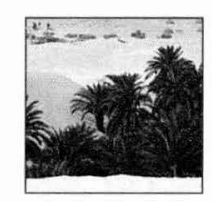

\section{Programme dynamiques agraires en situations sèches et irriguées}

Les conclusions de la synthèse sur l'avenir des zones sahéliennes d'Afrique publiée en 1992 tranchent avec le pessimisme ambiant. Les sociétés agraires des zones sèches font preuve d'un dynamisme certain, d'une grande capacité à adopter des innovations, et sont aptes au changement social. Comment expliquer alors le désengagement ou la diminution de l'aide publique en Afrique et en Amérique latine, dans I'ensemble des zones sèches, toujours marginalisées? La volonté politique s'est atténuée au fil des ans : les dernières grandes sécheresses ont plus de dix ans, et le lien entre montant de l'aide publique et sécheresse a été démontré. Mais surtout, I'analyse et l'évaluation des interventions étatiques, et de leur coût, ont démontré l'inadéquation et la faible rentabilité des actions proposées et menées, tant en termes de développement que d'environnement. Il est donc nécessaire d'élaborer et de tester de nouveaux outils pour la programmation de ces interventions et le suivi ou le contrôle de leurs effets.

C'est une des préoccupations importantes du programme.

\section{Systèmes agraires et intégration au marché}

Face à la croissance démographique toujours forte, les réponses des populations sont diverses. Ainsi, au Tchad, en collaboration avec les ministères concernés, une équipe a réalisé un zonage de la région de N'Djamena, fondé sur les potentialités physiques et la proximité par rapport au marché de la capitale et aux frontières du Nigeria et du Cameroun. Trois types de situation ont été mis en évidence : il y a croissance, développement ou crise.

La colonisation, qui met en valeur des terres vierges à l'est du Chari, correspond à une situation de croissance. L'accumulation de capital, qui naît des activités diversifiées (commerce, pêche, production rizicole irriguée, etc.) dans les zones frontalières à proximité des marchés urbains, correspond à une situation de développement. La surexploitation des ressources 


\section{DÉPARTEMENT \\ DES SYSTÈMES AGROALIMENTAIRES ET RURAUX}

\section{CIRAD-SAR}

\author{
Directeur Jacques Lefort \\ Directeur adjoint Marc Le Moigne \\ Directeur scientifique Jacques Faye \\ Directeur du développement \\ et des programmes \\ Directeur \\ administratif et financier \\ Vincent Dollé \\ Léandre Mas
}

\section{Programmes de recherche}

Dynamiques agraires en situations sèches et irriguées

Développement durable

en savanes et tropiques humides

Défis alimentaires urbains

et promotion des entreprises

Développement local

et dynamiques institutionnelles

\section{Unités de recherche}

Génie agronomique

et mécanisation

Economie des systèmes ruraux

Innovations dans les systèmes

agricoles et agroalimentaires

Génie et technologie alimentaires

Conception des équipements, énergie et informatique

Guy Pocthier

Michel Benoit-Cattin

Jean-Michel Yung

Anne-Lucie Wack

Gilles Vaitilingom

\section{Services d'appui technique}

Documentation Marie-Dominique Lafond Publications Monique Pellecuer Formation Jean-Luc Mazot naturelles, qui conduit à la déforestation, au surpâturage, à la dégradation de la fertilité des sols, correspond à une situation de crise, où les anciennes règles qui régissaient les relations entre éleveurs et agriculteurs sont bouleversées.
Ces mêmes logiques ont été identifiées dans le Nordeste brésilien, à Madagascar, au Burkina Faso. Elles mettent en évidence des intégrations au marché différenciées, liées aux « avantages comparatifs » de ces régions.

Des structures de planification régionale, créées avec la participation du CIRAD, sont progressivement dotées de systèmes d'information géographique leur permettant d'accompagner les évolutions des marchés et des systèmes agraires. Ces structures, telles que l'unité de planification de l'équipe municipale de Juazeiro (Etat de Bahia) au Brésil ou la cellule de recherche-développement de la zone des fleuves Logone et Chari au Tchad, mettent en place des actions de recherche-développement.

\section{Gestion " conservatoire " des ressources naturelles}

A Madagascar, au lac Alaotra, une procédure d'immatriculation foncière accélérée a été mise au point, par laquelle la propriété des terres de tanety est garantie dans un délai d'un an, au lieu de vingt actuellement. La motivation des producteurs pour I'accès au foncier facilite les actions de préservation et de restauration des ressources naturelles (reboisement, gestion de la fertilité, lutte contre l'ensablement).

Au Burkina Faso, I'évolution des modes de gestion des espaces pastoraux a été marquée par des mutations dues aux sécheresses et à leurs conséquences sociales et économiques. Par l'analyse et l'expérimentation, de nouveaux modes de relation entre sociétés pastorales et agricoles ont été mis en évidence. Des voies d'amélioration ont été testées, par exemple pour la régénération des espaces pastoraux et la reconstitution du cheptel. Au Brésil, les "parcours » individuels que l'on s'approprie en les clôturant conduisent à une différenciation sociale accrue. De nouvelles stratégies plus respectueuses de l'environnement, partant des traditions communautaires, sont en cours d'élaboration.

\section{Gestion des aménagements hydroagricoles}

Le désengagement des Etats est plus préoccupant dans les zones irriguées, où leurs interventions étaient particulièrement importantes. II se produit au moment 
même où la nature, la taille et le coût des aménagements hydroagricoles sont mis en question.

Plusieurs ateliers de travail organisés en 1992 par le CIRAD, la Banque mondiale, le ministère de la Coopération et du Développement et la CFD ont rappelé les risques écologiques liés à l'alluvionnement et à la salinisation des parcelles irriguées. Ils ont insisté sur les problèmes sociaux d'accès à la terre, ainsi que sur les contraintes économiques des marchés du riz et des produits de diversification. Autant d'obstacles graves à la prise en charge de l'entretien des réseaux hydrauliques par les paysans et à la pérennité des aménagements.

L'organisation des producteurs et la structuration du monde rural sont des solutions souvent proposées pour la gestion des aménagements. A Madagascar, le projet de petits périmètres irrigués conduit avec I'Office de développement rizicole (ODR) a montré les difficultés qu'ont les usagers, même sur des surfaces relativement limitées, à prendre en charge la gestion de l'eau, l'entretien des réseaux hydrauliques, le paiement des redevances.

Pourtant, en Afrique de l'Ouest, les aménagements spontanés réalisés à faibles coûts en dehors des périmètres irrigués montrent le dynamisme des sociétés rurales.

Ces constatations révèlent de nouveaux enjeux pour la recherche. Celle-ci doit être capable d'aider les politiques et les bailleurs de fonds à choisir les investissements les mieux adaptés aux situations géographiques et sociales. Les producteurs utiliseront les résultats pour définir tant les règles de gestion collective (eau, entretien des réseaux, foncier) que les choix techniques et économiques des exploitations.

Un projet en cours d'élaboration, commun à plusieurs départements du CIRAD, veut atténuer les effets négatifs des aménagements hydroagricoles sur l'environnement, améliorer la réponse technique aux nouvelles demandes et favoriser l'intégration aux marchés potentiels.

Il proposera aussi de nouveaux modes d'organisation précisant les fonctions et les rôles respectifs de l'Etat et des associations de producteurs. Ce projet intègre les actions de recherche actuellement menées sur le fleuve Sénégal et à l'Office du Niger (Mali), redéfinit leur problématique et associe les partenaires du CIRAD au sein de la CORAF.

\section{Publication}

\section{Le développement agricole au Sahel}

L'ouvrage Le développement agricole au Sahel, résultat d'une réflexion collective, est présenté en cinq tomes, dont le dernier rassemblera une bibliographie. Le tome I, "Milieux et défis », esquisse le cadre des défis et des possibles, à l'intérieur duquel les producteurs mettent en œuvre leurs pratiques. Le tome II, "Recherches et techniques", est un essai d'appréciation des techniques utilisables pour le développement. Le tome III, "Terrains et innovations ", présente onze situations d'innovation. Le tome IV, "Défis, recherches et innovations au Sahel ", résume les tomes précédents et donne des réponses argumentées aux questions : Quelles sont les solutions techniques mobilisables au Sahel ? Quels sont les principaux manques? Quelles raisons et quelles conditions décident le producteur (agriculteur, pasteur, pêcheur, artisan, etc.) à innover ou l'en découragent ? Les analyses effectuées remettent en cause le pessimisme qui imprègne les thèses et les discours relatifs aux régions sahéliennes et qui jette un doute sur les possibilités effectives de développement à long terme. La propension des sociétés sahéliennes à l'innovation est forte. Elle s'est forgée dans des contextes climatiques et économiques sévères. Elle est portée par des stratégies individuelles et collectives que développent les producteurs pour défendre leurs modes de vie ou pour les améliorer, voire les transformer. Elle se révèle tout à fait déterminante pour la diffusion des progrès techniques, dès lors qu'ils sont favorisés par des configurations socio-économiques incitatives. Reste, sur le plan opérationnel, la question centrale : Que faire pour libérer les capacités d'innovation des producteurs? Des suggestions sont présentées pour l'environnement économique et institutionnel et pour la recherche. Elles sont proposées à la critique des chercheurs, des acteurs institutionnels du développement, des représentants des organisations professionnelles et politiques. 


\section{Diversification des activités rurales}

Au Brésil, des politiques de crédit, élaborées à titre expérimental en collaboration avec la banque du Nordeste, permettent de diversifier les activités agricoles par la production maraîchère, de commercialiser les produits de l'élevage, de promouvoir les activités de service. Des Etats et des équipes municipales du Sertão interviennent pour aider à la constitution de petites entreprises d'artisanat et de construction.

Des créations de maisons de l'artisanat, des contrats de rénovation d'écoles témoignent des nouvelles orientations du développement rural.

A Madagascar, au lac Alaotra et dans la région d'Antsirabe, dans le cadre de la politique de privatisation de la médecine vétérinaire, un réseau d'agents revendeurs de produits vétérinaires a été mis en place. La formation de ces agents à l'intervention en milieu rural et à la gestion des stocks est assurée grâce à l'appui des entreprises pharmaceutiques.

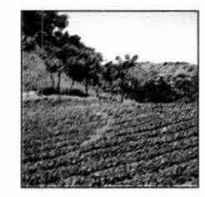

\section{Programme développement durable en savanes et tropiques humides}

Malgré leur potentiel de production, les régions de savanes et les régions tropicales humides sont menacées par l'accroissement démographique, par la rapidité de la transformation des écosystèmes et par l'instabilité des prix mondiaux des produits comme le café, le cacao ou le coton. La pérennité des systèmes de production postforestiers pose le problème particulier du renouvellement des plantations. Dans les zones de savanes, le faible revenu des agriculteurs entraîne un recours limité aux intrants. Diversifier la production, accentuer le rôle de l'élevage, limiter les pertes après la récolte et susciter des conjonctures favorables à de nouveaux débouchés y sont les principaux objectifs. Enfin, dans les régions d'agriculture intensive stabilisée, où l'insertion dans le marché est solidement établie, l'accent est mis sur la transformation des produits, leur commercialisation, et sur l'appui aux organisations de producteurs.

\section{Relance de la production de café et de cacao}

Malgré un effondrement du prix au producteur (-60\%) lié à la crise du marché international, les productions de café et de cacao restent les principales sources de revenu monétaire pour les agriculteurs de la zone méridionale du Cameroun. Les 26 milliards de francs CFA payés pour la récolte de 1991-1992 concernent 3 à 4 millions de Camerounais.

A la demande du ministère camerounais de l'agriculture, une étude sur la relance de la production paysanne de café et de cacao a été réalisée. Elle prend en compte les spécificités des situations régionales et les réactions des producteurs face au nouveau contexte économique. Elle montre clairement que les effets de la crise sont différents selon la culture pratiquée - cacao, café robusta ou café arabica -, le niveau de spécialisation et d'intensification des exploitations, la capacité de diversification, I'ancienneté des plantations et la facilité d'accès au marché.

Ainsi, les planteurs de robusta de la zone de Moungo, qui s'étaient spécialisés dans une caféiculture intensive, voient leurs systèmes de production entièrement remis en cause et réinvestissent dans une production vivrière d'autoconsommation. Les planteurs d'arabica des hauts plateaux, qui avaient engagé depuis plusieurs années une diversification dans les produits maraîchers et vivriers, renforcent cette spécialisation au détriment du café. Alors que les producteurs de cacao, dont les coûts de production sont assez faibles, réussissent à maintenir leur activité.

La situation du Cameroun face à la concurrence internationale est également évaluée. Le désengagement de l'Etat, la disparition du dispositif de stabilisation des prix et la libéralisation du commerce peuvent entraîner un nouveau dynamisme. La réorganisation en cours devrait aboutir à une meilleure prise en compte des réalités du marché international pour la fixation des prix intérieurs et à une gestion concertée de la filière entre les opérateurs économiques.

Au-delà de la conjoncture défavorable, les atouts dans le secteur du café et du cacao sont multiples : savoir-faire 


\section{SYSTÈMES AGROALIMENTAIRES ET RURAUX}

des planteurs, réserves en terres encore abondantes, perspectives de nouvelles règles du jeu.

Ce diagnostic d'ensemble dessine les contours d'une relance régionalisée de la production de café et de cacao. Il fournit une base chiffrée à la réflexion des acteurs de la filière. Il débouchera en 1993 sur des propositions d'interventions régionales.

\section{Petits producteurs de café et agro-industrie}

A l'initiative d'une firme industrielle, Unicafé, une étude sur les perspectives d'intégration professionnelle de la filière ivoirienne du café a été réalisée en collaboration avec un cabinet d'études juridiques.

L'analyse a porté sur la situation des producteurs, marquée par la chute des prix du café et la désorganisation de la commercialisation. Elle a également pris en compte la fin des monopoles industriels et l'autorisation du décorticage artisanal, qui modifient profondément tout le secteur de la transformation de ce produit.

L'étude propose la création d'un dispositif d'appui aux producteurs organisé autour de deux fonctions : une fonction commerciale, prise en charge par le secteur privé ; une fonction de soutien technique pour I'amélioration de la production et de la gestion des exploitations, confiée à une association professionnelle. Cette association, chargée de la promotion de la caféiculture ivoirienne, concevrait et réaliserait des opérations de formation, d'information, de conseil agricole et de recherche-développement. Gérée par les groupements de producteurs, les exportateurs et les industriels, elle serait l'interlocuteur privilégié des pouvoirs publics, qui réorganisent l'ensemble du système de vulgarisation agricole.

\section{Conservation des récoltes}

Dans le nord du Cameroun, la région de Garoua est touchée par la crise du coton. La diversification économique et le développement des initiatives villageoises dans le domaine agroalimentaire sont les objectifs d'un projet global de recherche associant I'IRA et plusieurs départements du CIRAD. Dans cette optique, on met au point, à petite échelle, des méthodes de conservation et de transformation des produits : transformation du maïs, du sorgho et de l'arachide ; conservation du niébé et de l'oignon.

Les résultats obtenus sur la conservation de l'oignon sont un bon exemple de l'apport de ce type de recherche. Avec une production de l'ordre de 30000 tonnes, l'oignon est, pour les agriculteurs de la région, une source de revenu évaluée à 1 milliard de francs CFA. En saison des pluies, les pertes au cours du stockage et du transport peuvent atteindre la moitié de la production. Les prix sur les marchés locaux en subissent le contrecoup : acheté

\section{Des produits pour le développement}

\section{Matériels agricoles pour la Réunion}

A la Réunion, une équipe du CIRAD a conçu une récolteuse de canne à sucre entière avec les industriels sucriers. Cette machine, spécialement étudiée pour les petites exploitations paysannes, permet de pallier l'absence de main-d'œuvre au moment de la récolte, sans pour autant bouleverser le système traditionnel. Le planteur, après le passage de la récolteuse, se retrouve dans les conditions de ramassage et de transport qu'il connait en coupe manuelle. II peut utiliser le chargeur et la remorque dont il dispose, ce qui n'est pas possible avec les récolteuses classiques en cannes tronçonnées.

Les systèmes d'élevage qui se sont développés dans les zones d'altitude de la Réunion sont fondés sur l'exploitation de l'herbe. Le pâturage et l'affouragement en vert ne suffisent pas à alimenter les troupeaux laitiers pendant la période hivernale froide et sèche (de juin à novembre). Or, les surplus d'herbe de la saison estivale humide, gorgés d'eau, sont difficiles à conserver dans les conditions traditionnelles. Une technique d'ensilage en balles rondes enrubannées améliore la qualité et la durée de la conservation de l'herbe. En évitant les pénuries en saison sèche, elle contribue à l'augmentation de la productivité du cheptel. 
3500 francs CFA pendant la période de récolte (de février à avril), le sac de 90 kilos vaut 25000 francs en novembre. Une recherche sur la conservation de l'oignon frais, réalisée en collaboration avec I'IRA, a montré que les pertes peuvent être ramenées de $42 \%$ à $18 \%$ par un stockage sur claies en couches minces dans une cellule aérée, et que les variétés violettes et jaune orangé ont la meilleure aptitude à la conservation.

\section{L'adoption des innovations par les agriculteurs}

Dans la région de Silvania (Etat de Goiás, au Brésil), représentative du cerrado central, de grandes exploitations de soja et d'élevage voisinent avec de petites et moyennes exploitations associant polyculture et élevage. Selon I'EMBRAPA, ces dernières adoptent peu les techniques proposées par la recherche, ce qui serait l'une des principales causes de la lenteur du développement agricole de la région. On cherche donc à favoriser la diffusion des innovations en caractérisant les groupes d'agriculteurs auxquels elles s'adressent.

La relation entre la famille et l'exploitation est à l'origine de stratégies différentes. Dans un premier groupe, la main-d'œuvre est constituée par les membres

\section{Des produits pour le développement}

\section{Biocarburants}

Les biocarburants réduisent la dépendance vis-à-vis de l'approvisionnement pétrolier. En outre, des mesures des polluants à l'échappement d'un moteur Diesel alimenté en huile végétale, réalisées avec l'ESEM, indiquent des rejets de dioxyde de carbone moins importants qu'avec un carburant classique. Une voiture de tourisme fonctionnant à l'huile de colza a déjà parcouru 4000 kilomètres depuis le début des essais. Un prototype de gazogène à balles de riz produit de façon continue 100 mètres cubes à l'heure de gaz combustible (pouvoir calorifique inférieur moyen de 4,5 mégajoules par mètre cube). Le procédé est applicable à des sous-produits pulvérulents comme la parche de café et la coque d'arachide. de la famille. Le producteur est surtout sensible aux moyens lui permettant d'accélérer l'accumulation de capital (terre, cheptel) et d'améliorer la productivité de son travail. Dans un deuxième groupe, la maind'œuvre familiale tend à être remplacée par des salariés ou par la mécanisation. Mieux insérés dans les échanges monétaires, les producteurs de ce groupe cherchent à augmenter leur profit. Un troisième groupe se caractérise par l'absence de relation directe entre l'exploitation et la famille, qui n'habite pas sur place et ne trouve là qu'un complément de revenu. Cette typologie devient un outil de base pour élaborer des méthodes de conseil de gestion d'exploitations agricoles.

\section{Relance de la culture du soja en Asie du Sud-Est}

En Indonésie et en Thaïlande, l'introduction d'innovations est également au cour d'un projet d'intensification de la production de soja, Sygap II, mené en collaboration avec le CGPRT. Une équipe composée d'agronomes et d'économistes travaille avec un réseau d'agriculteurs.

Dans certains des sites étudiés, les producteurs sont réticents à adopter les techniques recommandées en raison de l'instabilité des rendements du soja. Des méthodes adaptées de préparation des terres et de semis permettent de valoriser les ressources en eau et de réduire la variabilité de la production. Par ailleurs, culture du soja et riziculture sont souvent en compétition pour les disponibilités en main-d'œuvre. La mécanisation peut être à l'origine d'une évolution favorable.

L'amélioration des conditions de la récolte doit assurer une meilleure qualité des produits et par conséquent un meilleur débouché sur le marché. Les premiers résultats incitent les producteurs à tester eux-mêmes certaines propositions techniques.

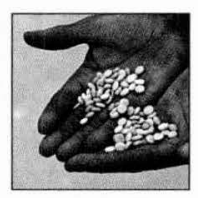

\section{Programme défis alimentaires urbains et promotion des entreprises}

Face à l'explosion démographique des villes du Sud, le programme défis alimentaires urbains et promotion des entreprises a été créé en 1992 pour valoriser 
les productions agricoles locales en mobilisant les entreprises qui les transforment et les commercialisent. Partant de l'analyse des marchés de consommation, des actions sont élaborées, mises en œuvre, testées pour contribuer à l'équilibre de l'offre des producteurs et de la demande alimentaire urbaine.

\section{La demande alimentaire urbaine}

Les enquêtes sur l'évolution de la consommation alimentaire, réalisées à Dakar, à Cotonou et à Garoua, soulignent que les produits locaux ne sont pas rejetés au profit des produits importés.

A Dakar, le nététu, condiment traditionnel à base de graines de néré, est toujours largement consommé par toutes les catégories de population, malgré la diffusion de cubes condimentaires industriels.

A Garoua, le maïs est une denrée dont la consommation se développe, notamment grâce aux moulins de quartier, de plus en plus nombreux, qui permettent d'en assurer facilement la transformation.

Ces résultats sont confirmés par l'analyse comparée des enquêtes de consommation effectuées depuis vingt ans en Afrique, dans les pays sahéliens, humides et subhumides. Une étude sur la valorisation des produits vivriers dans ces pays, réalisée pour le SPAAR, confirme que la ville joue un rôle d'entraînement pour

la production locale. Le manioc et l'igname trouvent ainsi de nombreux débouchés dans les centres urbains. Le gari et l'attiéké (semoule et couscous de manioc), aliments spécifiques de certaines zones culturelles, sont commercialisés dans des villes africaines où ils n'étaient pas connus. Ces travaux révèlent que, malgré un pouvoir d'achat encore limité, les citadins cherchent à diversifier leur alimentation. Dans ce contexte, la consommation de riz et de blé se développe, au même titre que celle de maïs, de tubercules et de légumes. La recherche peut contribuer à mieux concilier offre agricole rurale et demande urbaine.

\section{L'artisanat alimentaire}

Les enquêtes de consommation confirment également que la demande urbaine n'est pas homogène et que les marchés sont segmentés, d'où le caractère multiforme des entreprises agroalimentaires. Ce secteur a été étudié dans plusieurs pays : Bénin, Cameroun, Congo, Sénégal, Chili, Colombie, Panama.

En Afrique, le processus d'industrialisation du secteur vivrier se caractérise par le développement d'activités artisanales multiples et décentralisées. Ainsi, à Brazzaville, on a évalué à environ 2500 le nombre d'ateliers artisanaux de production de chikwangue et de foufou (pâte et farine de manioc). L'analyse de leur mode de fonctionnement révèle leurs atouts en termes d'adéquation à la demande urbaine, de souplesse d'adaptation et de capacité d'innovation. Cependant, ces unités, lorsqu'elles changent de taille, sont confrontées à des problèmes de financement, de productivité, de maîtrise de qualité. Ces difficultés justifient la mise en place d'opérations d'appui au Bénin et au Burkina Faso.

\section{Agro-industries rurales en Amérique latine}

En Amérique latine, I'analyse du secteur agroalimentaire a mis en évidence le rôle croissant des agro-industries rurales. Gérées par des producteurs agricoles individuels ou organisés ou par des entrepreneurs ruraux, ces petites entreprises agroalimentaires jouent un rôle très important dans la valorisation des ressources locales.

Elles se révèlent être aussi un catalyseur majeur pour la structuration du monde rural et l'organisation socioprofessionnelle des producteurs.

Des actions d'appui à ces entreprises sont menées en collaboration avec des institutions régionales de recherche-développement agroalimentaire. L'IICA, au Costa Rica, I'INTA, en Argentine, et I'INCAP, au Guatemala, participent au programme de développement de l'agro-industrie rurale en Amérique latine et aux Caraïbes (PRODAR). Ainsi, en Argentine, des méthodes de marchéage ont été adaptées pour élaborer la stratégie commerciale d'un réseau de petites entreprises rurales de production de confiture.

Des actions d'appui technologique ont été intensifiées. En Colombie et au Brésil, le procédé traditionnel de transformation du manioc en amidon a été étudié. L'amidon fermenté est utilisé comme matière première pour la fabrication de pain (pan de yuca et pan de bono 


\section{Rencontres internationales}

\section{Transformation des produits vivriers et innovation}

En association avec des partenaires français, béninois, sénégalais et camerounais, le CIRAD contribue à la mise au point d'innovations dans le secteur alimentaire. Engagé en 1988, ce travail s'est achevé en novembre 1992 par des Journées scientifiques, qui ont rassemblé une centaine de participants à Montpellier. L'intérêt d'une approche intégrée de la consommation alimentaire, des systèmes techniques de transformation et de la démarche d'innovation a été reconnu. Aborder la consommation en termes de styles alimentaires - intégrant les produits et les plats consommés, les modes d'approvisionnement, de transformation et de préparation, et les conditions de consommation - se révèle efficace. Les travaux menés au Sénégal avec l'ENEA, au Cameroun avec I'IRA, au Congo avec Agricongo, ont fourni d'intéressants exemples. L'analyse des techniques de production de nététu au Sénégal avec le CADEF et I'ISRA, de transformation du manioc en chikwangue au Congo avec l'ORSTOM, de valorisation des céréales et de l'oignon au Cameroun avec I'IRA a permis de comprendre comment une innovation s'inscrit dans un environnement technique, économique, social et culturel.

colombiens). Il possède un pouvoir de gonflement, alors que le manioc est dépourvu de gluten. Les recherches se poursuivent pour comprendre comment le procédé de fermentation et de séchage de l'amidon confère cette propriété spécifique. Ces travaux pourraient ouvrir de nouvelles et intéressantes perspectives de valorisation pour d'autres produits amylacés tropicaux comme l'igname, le mil, le sorgho ou le maïs. Parallèlement, en Colombie et en Equateur, des améliorations techniques ont été apportées dans de petites entreprises de production d'amidon de manioc afin d'accroître le taux d'extraction.

\section{Programme développement local et dynamiques institutionnelles}

Des initiatives privées, individuelles ou collectives, apparaissent dans les unités de production, de transformation et de valorisation des produits agricoles, dans les petites entreprises de service en milieu rural. L'importance de ces initiatives a conduit à créer un programme de recherche sur le développement local et les dynamiques institutionnelles.

\section{Développement de systèmes financiers ruraux}

Pour dynamiser les économies locales, un projet de développement de systèmes financiers ruraux veut lever les difficultés de financement rencontrées par les agriculteurs. Au Burkina Faso, l'équipe du projet a identifié les stratégies des producteurs et leurs besoins spécifiques de financement. Avec l'appui de la CFD, de nouveaux produits financiers, adaptés aux demandes locales, sont expérimentés en collaboration avec la Caisse nationale de crédit agricole. Un millier de petits crédits ont été mis en place auprès d'agriculteurs, d'artisans et de commerçants, avec un bon taux de recouvrement. Il faut maintenant suivre et évaluer les effets économiques et sociaux de ces nouvelles formules de crédit et élaborer un système de financement régional et national.

\section{Organisation des producteurs}

En Casamance, le Comité d'action pour le développement du Fogny (CADEF) s'est constitué en groupement d'intérêt économique en 1985. II rassemble actuellement vingt-cinq villages et compte plus de 4000 adhérents. La dynamique locale de développement fait l'objet d'un projet de recherche en association avec I'ISRA, la Fondation pour le progrès de l'Homme et le CIEPAC.

A partir d'une demande technique des producteurs suscitée par un environnement écologique en voie de dégradation, des systèmes de culture améliorés et diversifiés, intégrant l'élevage, ont été mis au point. 
Pour les mettre en œuvre, la recherche accompagne les producteurs, qui créent des entreprises de services: brigade de puisatiers, forge itinérante, unité de fabrication de grillage, banque de semences, structure de lutte phytosanitaire, pharmacie vétérinaire, etc. Le système de crédit donne des résultats contrastés. Les prêts destinés à la diversification des activités économiques ont un taux de recouvrement convenable. En revanche, ceux consacrés à l'acquisition de matériel agricole ont dû être suspendus. Cela confirme I'importance de la diversification des activités face à la crise de la production agricole.

Un réseau efficace d'animateurs paysans assurant le conseil technique et de gestion est un autre signe de la prise en charge progressive du développement par les groupements.

\section{Appui aux dispositifs de recherche-développement}

Les systèmes nationaux de recherche des pays du Sud et les structures qui les composent sont en crise souvent profonde et doivent faire face à des difficultés considérables. C'est l'occasion d'une ouverture à de nouveaux acteurs de la recherche publique, ou parfois privée, et à la prise en compte des demandes des agriculteurs et de leurs priorités de développement.

En 1992, le département a participé à la réorganisation des structures de recherche et de développement en Tunisie, en Algérie, en Angola et au Burkina Faso.

De la même manière, le programme grains de base contribue à l'organisation d'un système régional de recherche sur les productions vivrières. II regroupe les institutions de six pays d'Amérique centrale. Avec la participation de I'IICA, des équipes de recherchedéveloppement sont formées, un système d'information est constitué, des échanges scientifiques sont organisés. Le cycle de formation à la gestion des centres de recherche (FGCR), organisé avec la FAO et le CTA, a réuni en 1992 une vingtaine de cadres confirmés de la recherche.

D'autres formations sont centrées sur les relations entre recherche et développement. D'abord dispensées en France, elles s'exportent. Ainsi, au Chili, l'organisation non gouvernementale Agraria a accueilli la quatrième session d'assistance technique en milieu paysan. Cette formation a rassemblé 27 participants de 16 pays d'Amérique latine et de la Caraïbe pendant quatre semaines.

\section{Les thèses soutenues en 1992}

\section{Chercheurs du département}

Huiles végétales-biocombustible diesel ; influence de la nature des huiles et en particulier de leur composition en acides gras sur la qualité du carburant, par Gilles Vaitilingom, université d'Orléans.

Huiles végétales-biocombustible diesel ; incidence des aspects thermiques liés au type de moteur à combustion, par Pascal Higelin, université d'Orléans.

Propriétés physiques, hydriques et mécaniques de sols andiques de la Réunion ; facteurs d'évolution des horizons culturaux, implications agronomiques et écologiques, par Sylvain Perret, Ecole nationale supérieure agronomique, Montpellier.

\section{Accueil par le département}

Déshydratation osmotique de produits végétaux ; application à l'obtention de concentrés de tomate, par Ana Perez Carvajal (Costa Rica), université des sciences et techniques du Languedoc, Montpellier II.

Le séchage du poisson (Tilapia spp.) ; étude de la relation procédéqualité du produit ; application de terrain au Mali, par Nadine Zakhia (Liban), Ecole nationale supérieure des industries agricoles et alimentaires.

Etude et mise au point de méthodes de mesure de la biodégradabilité des matériaux d'emballage, par Véronique Coma (France), université de Reims.

Conception et réalisation d'un procédé automatisé de déshydratationimprégnation par immersion, par François Giroux (France), Ecole nationale supérieure des industries agricoles et alimentaires. 


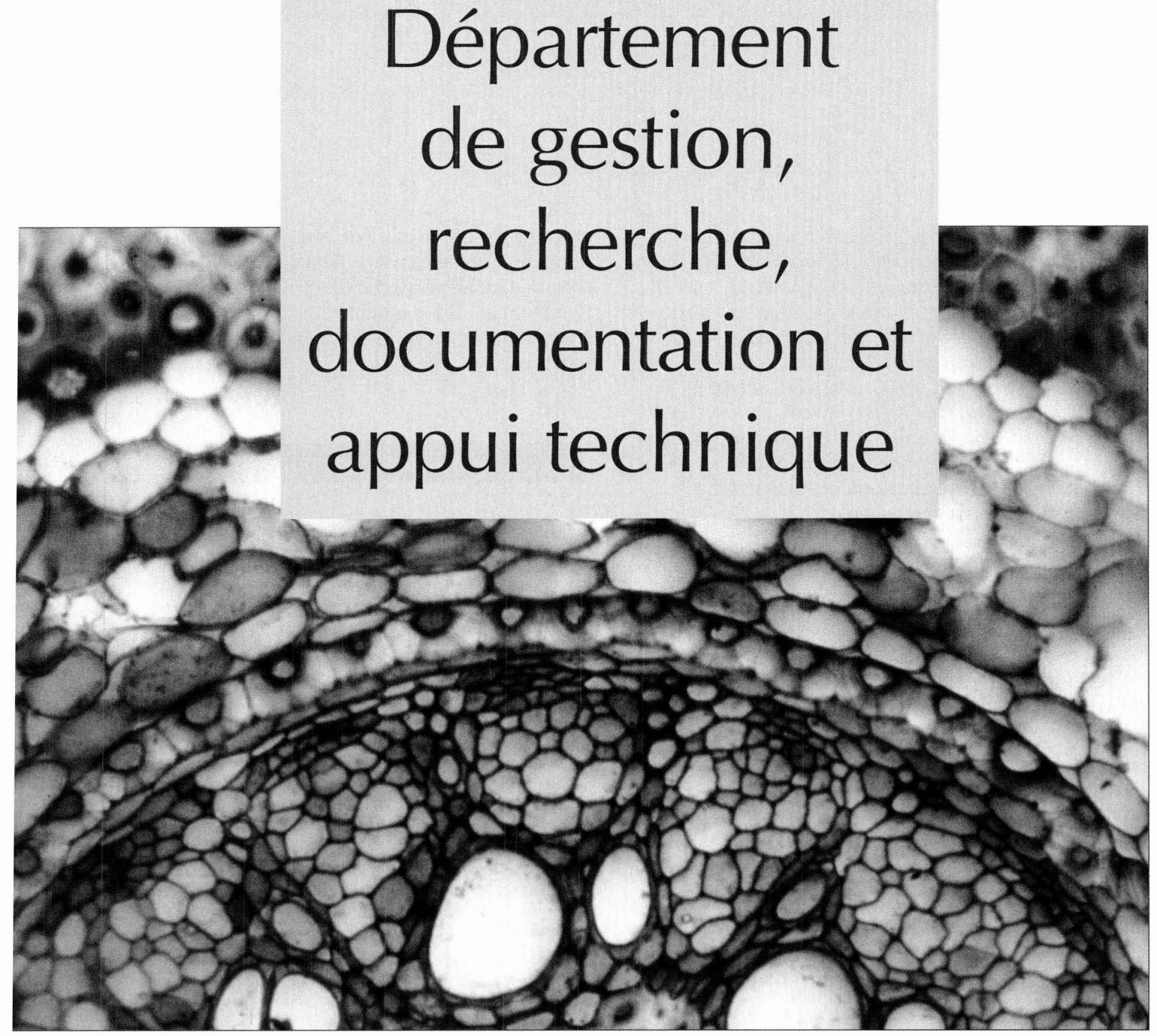

Le département de gestion, recherche, documentation et appui technique occupe une place particulière au sein du CIRAD.

Après avoir joué un rôle moteur, en 1984, au moment de la création de l'organisme, il est aujourd'hui structuré autour de deux pôles d'activité : un pôle de support administratif et financier pour la direction générale ; un pôle de recherche, qui a vocation à accueillir des programmes, des unités de recherche et des services d'intérêt commun. 


\section{RECHERCHE ET APPUI TECHNIQUE}

$\mathrm{L}$ e pôle de recherche du GERDAT constitue le cadre institutionnel dans lequel, sous l'impulsion de la direction scientifique du CIRAD et en liaison avec les départements, sont développés des thématiques scientifiques et des outils d'analyse indispensables à la stratégie scientifique de l'établissement. Les unités communes sont dotées de comités de pilotage associant les départements utilisateurs. Si I'un de ces derniers acquiert une compétence particulière dans le domaine considéré, la gestion de I'unité commune peut lui être confiée, en accord avec les autres départements.

Le périmètre du département GERDAT est donc appelé à varier dans le temps en fonction de la dynamique scientifique du CIRAD et des besoins des autres départements de l'établissement.

Il comprend aujourd'hui quatre unités de recherche communes et un programme. Deux unités nouvelles pourraient lui être rattachées dans le courant de l'année 1993, I'une sur la phytovirologie des régions chaudes, en association avec l'ORSTOM, l'autre sur les systèmes d'information géographique et la télédétection.

Le comité de pilotage de chaque unité de recherche, mis en place en 1993, devra veiller à assurer un équilibre dans la programmation de l'activité entre une fonction de service répondant aux besoins des départements impliqués et un certain degré d'autonomie permettant le renforcement des capacités scientifiques du CIRAD.

Les services centraux de formation, d'information scientifique et technique et $\mathrm{d}^{\prime}$ informatique, qui ont une utilité collective et une fonction de coordination, sont également rattachés au département GERDAT.

On trouvera ici un bilan succinct de l'activité des unités au cours de l'année 1992, le souci pour l'avenir étant $d^{\prime}$ assurer une meilleure synergie au sein de la communauté scientifique du CIRAD et de renforcer les ouvertures vers nos partenaires institutionnels.

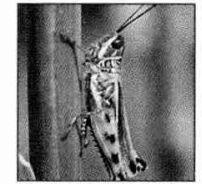

\section{Programme écologie et acridologie}

Le programme d'écologie et d'acridologie, Prifas, étudie le déterminisme des pullulations des criquets ravageurs d'importance économique et met au point des moyens de lutte en fonction des contextes économique et écologique. II participe à des recherches d'intérêt général dont les résultats sont disponibles pour la communauté internationale. II mène une politique de formation des scientifiques, $\mathrm{d}^{\prime}$ information des partenaires, de surveillance des situations acridiennes et de conseil en matière de stratégie de lutte.

En 1992, le programme s'est implanté au Brésil, au Sénégal et au Burkina Faso. Ses activités se sont étendues à la Russie, à la Chine et au Yémen. En outre, des contacts ont été établis avec le Costa Rica, I'Afrique du Sud, Madagascar et le Vietnam.

\section{Le modèle du criquet pèlerin}

Les pullulations de criquets pèlerins peuvent se développer dans une soixantaine de pays et y causer d'énormes ravages. Les travaux de modélisation de ce criquet, soutenus par la CCE et le FAC, ont pour but de mettre au point un outil de diagnostic directement utile aux opérations de lutte. On dispose à présent d'un prototype validé sur la période 1985-1992. Ce modèle démographique permet de mieux comprendre le passé récent et de simuler les effets de diverses hypothèses. Des recherches complémentaires sont entreprises sur la typologie acridoécologique de l'aire d'habitat de l'espèce, soit trente millions de kilomètres carrés. Les données seront gérées par un système d'information géographique.

\section{Impact écologique des traitements antiacridiens}

Au Burkina Faso, sous l'égide de l'OCLALAV, un projet d'évaluation de l'impact des traitements antiacridiens 


\section{RECHERCHE ET APPUI TECHNIQUE}

\section{DÉPARTEMENT DE GESTION, RECHERCHE, DOCUMENTATION ET APPUI TECHNIQUE}

\author{
CIRAD-GERDAT \\ $\begin{array}{rr}\text { Directeur } & \text { Jean-Marie Sifferlen } \\ \text { Directeur des recherches } & \text { Michel Eddi } \\ \text { Directeur } & \\ \text { administratif et financier Vincent Fabre-Rousseau }\end{array}$
}

Programmes de recherche

Ecologie et acridologie Michel Launois

\section{Unités de recherche communes}

Biotechnologies

appliquées à l'amélioration des plantes tropicales

Modélisation des plantes

Prospective et politique agricole

Analyse des sols et des plantes

Jacques Schwendiman Philippe de Reffye Michel Griffon Paul Fallavier

Services d'appui technique

Formation Information scientifique et technique Informatique

Aménagement et maintenance

Marc Roesch

Jean-François Giovannetti Joël Sor

François Roumens a été établi avec le service national de la protection des végétaux.

En préambule à ce projet, un atelier international sur les méthodes de recherche en écologie en Afrique a été organisé avec le concours de la CCE. II a eu lieu à Montpellier en février 1992. Les participants, chercheurs ou praticiens de terrain africains et européens, ont dressé un bilan des systèmes de surveillance et des recherches relatives à l'effet des pesticides sur l'environnement. Diverses expériences ont été confrontées. Les moyens d'évaluation des effets des traitements sur la faune non-cible ont été exposés. L'interprétation des tests écotoxicologiques sur les invertébrés terrestres, les méthodes d'étude des effets sur les oiseaux, I'utilisation d'organismes biologiques comme marqueurs sont autant d'aspects méthodologiques particuliers de la recherche dans ce domaine.

La première phase de travail sur le terrain a consisté à mettre au point une méthode de surveillance écotoxicologique. Les réactions des populations acridiennes, ainsi que celles des oiseaux et de certains groupes d'insectes, sont étudiées lors de traitements chimiques réalisés en conditions réelles par les services nationaux chargés de la lutte antiacridienne.

Ces études seront approfondies au cours des prochaines campagnes agricoles.

\section{Campagne antiacridienne en Afrique de l'Ouest}

A la demande de I'OCLALAV, une assistance scientifique et technique a été mise en place à Dakar durant la campagne acridienne de 1992.

Pour une meilleure synthèse des informations acridiennes, présentées sous forme d'un bulletin, une enquête a été entreprise auprès de chaque service de protection des végétaux des dix pays membres de l'OCLALAV. Cette enquête a porté sur la qualité des observations de terrain et sur leur interprétation ainsi que sur la qualité des opérations de lutte. Elle a permis de définir les moyens d'accélérer la centralisation des données à l'OCLALAV. Leur interprétation se fera en liaison avec l'équipe de Montpellier, et les résultats seront restitués dans les plus brefs délais aux pays utilisateurs.

\section{Acridologie au Brésil}

La région périamazonienne du Brésil subit depuis 1986 d'importantes pullulations d'acridiens. La nécessité d'une stratégie antiacridienne propre au contexte de la région a conduit à mettre en place sur le terrain, en association avec I'EMBRAPA, un projet de recherche 
soutenu par la CCE. A terme, une cellule brésilienne d'acridologie opérationnelle devrait être créée.

Les recherches bioécologiques portent sur des cas précis d'acridiens ravageurs de la région périamazonienne : le but est de mieux comprendre le déterminisme des pullulations et d'étudier l'évolution de l'environnement et ses conséquences sur le risque acridien. La description et le suivi saisonnier des biotopes acridiens sont réalisés par télédétection spatiale. Les données environnementales et biologiques sont intégrées à un système d'information géographique, en cours de création, destiné à faciliter la surveillance des populations acridiennes.

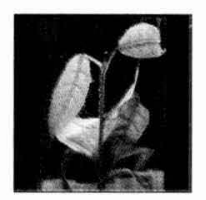

Unité de biotechnologies appliquées à I'amélioration des plantes tropicales

L'unité de recherche de biotechnologies appliquées à I'amélioration des plantes tropicales, Biotrop, adapte ou crée des méthodes de biologie moléculaire et cellulaire. Ces méthodes ne prétendent pas se substituer aux stratégies conventionnelles d'amélioration des plantes : elles contribuent à les rendre plus rapides et plus efficaces ou elles les complètent. En amont de la création variétale, elles interviennent pour la conservation et l'analyse des ressources génétiques. Dans le cadre de la création variétale, la transformation génétique permet d'ajouter des caractères particuliers à des variétés sélectionnées. En aval, les recherches sur les systèmes de multiplication conforme in vitro ont pour objectif la micropropagation.

Les quatre laboratoires de Biotrop — analyse du génome des espèces tropicales, ingénierie génétique, culture in vitro, histologie - rassemblent les chercheurs des départements du CIRAD qui utilisent les biotechnologies pour l'amélioration des espèces tropicales.

\section{La diversité génétique des plantes}

L'analyse de la diversité génétique des plantes, auparavant étudiée par électrophorèse d'isozymes, repose maintenant sur le marquage moléculaire par l'examen du polymorphisme de la longueur des fragments de restriction (RFLP), éventuellement complété par l'amplification aléatoire de séquences polymorphes d'ADN (RAPD). Les résultats acquis sur la diversité génétique du cacaoyer, de I'hévéa et du bananier sont rapportés dans les programmes correspondants.

\section{Cartographie du génome}

Les marqueurs moléculaires permettent aussi de cartographier le génome des plantes. La cartographie du sorgho a débuté en 1992. Celles de la canne à sucre, du cacaoyer et de l'hévéa sont en cours. La construction de la première carte génétique des bananiers diploïdes appartenant à l'espèce Musa acuminata vient de s'achever. La CCE soutient plusieurs de ces programmes.

En complément des méthodes précédentes, les techniques de polymerase chain reaction (PCR) ont été mises en œuvre sur trois espèces. Chez l'hévéa, la PCR apporte une simplification importante de la procédure de préparation des sondes pour la réalisation des RFLP : le protocole permet désormais d'amplifier efficacement les sondes sans étape de purification des plasmides. Elle facilite également le développement des marqueurs RAPD, qui s'ajoutent aux marqueurs RFLP. Le bananier se prête bien à I'utilisation de la méthode RAPD, et 28 loci supplémentaires complètent la carte établie à partir du croisement SF 265 x Banksii. Pour le cacaoyer, en dépit de difficultés méthodologiques, désormais surmontées, 28 marqueurs RAPD ont été utilisés pour I'analyse de la descendance UPA $409 \times$ POR.

\section{Régulateurs de croissance endogènes}

Fédérant des recherches menées par le CIRAD, I'ORSTOM et I'université Paris VI, I'étude 


\section{RECHERCHE ET APPUI TECHNIQUE}

des régulateurs de croissance endogènes a permis de suivre leur évolution chez les embryons somatiques et zygotiques d'Hevea brasiliensis. Le développement anormal d'une partie des embryons somatiques a été expliqué ; leur conversion en plantules est désormais maîtrisée de façon fiable et reproductible, grâce à un apport d'acide abscissique

ou à une dessiccation douce.

Chez le palmier à huile, l'anomalie de la morphogenèse florale induite par la culture in vitro a été reliée à un déficit en cytokinines. Ce déficit se produit dans des inflorescences femelles anormales issues d'un procédé de multiplication par cals à croissance rapide. On dispose désormais de marqueurs spécifiques qui permettent d'éliminer les cultures d'embryons susceptibles de donner naissance à des individus anormaux.

\section{Embryogenèse somatique en milieu liquide}

La maîtrise de l'embryogenèse somatique en milieu liquide intéresse diverses plantes comme l'hévéa, le riz, le bananier, le caféier et le palmier à huile.

Pour l'hévéa, le pas a été franchi du procédé de base à un procédé de multiplication végétative à grande échelle, ce qui constitue une première mondiale. En outre, I'approche analytique conduite pour induire la friabilité des cals a permis de comprendre les mécanismes qui sont à l'origine des résultats observés en culture in vitro. Cela garantit la maîtrise et donc la reproductibilité du phénomène.

Des suspensions embryogènes de bananiers diploïdes, obtenues à partir d'embryons zygotiques, ont été entretenues en éliminant systématiquement les fractions supérieures à un diamètre de 500 microns. On évite les pertes de capacité de maturation et de germination par un préconditionnement sur un milieu modifié pour ses macroéléments, suivi d'un étalement sur un milieu de maturation apportant des cytokinines. Cette séquence autorise désormais le développement harmonieux des embryons somatiques.
Pour les bananiers triploïdes, les suspensions à partir de jeunes fleurs mâles immatures n'ont pas encore abouti à la régénération de plantes. En revanche, cultivées avec le système d'immersion temporaire mis au point par le laboratoire, les suspensions ont un taux de prolifération exceptionnel. En outre, les changements de milieux peuvent être réalisés sans manipulation des tissus ou des cellules végétales. Mis au point sur le bananier, ce système de culture original a été appliqué avec succès aux microboutures de caféier et d'hévéa, ainsi qu'à leurs suspensions embryogènes. Son efficacité incite à le perfectionner encore.

En histologie, de nouvelles méthodes d'étude des suspensions cellulaires sont développées. Elles sont à l'origine d'une gamme de colorations rapides, faciles à mettre en œuvre, parmi lesquelles les marqueurs fluorescents ont une place importante. La méthode de cytométrie en flux a été adaptée à la détermination du niveau de ploïdie des plants régénérés. On sait maintenant évaluer l'activité cellulaire ou les potentialités d'enracinement en fonction des activités peroxydasique, phosphatasique ou ATPasique.

\section{Ingénierie génétique et transformation}

La bactérie Bacillus thuringiensis produit naturellement une gamme d'endotoxines qui ont des propriétés insecticides vis-à-vis d'un grand nombre de lépidoptères ravageurs des plantes. Ces toxines peuvent être utilisées pour produire des biopesticides.

Dans un premier temps, une collection de gènes de toxines clonés a été rassemblée avec la collaboration de l'INRA, de l'Institut Pasteur et d'universités nord-américaines. Cette collection a permis de produire chacune des toxines correspondant aux gènes. Après purification, des tests de toxicité sont conduits sur des insectes en élevage de façon à établir le lien avec la sensibilité du ravageur. La vérification in vitro de l'existence de récepteurs membranaires de la toxine dans l'intestin moyen des larves d'insectes est faite par histo-immunologie. Cette technique 


\section{RECHERCHE ET APPUI TECHNIQUE}

nécessite la production d'antisérums spécifiques. Afin d'augmenter le spectre $d^{\prime}$ insectes sensibles, plusieurs isolats de $B$. thuringiensis montrant des caractères originaux ont été analysés. De nouvelles toxines insecticides ont été isolées.

Pour éviter l'installation d'une résistance chez les insectes, on cherche à associer à $B$. thuringiensis des protéines à modes d'action différents. Ainsi, un gène inhibiteur de protéase de soja a été cloné dans un gène de toxine de la bactérie à la place de la séquence codant pour la sous-unité toxique. Cet inhibiteur de protéase a bien été produit sous forme cristallisée, comme les toxines naturellement générées par $B$. thuringiensis.

Les gènes de $B$. thuringiensis qui codent pour des endotoxines servent aussi à réaliser des constructions destinées à obtenir des plantes transgéniques résistantes aux insectes. L'unité est maintenant bien équipée pour les techniques $d$ 'insertion directe des gènes par électroporation des protoplastes et bombardements de microparticules.

La maîtrise de la régénération de protoplastes de riz a été étendue à de nouvelles variétés d'intérêt majeur pour les programmes de résistance variétale aux insectes. Des expressions transitoires de gènes introduits par électroporation ou polyéthylène-glycol sont d'intensité supérieure ou comparable à celles décrites dans la littérature. L'évaluation au champ des lignées protoclonales obtenues en 1991 a montré des variations parmi les caractères agronomiques, variations qui restent cependant compatibles avec une utilisation en croisement.

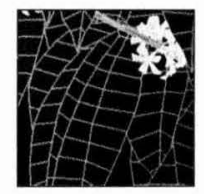

\section{Unité de modélisation des plantes}

On entend par modélisation des végétaux I'expression sous forme mathématique de phénomènes biologiques comme la croissance. Cette approche permet de réduire
I'ampleur et la durée des expérimentations sur le terrain. De plus, par l'informatique graphique, les résultats de ces expérimentations virtuelles sont visualisés en trois dimensions.

En 1992, l'unité de modélisation des plantes a développé ses relations avec I'INRA et I'ORSTOM, partenaires scientifiques traditionnels, de même qu'avec des structures agro-industrielles comme la SEITA, des serristes, des champignonnistes, des exploitants forestiers. La modélisation est un outil généraliste utilisé dans des disciplines très diverses (amélioration des plantes, agroforesterie, épidémiologie, gestion d'espaces végétaux). Des logiciels d'application ont été installés chez différents partenaires. Ce réseau d'utilisateurs pilotes est une première étape dans la diffusion de la méthode. On prévoit ensuite la formation d'équipes de modélisation au sein des organismes demandeurs.

De nouveaux accords ont été conclus avec des spécialistes de l'image de synthèse, qui sont de plus en plus nombreux à adopter le logiciel Amap pour des projets de conception de paysages.

Actuellement, des images de synthèse présentant des plantes calculées et simulées par Amap à des fins diverses - architecture, urbanisme, publicité, pédagogie, aménagement — sont produites dans plus de cent sites dans le monde.

\section{Modélisation des végétaux}

La modélisation des plantes pérennes, entreprise en 1990, est maintenant appliquée au cacaoyer, au caféier, au cocotier pour le département des cultures pérennes, aux espèces forestières en collaboration avec I'INRA et I'IDF, et aux espèces fruitières avec le CTIFL et I'INRA.

L'avancée dans la connaissance de l'architecture et de la croissance de ces végétaux a permis de mieux appréhender les aspects agronomiques de densité, de taille, d'élagage. Les potentialités de production sont mieux analysées grâce à une meilleure connaissance de la floraison et de la fructification. 
En 1992, de nouvelles collaborations ont été mises en place dans des domaines d'application spécifiques : le géranium avec le département des cultures annuelles à la Réunion, les nicotianées avec I'ITB, le champignon de couche avec la CACS, le figuier avec I'AMIFEL.

Des maquettes numériques issues de la modélisation ont été réalisées pour des études épidémiologiques sur les viroses du manioc, en collaboration avec I'ORSTOM, et sur les Phytophthora du cocotier, avec le département des cultures pérennes.

Des bilans radiatifs d'association de végétaux cultivés sont établis sur maquettes numériques : un bilan a été réalisé pour des caféiers sous ombrage d'érythrine au Costa Rica ; des mesures effectuées sous cocotier en 1992 en Côte-d'Ivoire vont se poursuivre au Vanuatu, où I'association cacaoyer-cocotier sera analysée.

Les interactions entre les diverses espèces des systèmes agroforestiers nécessitent des analyses complexes.

L'utilisation de maquettes numériques devrait permettre, pour chaque espèce, de préciser les productions de biomasse selon l'espèce, les travaux d'entretien et de taille.

Afin de créer une base de données sur les combustibles destinée à un logiciel de simulation de la propagation des incendies forestiers, I'unité s'est vu confier la modélisation de plusieurs espèces de végétaux méditerranéens.

Des travaux de modélisation d'une phanérogame sous-marine, Posidonia oceanica, ont été réalisés dans le cadre d'une convention avec le laboratoire d'environnement marin du littoral de l'université de Nice.

\section{Infographie}

Le développement informatique des logiciels de visualisation, étroitement lié à la modélisation, s'est poursuivi dans plusieurs directions. Le logiciel évolue et s'enrichit.
Pour assurer une large diffusion du moteur de croissance Amap et des bases de données végétales, des interfaces avec des logiciels renommés dans le monde de l'image de synthèse - Explore, Softimage, Wavefront — ont été réalisées.

Une adaptation du logiciel Amap permet maintenant de l'utiliser avec des ordinateurs moins performants que les stations graphiques. Les bases de données des végétaux, régulièrement complétées, comptent plus de deux cents fichiers de paramètres commercialisables. Un développement spécifique s'applique aux projets d'aménagement de milieux naturels : reboisements, réhabilitation de sites, implantation de voies ferrées, de routes, d'ouvrages d'art.

La végétation Amap, après avoir été adoptée par les spécialistes de l'image pour son réalisme visuel, devrait, en raison de sa valeur scientifique, intéresser les organismes impliqués dans la modélisation des paysages.

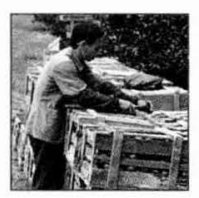

\section{Unité de prospective et politique agricole}

L'unité de recherche en prospective et politique agricole est née d'un double constat : les politiques d'ajustement structurel n'ont pas que des effets positifs

sur I'agriculture ; toute politique agricole a une durée de vie limitée et les changements sont souvent difficiles. Afin d'éclairer les avenirs possibles et d'aider les décideurs à identifier des politiques nouvelles, I'unité utilise la prospective et la modélisation.

L'objectif principal est de mettre au point des modèles représentatifs du secteur agricole et de son insertion dans l'économie globale qui prennent bien en compte les comportements des agents économiques.

Ces modèles, d'un maniement simple et rapide, fût-ce au détriment de la précision prédictive des résultats, ont pour vocation majeure l'aide à la décision. 


\section{Analyse des politiques d'ajustement structurel}

L'analyse poursuivie dans différents pays d'Amérique latine fait suite au séminaire sur les politiques d'ajustement structurel organisé avec I'IICA en 1989.

Elle révèle que les mesures d'ajustement ont poussé le secteur agricole à une plus grande compétitivité. Dans ce contexte, la baisse des prix internationaux de la plupart des produits agricoles a provoqué la recherche de nouveaux débouchés pour l'exportation (des fruits en particulier), mais les nouveaux marchés semblent limités.

\section{Politiques agricoles et modélisation}

Les modèles caractérisent les comportements des producteurs, et d'une manière générale des agents économiques, pour simuler leurs réactions à des modifications de leur environnement économique. Ils servent à identifier les effets résultant du jeu des différentes variables et à explorer d'autres scénarios.

Dans cette optique, on fait appel à la combinaison de modèles de ménages agricoles et de modèles d'équilibre utilisés en statistique comparative.

L'année 1992 a été consacrée à évaluer les différentes formes de modélisation et à proposer des améliorations pour les modèles de ménages, pour l'analyse de filières et pour les modèles d'équilibre général ou partiel calculé.

Ainsi, la représentation des filières et du secteur agricole a été complétée par la prise en compte des institutions économiques et sociales dans les modèles en identifiant les " coûts de transaction".

Différents projets, préparés par des analyses prospectives, sont destinés à identifier les principaux aspects de politique agricole par grandes régions : politiques agricoles et intégration en Amérique centrale ; politiques agricoles et diversification en Asie du Sud-Est ; politiques agricoles et régionalisation en Afrique de I'Ouest (CREPAG). Cette dernière étude

\section{Rencontres internationales}

\section{Economie institutionnelle et agriculture}

Organisé par l'université de l'Etat du Michigan, I'université d'Indiana et le CIRAD, le séminaire sur le thème "Economie institutionnelle et agriculture ", qui s'est tenu à Montpellier du 7 au 9 septembre 1992, a réuni une centaine de participants. Les intervenants, anglais, américains, africains et français, ont confronté les théories institutionnalistes aux réalités économiques et sociales. Les réflexions ont porté sur l'apport de ces théories à l'analyse du secteur agricole des pays en développement : Comment proposer des évolutions favorisant une gestion durable des terres? L'analyse économique du fonctionnement interne des unités sociales de base (ménages, lignages) peut-elle éclairer le comportement productif par rapport aux prix ? Peut-on expliquer le succès des filières cotonnières francophones par l'existence de contrats?

a été réalisée avec le ministère de la Coopération et du Développement.

Par ailleurs, I'unité a participé, dans le cadre du SPAAR, à I'analyse des besoins à long terme de l'Afrique tropicale humide en matière de recherche agronomique.

\section{Politiques agricoles : enjeux et propositions}

Aux enjeux traditionnels de diffusion de techniques nouvelles, de soutien des revenus, d'accroissement de la production et de la productivité s'ajoutent des enjeux nouveaux : la compétitivité des filières, la diversification des productions, la constitution d'espaces régionaux et le maintien des équilibres 
du milieu naturel. La définition d'une politique, c'est-à-dire d'un ensemble généralement complexe de mesures devant répondre simultanément à différents objectifs, impose de bien décrire les relations possibles entre moyens et objectifs. Des travaux explorent les graphes d'objectifs correspondant aux nouveaux enjeux, en particulier dans le domaine de l'environnement.

La crise institutionnelle des agricultures africaines ainsi que la lenteur et les difficultés d'application des politiques de libéralisation incitent à approfondir I'analyse des institutions et à diversifier les solutions. La théorie des choix publics et les principes de décentralisation et de subsidiarité permettent de définir un large spectre de formes institutionnelles possibles pour les services liés à l'agriculture. Cela concerne, par exemple, la recherche agronomique, la vulgarisation, les services vétérinaires, le crédit, les approvisionnements, la commercialisation. De même, on peut imaginer différentes formes institutionnelles de propriété pour des ressources naturelles - sols, eaux, forêts, pâturages. Ces travaux, notamment en ce qui concerne la gestion des " communs", suscitent un nouveau courant de recherche en économie de l'environnement.

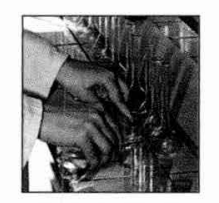

\section{Unité d'analyse des sols et des plantes}

L'unité d'analyse des sols et des plantes conduit des recherches en chimie analytique et en sciences du sol pour améliorer la précision et la signification des analyses qui lui sont confiées et mieux comprendre les mécanismes physico-chimiques expliquant les comportements des sols et des plantes.

\section{Le cuivre dans les tourbes de Sumatra}

A Sumatra, dans le projet de plantation de cocotiers sur tourbe, auquel participe le département des cultures pérennes du CIRAD, les expériences agronomiques menées depuis 1987 ont montré que la principale déficience minérale est celle du cuivre. On cherche à mieux comprendre la dynamique de rétentionlibération du cuivre apporté aux tourbes afin d'en déduire des recommandations sur les doses et les modes d'apport.

Les premiers résultats mettent en évidence deux paramètres: I'âge de la tourbe et la forme chimique de l'apport de cuivre. A l'installation de la plantation (drainage, compaction), la transformation physique de la tourbe déclenche une évolution qui, appréciée sur une durée de quatre ans, augmente considérablement sa capacité de rétention. La forme des apports a peu d'influence sur la dynamique du cuivre. La forme sulfate, utilisée couramment, entraîne le lessivage du magnésium et du potassium. La forme carbonate a l'avantage de relever le $\mathrm{pH}$, très acide, mais se trouve difficilement sur le marché.

\section{La résistance du maïs à la toxicité aluminique}

Les rendements du maïs cultivé sur les sols tropicaux acides dans les régions humides sont limités principalement par la toxicité aluminique. Sa correction par le chaulage n'est pas envisageable pour des raisons économiques. En effet, le pouvoir tampon élevé devrait être compensé par des apports considérables de chaux. De même, la correction par un apport de matière organique n'est souvent pas possible, faute de disponibilité.

L'utilisation de variétés adaptées à l'acidité est une voie possible pour assurer des rendements suffisants. Les travaux de sélection sont longs. En relation avec les sélectionneurs du département des cultures annuelles, des méthodes de test précoce de la résistance à la toxicité aluminique sont en cours de mise au point. Des variétés brésiliennes, dont la tolérance sur le terrain est établie, ont été cultivées sur des solutions nutritives de composition identique à celle des solutions de sols. C'est là l'originalité de ce travail. La croissance des systèmes racinaires est mise en relation avec 


\section{RECHERCHE ET APPUI TECHNIQUE}

la résistance à la toxicité sur le terrain. On s'attachera ensuite à identifier les mécanismes physiologiques responsables des différences de comportement variétal. Les universités de Hanovre, Barcelone, Rennes et Montpellier sont associées à cette recherche.

\section{Enseignement assisté par ordinateur}

En collaboration avec le CNUSC, un cours de deux heures sur la dynamique du potassium dans les sols a été conçu à l'aide du logiciel Druid, développé par I'université Paris VII. Il est destiné à des techniciens agricoles chinois, dans le cadre d'un projet de développement mené dans la province du Jiangsu (Chine). L'enseignement, assisté par ordinateur, s'adapte à la progression individuelle : le logiciel gère l'évolution de chaque stagiaire en fonction des résultats obtenus aux exercices. L'analyse des réponses, proche des techniques d'intelligence artificielle, aboutit à une évaluation précise des résultats de chacun. Le didacticiel réunit divers supports : textes, graphiques, animations, sons, photographies.

Cette technique, quoique d'élaboration longue - une heure de cours représente environ deux cents heures de préparation -, contribue à la valorisation et à la diffusion des connaissances. Une expertise de l'efficacité de la technique sera réalisée en Chine en 1993.

\section{Le service de formation}

L'essentiel de l'activité du service de formation du CIRAD se situe dans deux domaines : I'organisation de la formation continue pour le personnel de l'établissement; I'élaboration de plans de formation et l'organisation de formations professionnelles et diplômantes pour les chercheurs et techniciens d'institutions partenaires.

En 1992, le plan de formation interne du CIRAD a touché 502 personnes. Les secteurs prédominants ont été l'acquisition de techniques de laboratoire, I'informatique, la biométrie, la télédétection et les langues.

Le service a participé à l'actualisation des plans de formation de I'IRA et de I'IRZ au Cameroun, du FOFIFA à Madagascar et de I'INERA au Burkina Faso. Une centaine de chercheurs sont concernés, dont $25 \%$ pour des formations diplômantes et $75 \%$ pour des programmes de courte durée. L'IRAG (Guinée) a fait appel au CIRAD pour l'élaboration et la réalisation de son plan pluriannuel de formation. Environ 120 chercheurs en bénéficient et l'essentiel des formations est organisé dans le pays même.

Pour ces contrats de formation et à la demande de nombreux autres partenaires, le service de formation a assuré l'organisation d'environ 600 stages, qui se sont déroulés soit au sein du CIRAD soit dans d'autres organismes de recherche, des établissements industriels, des organisations paysannes. Pour leur part, les laboratoires du CIRAD ont accueilli 490 chercheurs étrangers pour une durée moyenne d'un mois et demi.

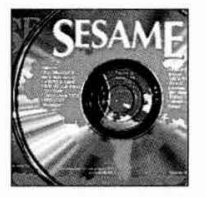

\section{Le service central d'information scientifique et technique}

Les activités du service central d'information scientifique et technique se sont déployées, en 1992, autour des publications et de l'appui documentaire aux chercheurs.

Une étude sur les publications scientifiques et techniques des départements du CIRAD a été réalisée. A partir d'une évaluation de l'impact de ces publications et des moyens humains et financiers qui leur sont affectés, une politique éditoriale a été définie en accord avec le conseil scientifique du CIRAD. Cette politique prévoit une publication accrue dans les revues internationales, le renouvellement des périodiques du CIRAD en faveur $d^{\prime}$ un public professionnel et des agents 


\section{RECHERCHE ET APPUI TECHNIQUE}

du développement, et la constitution d'une série de collections : documents de travail, documents de recherche, synthèses, bibliographies, colloques.

Dans le secteur documentaire, le service développe son programme de diffusion sélective de l'information. En 1992, plus de 800 profils documentaires ont été envoyés aux chercheurs dans plus de 50 pays. Le service assure, pour le compte du CTA, I'appui documentaire des chercheurs nationaux d'Afrique de l'Ouest, d'Afrique centrale, d'Afrique de I'Est, d'Afrique australe et de I'océan Indien. Enfin, il enrichit sa base de données, notamment dans le domaine de la littérature produite. Cette base comportait à la fin de 1992 plus de 125000 références.

Les conclusions de la première revue externe du service central d'information scientifique et technique, qui s'est déroulée au cours du quatrième trimestre de 1992, devraient lui permettre de préciser ses missions et son organisation.

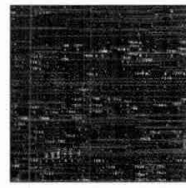

\section{Le service central d'informatique}

La réflexion sur les besoins des utilisateurs de l'informatique et sur l'évolution des offres technologiques a marqué l'année 1992. Elle s'est concrétisée par l'élaboration d'une programmation pour les cinq années à venir, 1993-1997.

Ce plan est construit à partir d'un nombre restreint d'idées fortes, et sa mise en œuvre est déjà engagée.

L'effort porte en priorité sur l'équipement individuel de base. Chaque chercheur doit être doté d'un microordinateur suffisamment puissant pour accueillir une interface graphique comme Windows. Le matériel destiné aux agents expatriés doit être adapté à leurs conditions de travail. Parmi les ordinateurs de gamme moyenne, on a choisi des machines fonctionnant sous le système d'exploitation Unix. Elles constituent en effet un standard reconnu dans la plupart des domaines d'application.

Tous les chercheurs doivent avoir accès aux techniques de pointe - statistiques graphiques, analyse d'images, systèmes d'information géographique, systèmes experts, modélisation, bases de données de grande dimension - pour traiter, valoriser, stocker leurs données et leurs documents. C'est dans cet esprit que le service central d'informatique réalise, en collaboration avec les disciplines concernées, des logiciels scientifiques fonctionnant sur microordinateurs. Le système expert $\mathrm{d}^{\prime}$ aide au diagnostic des maladies de la canne à sucre et le programme d'analyse statistique et graphique de données en sont deux exemples. Ce dernier, particulièrement destiné aux agents expatriés, a été conçu dans le cadre d'une action thématique programmée du CIRAD associant I'ITCF et I'INA-PG.

Un réseau informatique d'entreprise se crée, grâce auquel chaque poste de travail communique avec les autres et peut avoir accès à des systèmes Unix décentralisés et spécialisés par discipline. Le support physique de ce réseau est déjà en grande partie installé sur le centre de Montpellier (1 000 points d'entrée).

Les chercheurs travaillant à l'étranger doivent aussi bénéficier de la communication en réseau. C'est pourquoi le CIRAD s'est associé avec I'ORSTOM pour utiliser le réseau intertropical d'ordinateurs (RIO), qui met à leur disposition un ensemble d'outils de communication avec la communauté scientifique internationale.

En matière de gestion, la mise en place de procédures automatisées homogènes et la création d'un système $d^{\prime}$ information tenant compte à la fois de l'autonomie des départements et des besoins en informations synthétiques au niveau central sont favorisées. Le CIRAD s'est équipé d'un système d'information comptable qui permet de suivre les opérations de recherche en temps réel et de rassembler les éléments nécessaires à I'élaboration de son bilan financier. 


\section{RECHERCHE ET APPUI TECHNIQUE}

\section{Les thèses soutenues en 1992}

Chercheurs du département

Surplus agricoles et stratégies de production, par Marc Roesch, université Montpellier I.

Accueil par le département

Etude de la transplantation de boutures de Posidonia oceanica (L.) Delile, phanérogames marines ; modélisation de I'architecture et du mode de croissance, par Heika Molenaar (France), université de Nice-Sophia Antipolis. 


\section{Le CIRAD en bref}

L'organisation générale

\begin{tabular}{c}
\hline Les conseils \\
\hline Les missions par champ disciplinaire \\
\hline $\begin{array}{c}\text { Les directeurs d'agence, délégués } \\
\text { et correspondants }\end{array}$ \\
\hline Le CIRAD dans le monde \\
Le budget \\
Les personnels \\
\hline La formation des chercheurs
\end{tabular}




\section{LE CIRAD EN BREF}

\section{L'organisation}

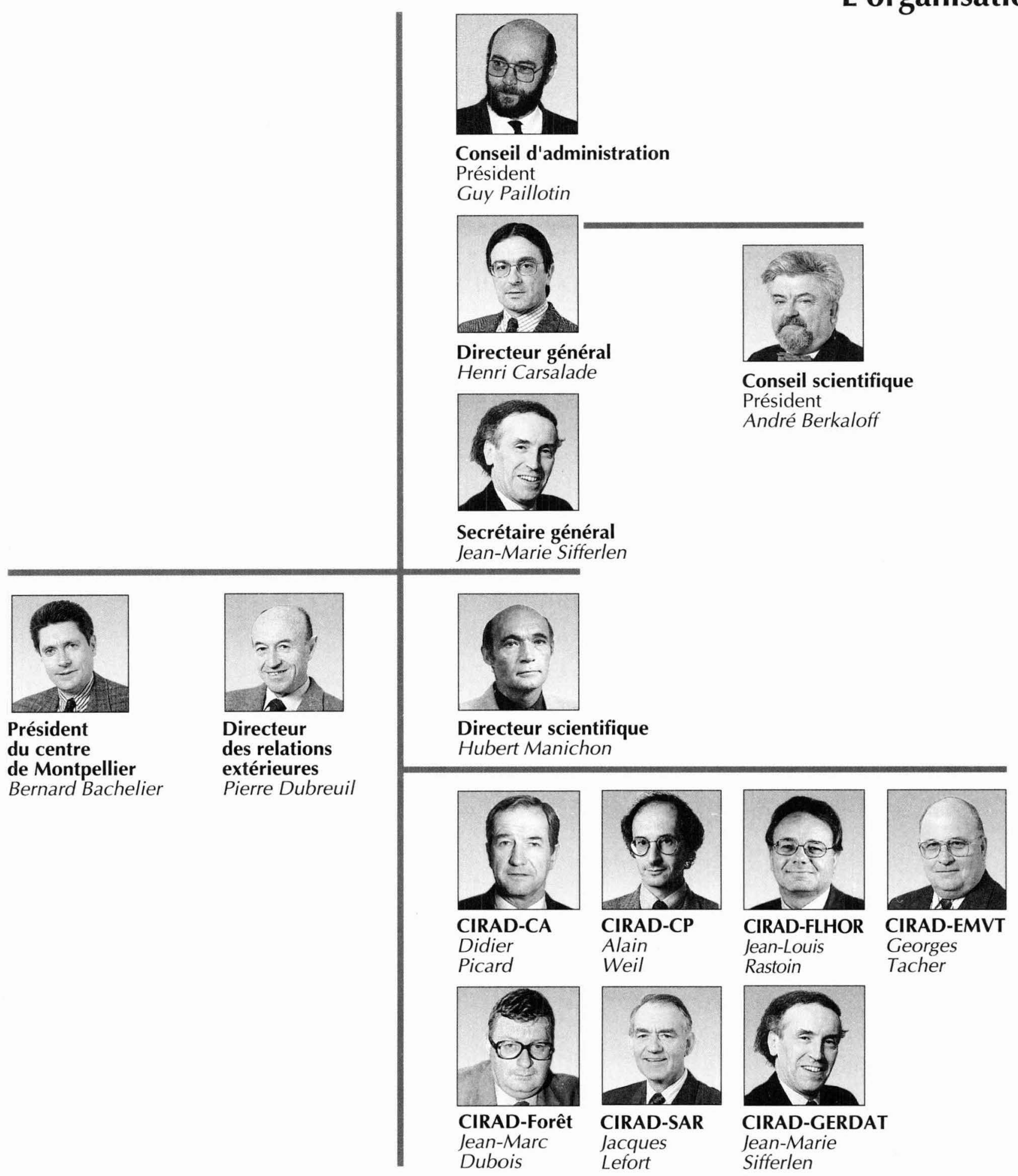




\section{générale du CIRAD en 1993}

\section{Secrétariat général}

Directeur de la comptabilité et des affaires financières

Marc Gélis

\section{Conseiller spécial}

Raoul Tuffery

Personnel

Danielle Bonneau

Affaires juridiques

Hervé de Font-Réaulx

Informatique

Joël Sor

Aménagement et maintenance François Roumens

\section{Départements et territoires d'outre-mer}

Délégué

François Pointereau

Directeurs d'agence dans les DOM-TOM

(voir page 108)

\section{Information scientifique et technique}

Chef du service central Jean-François Giovannetti

Documentation, bibliothèque Jan van der Burg

Edition

Michelle Jeanguyot

\section{Direction des relations extérieures}

Directeur adjoint

Michel de Nucé de Lamothe

Afrique

Maurice Izard

Amérique latine

Jean Laboucheix

Asie, Pacifique sud

Patrick Safran

Organisations

internationales

Marie de Lattre

Valorisation

Alain Guyot

Actions promotionnelles

Anne Hébert

Relations presse

Benoit Catrisse

Délégués

et correspondants outre-mer

(voir page 108)

\section{Direction scientifique}

Directeur adjoint Michel Eddi

\section{Missions \\ par champ disciplinaire}

Agronomie, gestion

de l'environnement

et des ressources naturelles

Jean-Joseph Lacoeuilhe

Jean Pichot

Connaissance

et amélioration des plantes

Michel Jacquot

Défense des cultures

Jean-Loup Notteghem

Productions animales

Gérard Matheron

Technologie

François Challot

Economie et sociologie

Michel Griffon

Télédétection

Jacques Imbernon

Biométrie

Xavier Perrier

\section{Services}

Formation

Auditeur interne

Antoine Bourgeois
Marc Roesch 


\title{
LE CIRAD EN BREF
}

\section{Les conseils du CIRAD}

\section{Le conseil d'administration en 1993}

\author{
Président Guy Paillotin \\ Représentants de l'Etat \\ Rémy Pochat, représentant du ministre chargé de la Recherche \\ et de I'Espace \\ Jean Nemo, représentant du ministre chargé de la Coopération \\ et du Développement \\ François Mongin, représentant du ministre chargé de l'Economie, \\ des Finances et du Budget \\ Pierre Marsal, représentant du ministre chargé de I'Agriculture \\ et du Développement rural \\ Gérard Plouchart, représentant du ministre chargé des Départements \\ et Territoires d'outre-mer
}

Président de I'Institut national de la recherche agronomique

Personnalités extérieures au CIRAD choisies en raison de leurs compétences

Représentants du personnel

Le conseil scientifique en 1993

Président

Membres externes

Membres internes Jean-Joseph Lacoeuilhe, Jean Pichot, Ange-Marie Risterucci

\section{Guy Paillotin}

Jacques Alliot, directeur délégué à la CFD

Alain Godard, directeur général de Rhône-Poulenc Agrochimie Michel Levallois, président de l'ORSTOM

Marcel Mazoyer, professeur à I'INA-PG

Jacques Poly, conseiller d'Etat

Henry Jouve, président de I'AFDI

Henri Calba, Jean-Pierre Denis, Eric Jallas,

André Berkaloff, université Paris XI

Lawrence Busch, Michigan State University

Alain Coleno, INRA

Antoine Cornet, ORSTOM

Louise Fresco, université de Wageningen

Philippe Lacombe, ENSA Montpellier

John Perfect, NRI

Michel Sedogo, CNRST

François Bertin, René Billaz, Vincent Dollé, Stéphane Guilbert, Bernard Mallet, Hervé Saint Macary, Marcel Tissot 


\section{LE CIRAD EN BREF}

\section{Les missions par champ disciplinaire en 1993}

\section{Agronomie, gestion de l'environnement et des ressources naturelles}

Défense des cultures

\section{Connaissance et amélioration des plantes}

Chargés de mission

Jean-Joseph Lacoeuilhe

Jean Pichot

Comité scientifique

Président Jean-Claude Rémy, ENSA Montpellier

Membres externes Bruno Delvaux, université catholique de Louvain

Alain Capillon, INA-PG

Jean-Marc Meynard, INRA, INA-PG

Pierre Milleville, ORSTOM

Bernard Saugier, université Paris XI

Bernard Seguin, INRA

Franck Warembourg, CNRS

Membres internes Représentants des départements
Chargé de mission Michel Jacquot
Adjoint Dominique Nicolas
Comité scientifique
Président
Membres externes
Yvette Dattée, GEVES
André Charrier, ORSTOM, ENSA Montpellier
Yves Chupeau, INRA
Michel Delseny, université de Perpignan
Alain Deshayes, INRA
Serge Hamon, ORSTOM
Yves Hervé, ENSA Rennes
Membres internes Représentants des départements

Chargé de mission Jean-Loup Notteghem

Adjoint Maurice Vaissayre

Comité scientifique

Président

Membres externes

Michel Dron, université Paris XI, centre d'Orsay

Jean Dunez, INRA

Pierre Ferron, INRA

Yves Gillon, ORSTOM

Hervé Lecoq, INRA

Jacques Luisetti, INRA

Nicole Pasteur, CNRS

Guy Riba, INRA

Membres internes Représentants des départements 


\section{LE CIRAD EN BREF}

\section{Productions animales}

\section{Technologie}

\section{Economie et sociologie}

Chargé de mission Gérard Matheron

\section{Comité scientifique}

Président

Membres externes

Membres internes

Chargé de mission

Comité scientifique

Président

Membres externes

François Challot
Julien Coléou, INA-PG

Roland Billard, Muséum national d'histoire naturelle Alain Bourbouze, IAM

Bernard Faye, INRA

Jacques Renoux, université Paris XII

Michel Theriez, INRA

Jacques Thimonier, ENSA Montpellier

Représentants des départements

Antoine Gaset, ENSC Toulouse

Yves Barbet-Massin, Renault-Agriculture

Georges Bruge, Rhône-Poulenc

André Chieng, AEC

Yves Darricau, ONUDi

Pierre Germain, ENSAIA

Yves Lemaire, Technisucre

Christiane Mercier, BSN

René Urien, CEMAGREF

Jean-Anne Ville, ANVAR

Roland Violot, SIAL

Membres internes Représentants des départements

\section{Chargé de mission Michel Griffon}

\section{Comité scientifique}

Président

Membres externes
Philippe Lacombe, ENSA Montpellier

Jean-Pierre Bertrand, INRA

Catherine Bonjean, CERDI

Pierre Campagne, IAM

Jean Chataignier, INRA

Johnny Egg, INRA

Jean-Marc Gastellu, ORSTOM

Jean-Charles Hourcade, CNRS

Michel Labonne, INRA

Yves Léon, INRA

Jean-Pierre Prod'homme, INA-PG

Michel Vernières, université Paris I

Membres internes 


\section{LE CIRAD EN BREF}

\section{Télédétection}

Chargé de mission Jacques Imbernon

Comité scientifique

Président

Membres externes

Claude Klapisz, université Paris VII

Jean-Paul Cheylan, CNRS

Michel Deshayes, CEMAGREF

Christine King, BRGM

Hervé Le Men, IGN

Jacques Noël, ORSTOM

Gilbert Saint, CNES

Bernard Seguin, INRA

Membres internes Représentants des départements

Biométrie

Chargé de mission Xavier Perrier

Comité scientifique

Président René Tomassone, INA-PG

Membres externes Yves Escoufier, université Montpellier II

Francis Laloue, ORSTOM

Membres internes Représentants des départements 


\section{Directeurs d'agence, délégués et correspondants du CIRAD}

\section{Dans les départements et territoires d'outre-mer}

Guadeloupe et Martinique

Guyane Nouvelle-Calédonie

Réunion
Jean Servant, directeur

Jean-Jacques Baraer, directeur adjoint

Jean-François Julia, directeur

Claude Calvez, directeur

Michel Hoarau, directeur

Yves Bertin, directeur adjoint

\section{A l'étranger}

Bénin

Brésil

Burkina Faso

Burundi

Cameroun

Comores

Congo

Costa Rica

Côte-d'Ivoire

Etats-Unis

Gabon

Guatemala

Guinée

Honduras

Indonésie

Madagascar

Malaisie

Mali

Maroc

Maurice

Nicaragua

Panama

Philippines

République d'Afrique du Sud

Sénégal

Singapour

Tchad

Thaïlande

Vanuatu
Christian Gaborel, correspondant

Jean-Marie Kalms, délégué

Robert Nicou, délégué

Gérard Fourny, correspondant

Jean-Louis Messager, délégué

Michel Hoarau, délégué (en résidence à la Réunion)

Olivier Hamel, correspondant

Jean Laboucheix, délégué pour l'Amérique latine et les Caraïbes

Jacques Teissier, délégué

Jill Barr, correspondant

Patrice de Vernou, correspondant

Jean Laboucheix, délégué (en résidence au Costa Rica)

Edmond Viricelle, correspondant

Jean Laboucheix, délégué (en résidence au Costa Rica)

Pierre Rondot, délégué

Jean-Louis Reboul, délégué

Patrick Durand, correspondant (en résidence à Singapour)

Jean Charoy, délégué

François Bertin, correspondant

Michel Hoarau, délégué (en résidence à la Réunion)

Jean Laboucheix, délégué (en résidence au Costa Rica)

Jean Laboucheix, délégué (en résidence au Costa Rica)

Guy Bénard, correspondant

Loïc Desselas, correspondant

Edmond Viricelle, délégué

Patrick Durand, correspondant

Daniel Bourzat, correspondant

Jean-Claude Vincent, délégué

Guy Mossu, délégué 


\section{LE CIRAD EN BREF}

\section{Le CIRAD en Afrique et dans l'océan Indien}

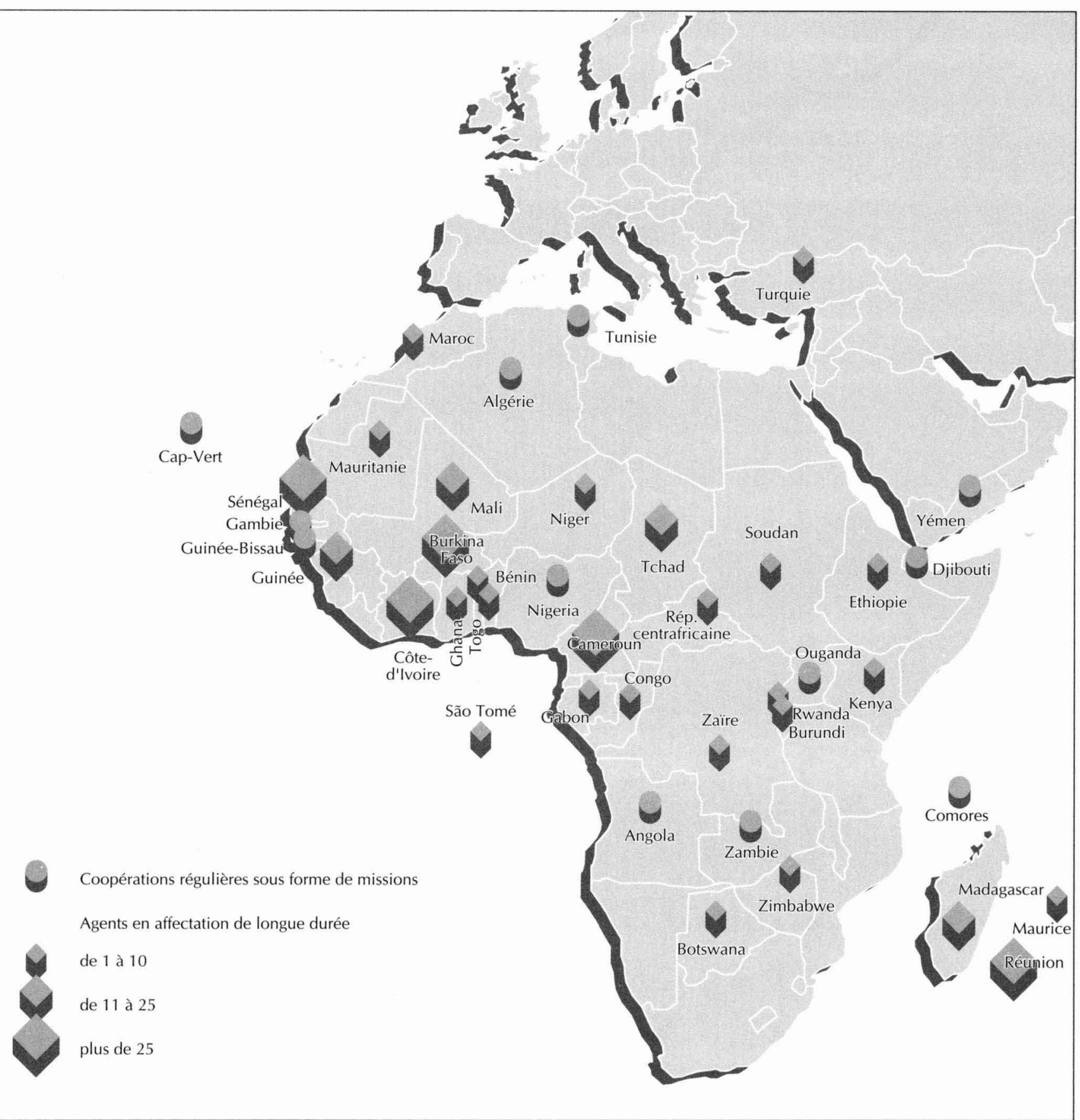




\section{Le CIRAD en Amérique latine et dans les Antilles}

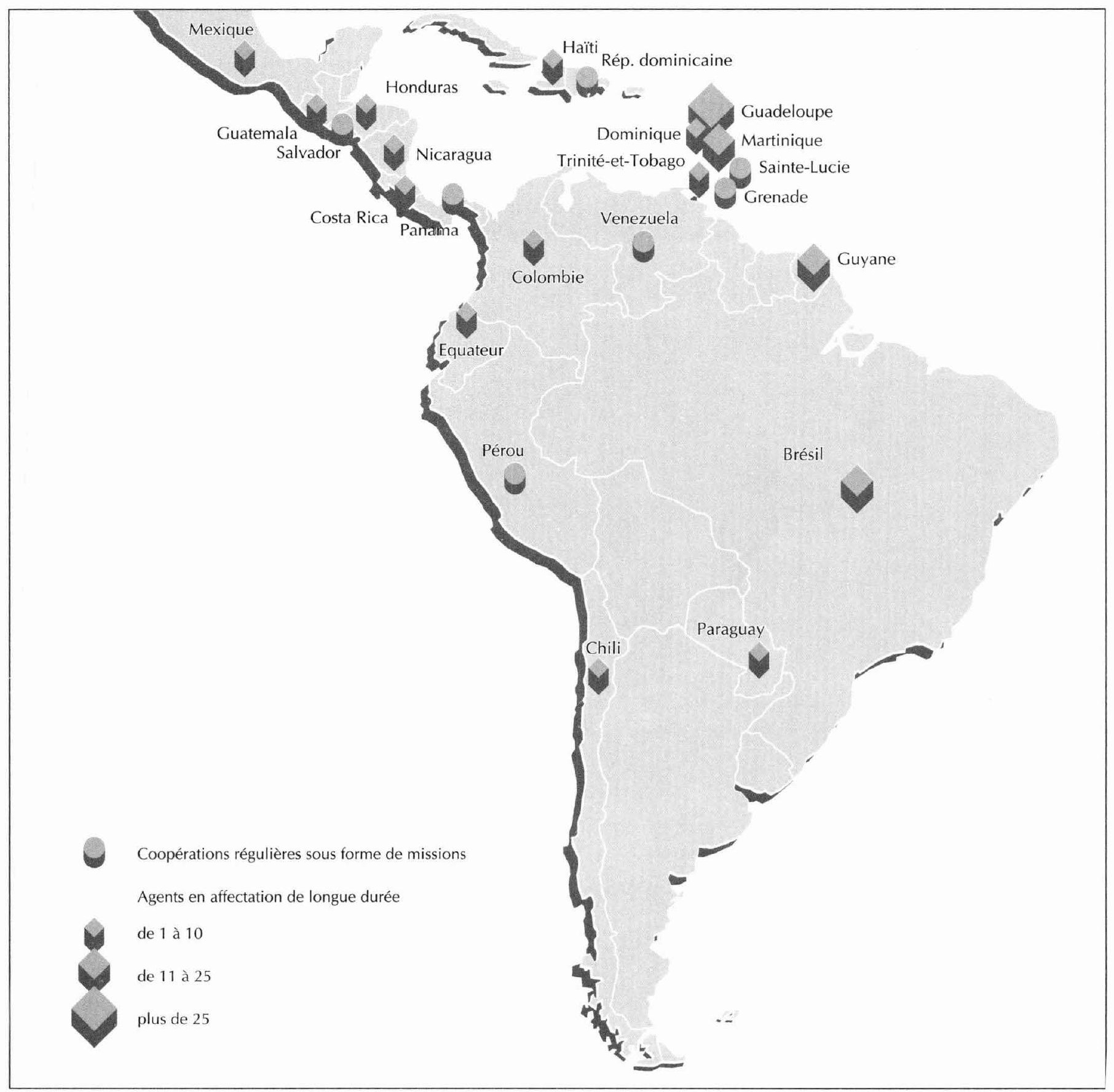




\section{LE CIRAD EN BREF}

\section{Le CIRAD en Asie et dans le Pacifique}

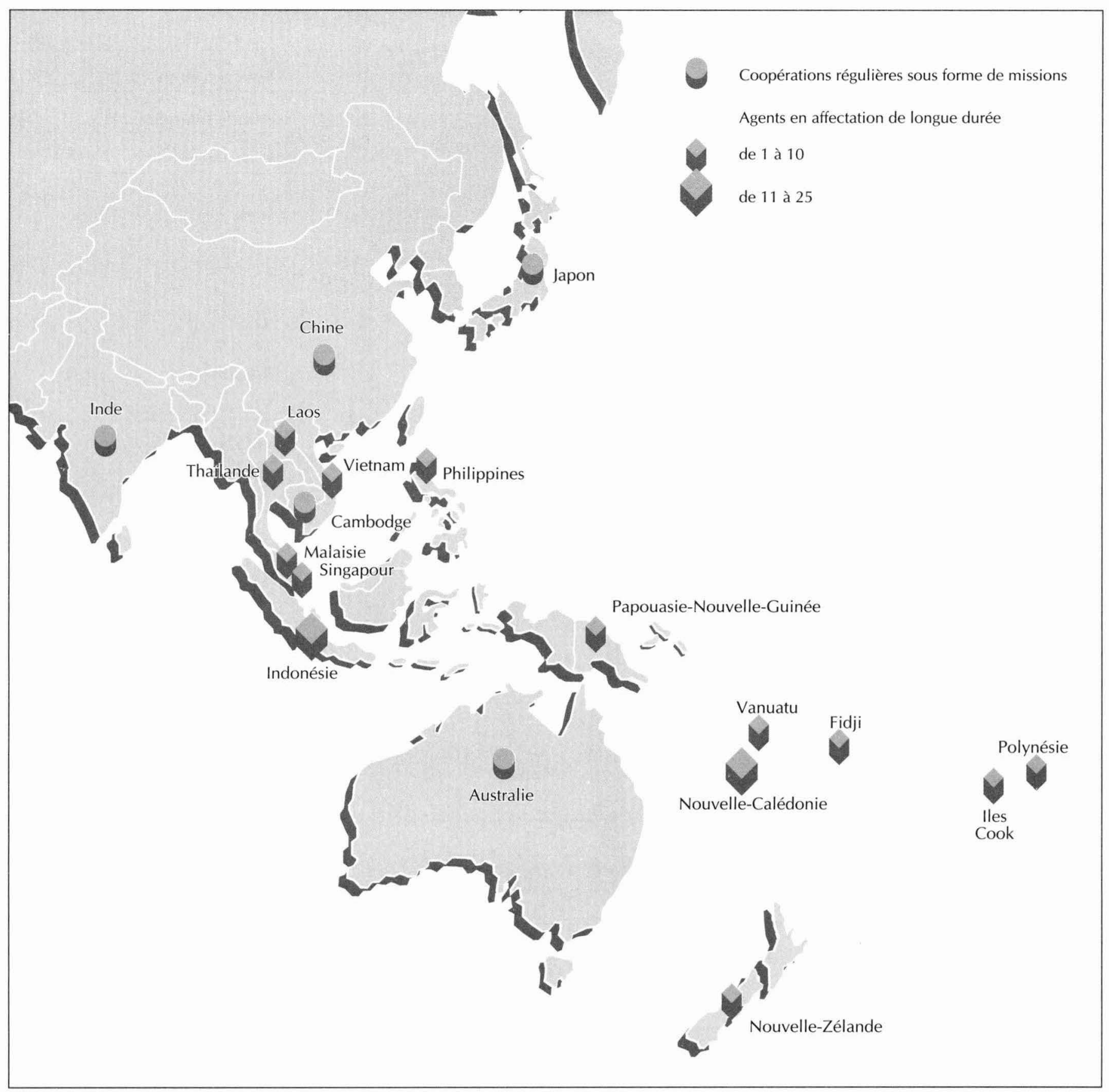




\section{LE CIRAD EN BREF}

\section{Le budget en 1992 : 945,3 millions de francs}

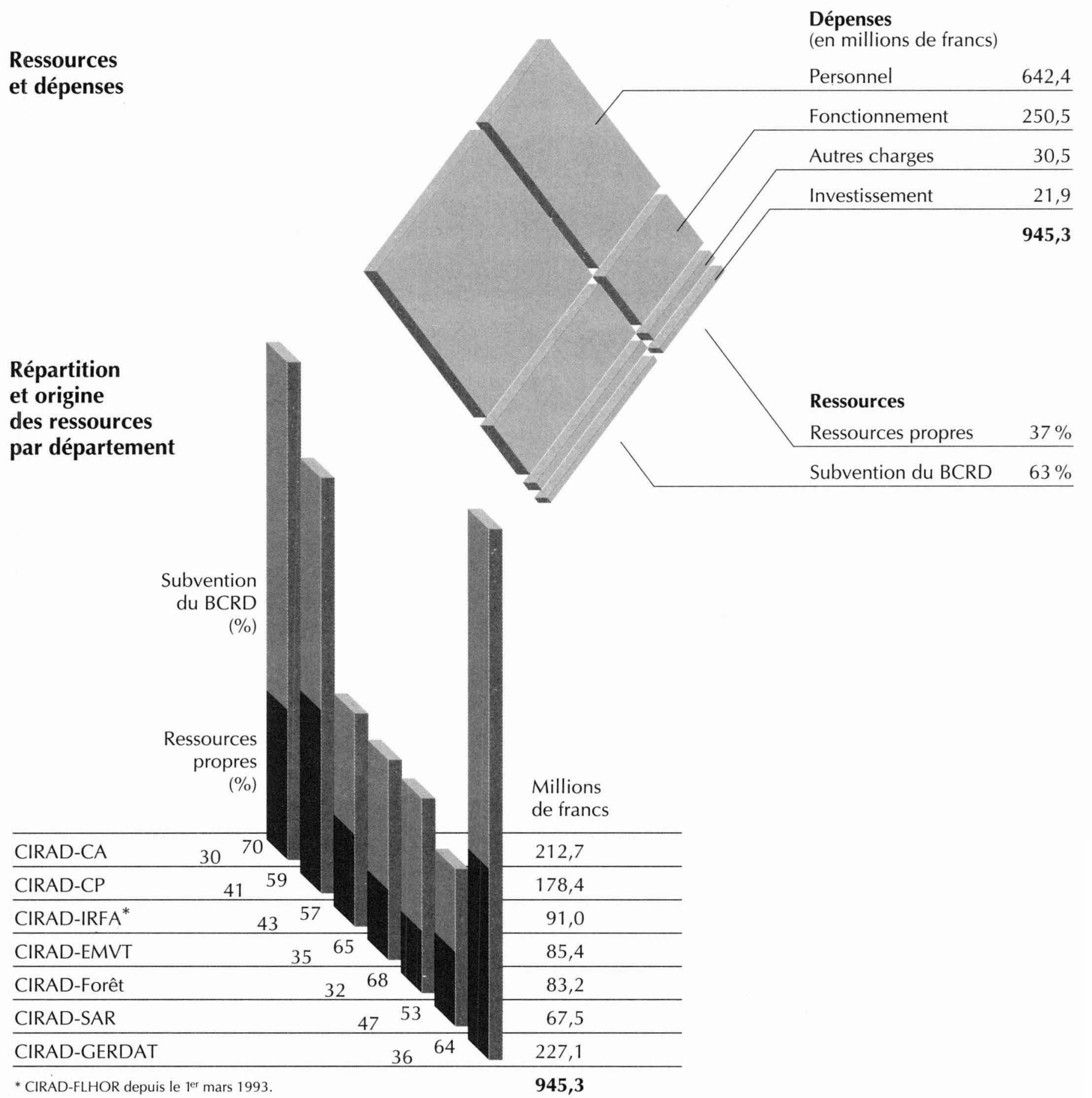




\section{LE CIRAD EN BREF}

\section{Les personnels en 1992 : 1789 agents*}

\section{Répartition par catégorie et localisation}

Cadres en métropole 471

Collaborateurs et agents de maîtrise en métropole

585

Cadres dans les DOM-TOM

et à l'étranger

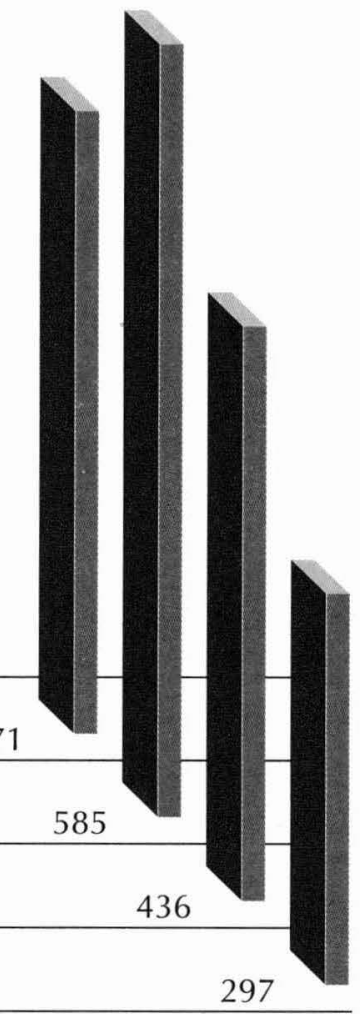

dans les DOM-TOM et à I'étranger

\section{Effectifs}

par département

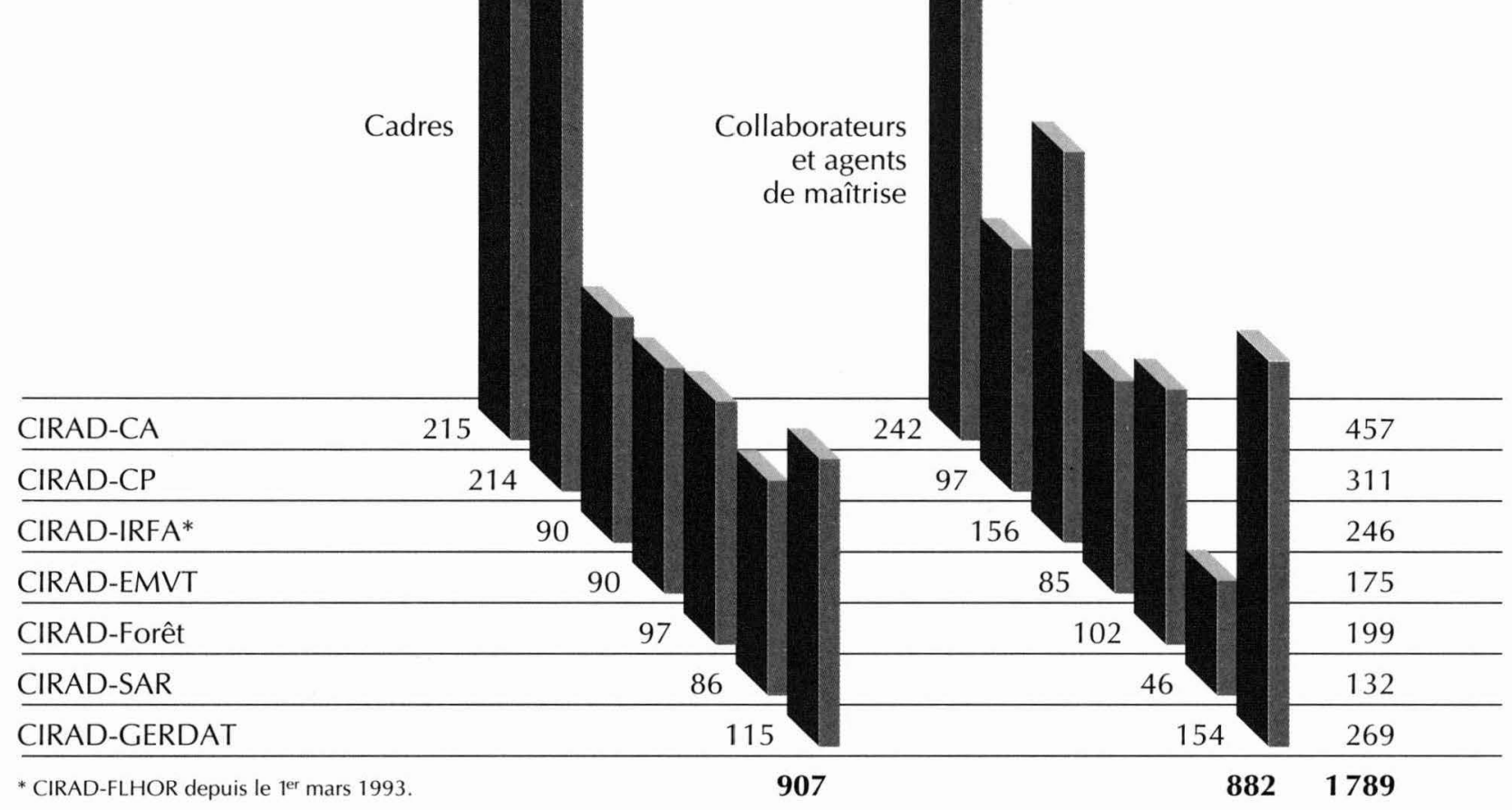




\section{LE CIRAD EN BREF}

\section{Les 907 cadres}

\section{Répartition géographique}

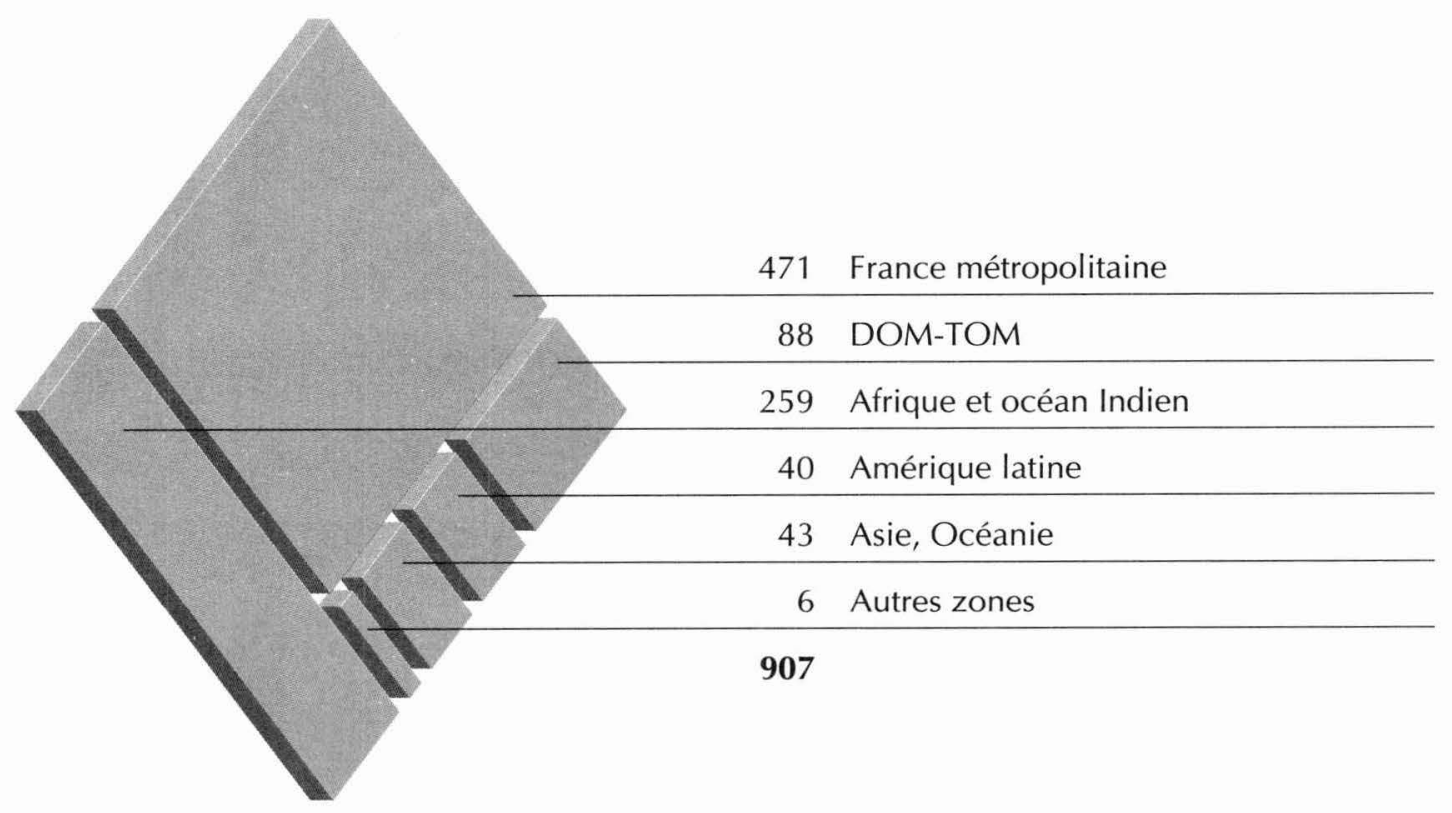

Répartition des cadres scientifiques par discipline

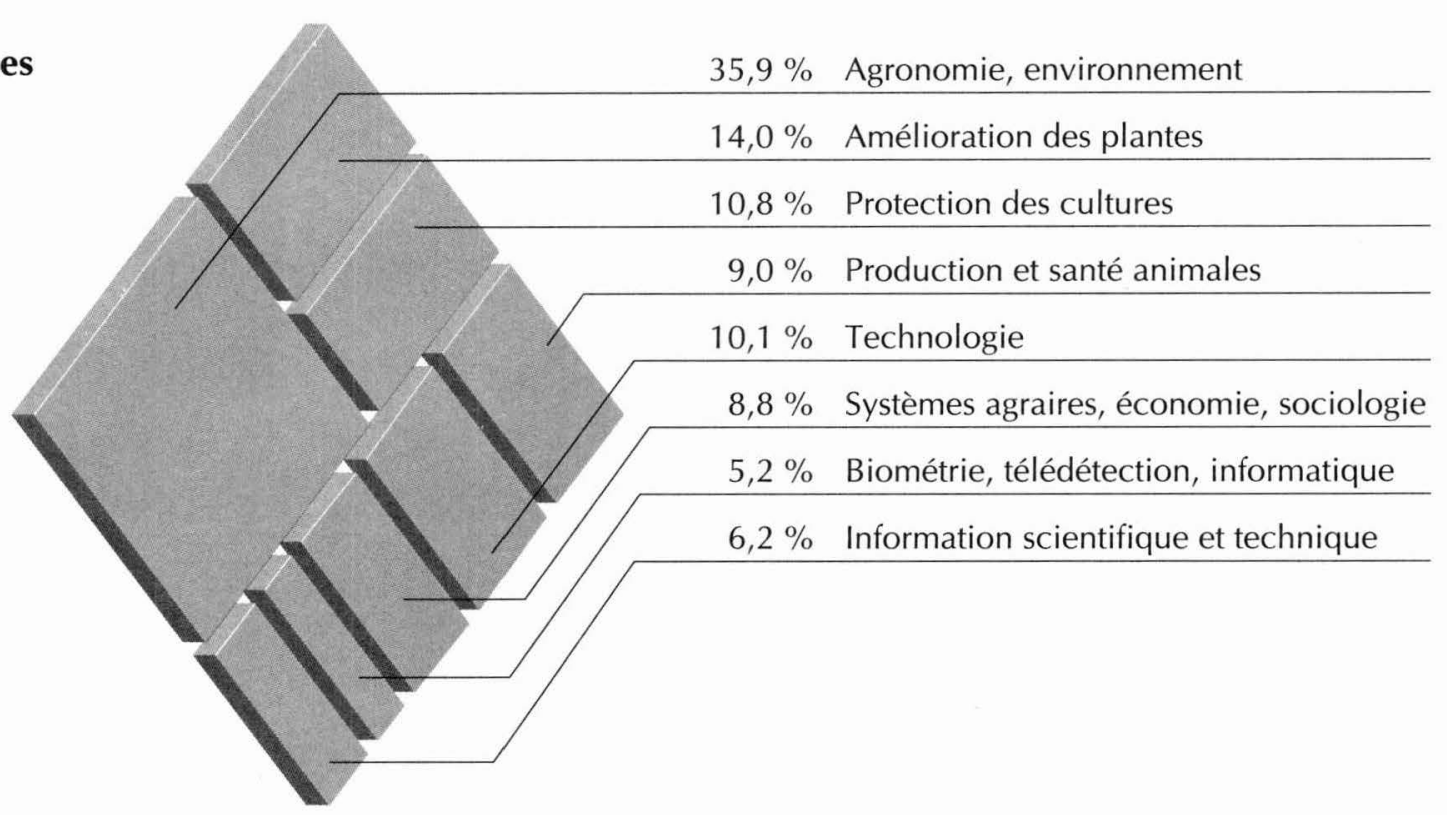




\section{La formation des chercheurs en 1992}

Répartition par discipline et type de formation

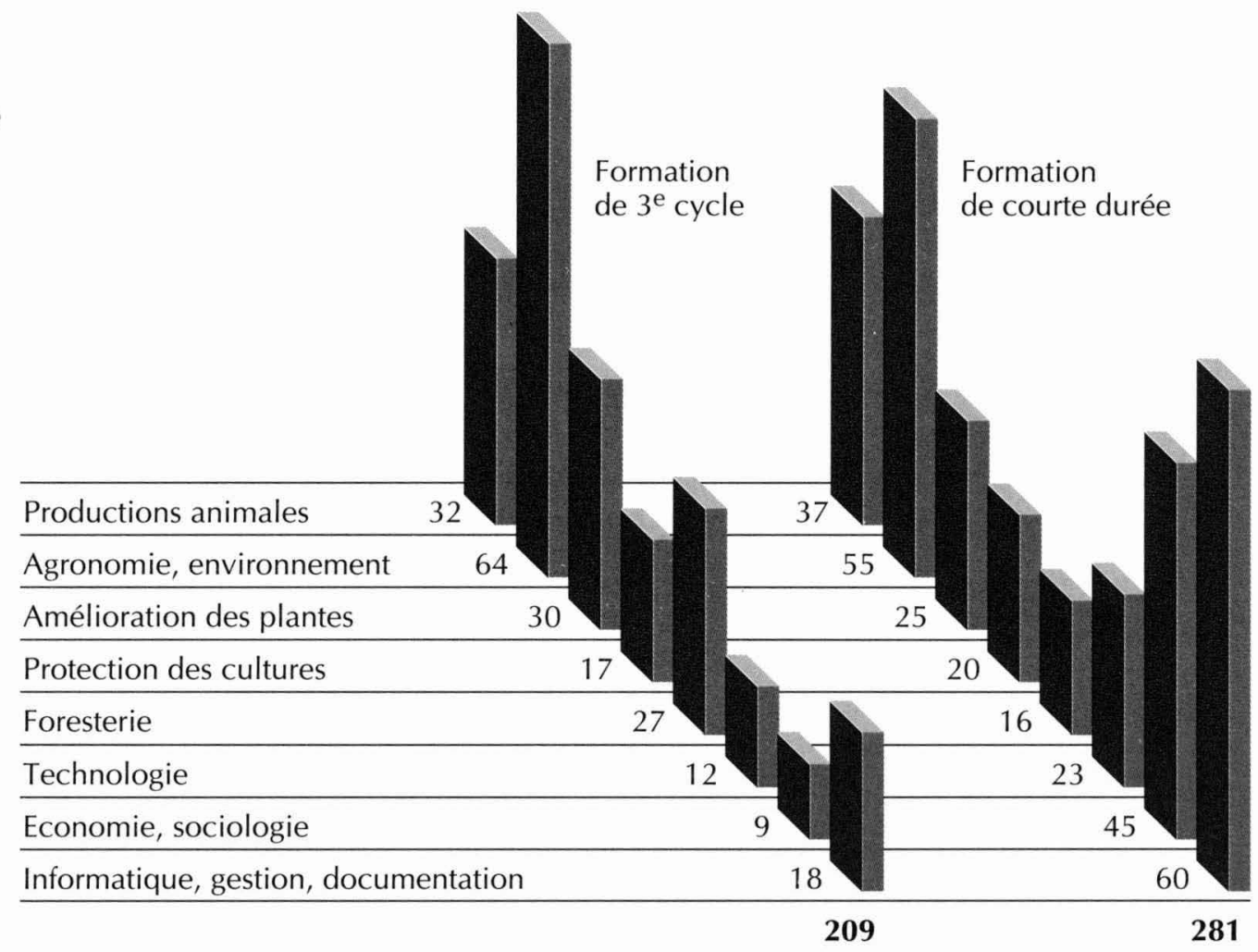

Origine géographique des chercheurs en formation

Afrique du Nord

Afrique de l'Ouest

Afrique centrale

Afrique de l'Est

Afrique australe, océan Indien

Amérique latine, Caraïbes

Moyen-Orient, Asie, Océanie

Europe*

* Dont 215 de France.
Formation

Formation de $3^{\mathrm{e}}$ cycle

209 


\section{Annexes}

Les actions thématiques programmées

Liste des sigles

Les adresses du CIRAD 


\title{
Les actions thématiques programmées financées en 1992
}

\author{
Champ disciplinaire Thème \\ Partenaires
}

\section{Agronomie, environnement}

Eau-sol-plantes

Connaissance du milieu et télédétection

Fertilité

Association de cultures

Ecophysiologie

Biotechnologie

\section{Amélioration des plantes}

Connaissance et fonctionnement hydrique des racines en sols dégradés

Reconnaissance des couverts végétaux et analyse des états de surface

Intégration à des données satellitaires SPOT des données issues d'un modèle numérique de terrain et de documents cartographiques existants (Madagascar)

Fertilisation potassique et modélisation de l'offre

Quantification et évolution du rôle d'un aménagement intégré sur les bilans hydriques et minéraux d'un bassin versant

Caféiculture et association de légumineuses

Transfert radiatif en plantations associées cocotier-cacaoyer. Simulation des meilleurs arrangements de plantations par la voie de la modélisation des architectures. Influence de ces arrangements sur la microclimatologie

Modèles de croissance et développement des cultures annuelles : méthode d'évaluation de solutions disponibles et applications
Université de Hohenheim (Allemagne), INRA

CIRAD-GERDAT, CIRAD-CA, CIRAD-CP

Socfindo (Indonésie)

CIRAD-Forêt, CIRAD-CP

FOFIFA (Madagascar), ORSTOM CIRAD-SAR, CIRAD-GERDAT, CIRAD-CA

DRA, IFDC (Togo), IDESSA (Côte-d'Ivoire), INERA (Burkina Faso), IMG, INRA CIRAD-GERDAT, CIRAD-CA

CEMAGREF, ENSAM, IMG, ORSTOM CIRAD-CA

ISABU (Burundi)

CIRAD-CA, CIRAD-CP

IDESSA (Côte-d'Ivoire), INRA

CIRAD-CP, CIRAD-GERDAT

INRA

CIRAD-CA, CIRAD-CP, CIRAD-FLHOR, CIRAD-GERDAT
Sélection Stratégies d'amélioration des plantes pérennes

Etude de la diversité génétique des plantes tropicales et de leurs parasites par RFLP
INRA

CIRAD-Forêt, CIRAD-CP

INRA, CNRS, Limagrain

CIRAD-GERDAT, CIRAD-CP, CIRAD-FLHOR 
Champ disciplinaire Thème

Biotechnologie (suite)

Utilisation du RFLP pour l'analyse des populations des parasites des plantes: champignons et trypanosomes

Embryogenèse somatique et culture cellulaire en milieu liquide (hévéa, palmier à huile, riz)

Transformation génétique du cotonnier et du caféier pour la création de plantes résistantes aux insectes

Application des techniques de PCR à l'étude génétique des plantes tropicales. Objectifs et intérêts
Partenaires

Institut G. Roussy, université Paris XI

CIRAD-CA, CIRAD-CP, CIRAD-FLHOR

ORSTOM

CIRAD-GERDAT, CIRAD-CA, CIRAD-CP, CIRAD-FLHOR

PGS (Belgique), INRA

CIRAD-GERDAT

CIMMYT (Mexique), INRA, CNRS

CIRAD-GERDAT, CIRAD-CA, CIRAD-CP, CIRAD-FLHOR

\section{Protection des cultures}

Phytopathologie

Entomologie

pas

Mise au point de tests précoces

pour la résistance des plantes aux nématodes

Etude du virus du clump de l'arachide en Afrique de l'Ouest

Analyse des composantes de la résistance des plantes et applications à l'amélioration variétale

Système d'avertissement agricole par l'utilisation des phéromones

\section{Production et santé} animales

Aquaculture
Valeur alimentaire des sous-produits agricoles pour l'alimentation en pisciculture tropicale

Analyse corrélée de l'apparition du dimorphisme de la croissance chez Oreochromis niloticus (Cichlidae) mâle et de la mise en place de la différenciation gonadique du sexe et de la puberté : rôle des hormones stéroïdes et de croissance $(G H)$
CIRAD-CP

INRA, ENSA Rennes, ORSTOM

CIRAD-CP, CIRAD-FLHOR

CNRS, ORSTOM

CIRAD-CA, CIRAD-CP

INERA (Burkina Faso), CRBP (Cameroun) CIRAD-CA, CIRAD-FLHOR, CIRAD-CP

INRA, ORSTOM, IFREMER

CIRAD-Forêt, CIRAD-EMVT

INRA, ORSTOM

CIRAD-EMVT 


\section{ANNEXES}

Champ disciplinaire Thème

Santé animale

\section{Technologie}

Filières

Innovations technologiques dans

la production alimentaire (filières courtes)

Conditions d'émergence

et de fonctionnement des entreprises

agroalimentaires rurales

Procédés

Valorisation par la stabilisation de produits alimentaires d'origine animale
Partenaires

Université de Berne (Suisse), INRA CIRAD-EMVT

ILRAD (Kenya), GTZ (Allemagne), CIRDES (Burkina Faso), université Bordeaux II CIRAD-EMVT

\section{Systèmes agraires, économie, sociologie}

Economie de la production sur les hautes terres malgaches

Les organisations paysannes face au désengagement de l'Etat

L'an 2010 à la Réunion : des scénarios prospectifs pour raisonner la recherche agronomique
ENSIAAC (Cameroun), ENEA, ISRA, CIEPAC (Sénégal), ENSIA, ORSTOM

CIRAD-SAR, CIRAD-CA

Université d'Oxford (Grande-Bretagne), université de Córdoba (Espagne), IICA (Costa Rica), DIMAC (Mexique), CCE, université Lyon II, université Montpellier I, ENSIA

CIRAD-SAR, CIRAD-CA, CIRAD-CP

ENSAIA, GRET, IFREMER, INRA, université de Clermont-Ferrand, université Montpellier II CIRAD-SAR, CIRAD-Forêt, CIRAD-EMVT

FOFIFA, Ecole normale (Madagascar), INRA, université Paris I

CIRAD-Forêt

ISRA, SAED, IRAM, CIEPAC (Sénégal) CIRAD-SAR, CIRAD-EMVT, CIRAD-CA

INRA, ministère de l'Agriculture, CEVAD, $C A H, S \cup A D$, université de la Réunion CIRAD-CA, CIRAD-SAR, CIRAD-Forêt, CIRAD-EMVT, CIRAD-FLHOR

\section{Biométrie}

Elaboration d'un logiciel statistique regroupant les logiciels CSTAT et Lisa
ITCF, ORSTOM

CIRAD-GERDAT, CIRAD-CA, CIRAD-CP, CIRAD-FLHOR, CIRAD-EMVT, CIRAD-Forêt, CIRAD-SAR 


\section{Liste des sigles}

ACSAD, Arab Center for the Study of Arid Zones and Dry Lands, Syrie

ADEME, Agence de l'environnement et de la maîtrise de l'énergie, France

ADRAO, Association de développement de la riziculture en Afrique de I'Ouest, Liberia

AEC, Asiatique européenne de commerce, France

AFDI, Agriculteurs français et développement international, France

AFRD, Agency for Forestry Research and Development, Indonésie

AGRHYMET, Centre régional de formation et d'application en agrométéorologie et hydrologie opérationnelle, Niger

AIEA, Agence internationale pour l'énergie atomique, Autriche

AMIFEL, Association méditerranéenne des régions productrices de fruits et légumes, France

ANDE, Agence nationale de développement de I'élevage, République centrafricaine

ANVAR, Agence nationale de valorisation de la recherche, France

BDPA, Bureau pour le développement de la production agricole, France

BRGM, Bureau de recherches géologiques et minières, France

BSN, Boussois-Souchon-Neuvesel, France

CACS, Coopérative agricole des champignonnistes du Saumurois, France

CADEF, Comité d'action pour le développement du Fogny, Sénégal

$\mathrm{CAH}$, Commissariat à l'aménagement des Hauts, France

CATIE, Centro Agronómico Tropical de Investigación y Enseñanza, Costa Rica

CCE, Commission des communautés européennes, Belgique

CEMAGREF, Centre national du machinisme agricole, du génie rural, des eaux et des forêts, France

CENIPALMA, Centro de Investigación en Palma de Aceite, Colombie

CEPGL, Communauté économique des pays des Grands LaCS

CERDI, Centre d'études et de recherches sur le développement international, France

CFCS, Centre français de la canne et du sucre, France
CFD, Caisse française de développement, France

CGPRT, Regional Co-ordination Centre for Coarse Grains, Pulses, Roots and Tuber Crops in the Humid Tropics of Asia and the Pacific, Indonésie

CIAT, Centro Internacional de Agricultura Tropical, Colombie

CIDT, Compagnie ivoirienne pour le développement des textiles, Côte-d'Ivoire

CIEPAC, Centre international pour l'éducation permanente et l'aménagement concerté, Côte-d'Ivoire

CIFOR, Centre for International Forestry Research, Indonésie

CIHEAM, Centre international des hautes études agronomiques méditerranéennes, France

CIMMYT, Centro Internacional de Mejoramiento de Maíz y Trigo, Mexique

CIP, Centro Internacional de la Papa, Pérou

CIPEA, Centre international pour l'élevage en Afrique, Mali

CIRDES, Centre international de recherche-développement sur l'élevage en zone subhumide, Burkina Faso

CMDT, Compagnie malienne pour le développement des textiles, Mali

CNES, Centre national d'études spatiales, France

CNRS, Centre national de la recherche scientifique, France

CNRST, Centre national de la recherche scientifique

et technique, Burkina Faso

CNUED, Conférence des Nations unies pour

I'environnement et le développement, Brésil

CNUSC, Centre national universitaire sud de calcul, France

COLEACP, Comité de liaison Europe-Afrique-Caraïbes-

Pacifique, France

CORAF, Conférence des responsables de la recherche agronomique africains

CORDET, Commission de coordination de la recherche dans les départements et territoires d'outre-mer, France

CRBP, Centre régional bananiers et plantains, Cameroun CREPAG, Coordination régionale et politiques agroalimentaires, Burkina Faso

CRETF, Centre régional d'enseignement technique féminin, Sénégal

CTA, Centre technique de coopération agricole et rurale,

Pays-Bas

CTIFL, Centre technique interprofessionnel des fruits

et des légumes, France 


\section{ANNEXES}

DIMAC, Diversification et intensification dans la marge de l'aire caféière, Mexique

DRA, Direction de la recherche agronomique, Togo

ECART, European Consortium for Agricultural Research in the Tropics

EMBRAPA, Empresa Brasileira de Pesquisa Agropecuária, Brésil

ENEA, Ecole nationale d'économie appliquée, Sénégal

ENGREF, Ecole nationale du génie rural, des eaux et des forêts, France

ENSA, Ecole nationale supérieure agronomique, France

ENSAIA, Ecole nationale supérieure d'agronomie et des industries alimentaires, France

ENSAM, Ecole nationale supérieure agronomique de Montpellier, France

ENSC, Ecole nationale supérieure de chimie, France

ENSIA, Ecole nationale supérieure des industries agricoles et alimentaires, France

ENSIAAC, Ecole nationale supérieure des industries agricoles et alimentaires du Cameroun, Cameroun

ENVA, Ecole nationale vétérinaire d'Alfort, France

ESEM, Ecole supérieure de l'énergie et des matériaux,

France

FAC, Fonds d'aide et de coopération, France

FAO, Food and Agriculture Organization of the United Nations, Italie

FED, Fonds européen de développement, Belgique

FIC, Fonds interministériel pour la Caraïbe, France

FOFIFA, Centre national de la recherche appliquée au développement rural, Madagascar

GCRAI, Groupe consultatif pour la recherche agricole internationale, Etats-Unis

GEVES, Groupement d'étude et de contrôle des variétés et des semences, France

GRET, Groupe de recherche et d'échanges technologiques, France

GTZ, Deutsche Gesellschaft für Technische

Zusammenarbeit, Allemagne

IAM, Institut agronomique méditerranéen, France IBPGR, International Board for Plant Genetic Resources, Italie

ICRISAT, International Crops Research Institute for the Semi-Arid Tropics, Inde
ICSB, Innoprise Corporation Sdn. Bhd., Malaisie IDEFOR, Institut des forêts, Côte-d'Ivoire

IDESSA, Institut des savanes, Côte-d'Ivoire

IDF, Institut national des forêts, France

IER, Institut d'économie rurale, Mali

IFDC, International Fertilizer Development Centre, Etats-Unis

IFREMER, Institut français de recherche pour I'exploitation de la mer, France

IGN, Institut géographique national, France

IICA, Instituto Interamericano de Cooperación para la Agricultura, Costa Rica

IICT, Instituto de Investigação Científica Tropical, Portugal

ILRAD, International Laboratory for Research on Animal Diseases, Kenya

IMBB, Institute of Molecular Biology and Biotechnology (Insect Group), Grèce

IMG, Institut de mécanique de Grenoble, France

INA-PG, Institut national agronomique, Paris-Grignon, France

INCAP, Instituto de Nutrición de Centro América y Panamá, Guatemala

INERA, Institut d'études et de recherches agricoles, Burkina Faso

INIAA, Instituto Nacional de Investigación Agraria y Agroindustrial, Pérou

INIBAP, International Network for the Improvement of Banana and Plantain, France

INRA, Institut national de la recherche agronomique, France INTA, Instituto Nacional de Tecnología Agropecuária, Argentine

IRA, Institut de la recherche agronomique, Cameroun IRAG, Institut agronomique de Guinée, Guinée

IRAM, Institut de recherches et d'applications des méthodes de développement, France

IRAP, Institut de recherches appliquées sur les polymères, France

IRAZ, Institut de recherche agronomique et zootechnique, Burundi

IRBET, Institut de recherches en biologie et écologie tropicale, Burkina Faso

IRRDB, International Rubber Research and Development Board, Grande-Bretagne 


\section{ANNEXES}

IRRI, International Rice Research Institute, Philippines IRZ, Institut de recherches zootechniques, Cameroun ISABU, Institut des sciences agronomiques du Burundi, Burundi

ISHS, International Society for Horticultural Science, Pays-Bas

ISOPB, International Society of Oil Palm Breeders ISRA, Institut sénégalais de recherches agricoles, Sénégal ITB, Institut du tabac de Bergerac, France

ITCF, Institut technique des céréales et des fourrages, France IVIA, Instituto Valenciano de Investigaciones Agrarias, Espagne

KIT, Koninklijk Instituut voor de Tropen, Pays-Bas MRSTD, Ministère de la recherche scientifique et technologique pour le développement, Madagascar NOAA, National Oceanographic and Atmospheric Administration, Etats-Unis

NRI, Natural Resources Institute, Grande-Bretagne OCLALAV, Organisation commune de lutte antiacridienne et de lutte antiaviaire, Sénégal

ODR, Office de développement rizicole, Madagascar

OFI, Oxford Forestry Institute, Grande-Bretagne

OIAC, Organisation interafricaine du café, Côte-d'Ivoire

OIE, Office international des épizooties, France

ONADEF, Office national du développement des forêts, Cameroun

ONF, Office national des forêts, France

ONUDI, Organisation des Nations unies pour

le développement industriel, Autriche

ORRAF, Office of the Rubber Replanting Aid Fund, Thaïlande
ORSTOM, Institut français de recherche scientifique pour le développement en coopération, France

PGS, Plant Genetic Systems, Belgique

PORIM, Palm Oil Research Institute of Malaysia, Malaisie PROMECAFE, Programa Cooperativo Regional para la Protección y Modernización de la Caficultura (IICA), Costa Rica

RRIT, Rubber Research Institute of Thailand, Thaïlande SAED, Société d'aménagement et d'étude du delta et des vallées du fleuve Sénégal et de la Falémé, Sénégal $\mathrm{SAPH}$, Société africaine de plantations d'hévéas, Côte-d'Ivoire

SEAMEO, Southeast Asian Ministers of Education Organization, Thaïlande

SEITA, Société d'exploitation industrielle des tabacs et allumettes, France

SIAL, Salon international de I'alimentation, France SIARC, Section ingénieurs industries agroalimentaires des régions chaudes (ENSIA), France

SNRA, Systèmes nationaux de recherche agricole SOCAPALM, Société camerounaise de palmeraies, Cameroun

SOCFINDO, Société financière indonésienne, Indonésie SOFITEX, Société burkinabé des fibres textiles, Burkina Faso SPAAR, Special Program for African Agricultural Research, Etats-Unis

SUAD, Service d'utilité agricole de développement, France UAIC, Unité d'afforestation industrielle du Congo, Congo USDA, United States Department of Agriculture, Etats-Unis WINBAN, Windward Islands Banana Growers' Association, Trinité-et-Tobago 


\title{
Les adresses du CIRAD
}

\author{
Siège social \\ 42, rue Scheffer \\ 75116 Paris \\ France \\ Téléphone : (1) 47043215 \\ Télécopie : (1) 47551530 \\ Télex : $648729 \mathrm{~F}$
}

Centre de recherche de Montpellier

2477, avenue du Val de Montferrand

BP 5035

34032 Montpellier Cedex 1

France

Téléphone : 67615800

Télécopie : 67615986

Télex : $480762 \mathrm{~F}$

\section{Les départements du CIRAD}

CIRAD-CA

Département des cultures annuelles 45 bis, avenue de la Belle Gabrielle 94736 Nogent-sur-Marne Cedex, France Téléphone : (1) 43944300

Télécopie : (1) 43944491

Télex : $264656 \mathrm{~F}$

\section{CIRAD-CP}

Département des cultures pérennes 12, square Pétrarque

75116 Paris, France

Téléphone : (1) 45536025

Télécopie : (1) 45536811

Télex : $645491 \mathrm{~F}$

\section{CIRAD-FLHOR}

Département des productions fruitières et horticoles

26, rue Poncelet 75017 Paris, France

Téléphone : (1) 40537050

Télécopie : (1) 40530426

Télex : $645992 \mathrm{~F}$

\section{CIRAD-EMVT}

Département d'élevage et de médecine vétérinaire

10 , rue Pierre Curie 94704 Maisons-Alfort Cedex, France Téléphone : (1) 43688873

Télécopie : (1) 43752300

Télex : $262017 \mathrm{~F}$ 


\section{ANNEXES}

CIRAD-Forêt

Département des forêts

45 bis, avenue de la Belle Gabrielle

94736 Nogent-sur-Marne Cedex, France

Téléphone : (1) 43944300

Télécopie : (1) 43944329

Télex : $264653 \mathrm{~F}$

\section{CIRAD-SAR}

Département des systèmes agroalimentaires et ruraux

2477, avenue du Val de Montferrand

BP 5035

34032 Montpellier Cedex 1, France

Téléphone : 67615800

Télécopie : 67414015

Télex : $485221 \mathrm{~F}$

\section{CIRAD-GERDAT}

Département de gestion, recherche, documentation et appui technique 42, rue Scheffer 75116 Paris, France Téléphone : (1) 47043215

Télécopie : (1) 47551530

Télex : $648729 \mathrm{~F}$
Le CIRAD dans les DOM-TOM

\section{Guadeloupe}

$M$. le directeur

Agence du CIRAD

Station IRFA de Neufchâteau

Sainte-Marie

97130 Capesterre-Belle-Eau

Téléphone : (590) 863021

Télécopie : (590) 868077

Télex : 919121 GL

\section{Guyane}

$M$. le directeur

Agence du CIRAD

BP 701

97387 Kourou Cedex

Téléphone : (594) 320430

Télécopie : (594) 324227

Télex : 910323 FG

\section{Martinique}

$M$. le directeur

Agence du CIRAD

BP 427

97204 Fort-de-France Cedex

Téléphone : (596) 602394 ou 516690

Télécopie : (596) 600924

Télex : 912249 MR

\section{Nouvelle-Calédonie}

$\mathrm{M}$. le directeur

Agence du CIRAD

BP 73

Païta

Téléphone : (687) 353684

Télécopie : (687) 353223

\section{Réunion}

$M$. le directeur

Agence du CIRAD

Station de La Bretagne

97487 Saint-Denis Cedex

Téléphone : (262) 525009

Télécopie : (262) 526860

Télex : 916033 RE 


\section{A NNEXES}

\section{Le CIRAD à l'étranger}

Bénin

M. le correspondant

BP 715

Cotonou

Téléphone : (229) 313446

Brésil

$M$. le délégué

SCLN 405

Bloco D, Entrada 49, Sala 209

Brasilia DF

Téléphone : (55) 613470022

Télécopie : (55) 613470022

Télex : 614688 BR (att. CIRAD)

\section{Burkina Faso}

$M$. le délégué

BP 596

Ouagadougou 01

Téléphone : (226) 307070

Télécopie : (226) 307617

\section{Burundi}

$M$. le correspondant

c/o ISABU

BP 795

Bujumbura

Téléphone : (257) 223390

Télécopie : (257) 223840

\section{Cameroun}

$M$. le délégué

BP 2572

Yaoundé

Téléphone : (237) 212541

Télécopie : (237) 202969

Télex : 8202 ou 8531 KN

\section{Congo}

M. le correspondant

BP 1291

Pointe-Noire

Téléphone : (242) 943184

Télécopie : (242) 944797

Télex : 8303 KG (att. CIRAD)

\section{Costa Rica}

M. le délégué pour l'Amérique latine et les Caraïbes

Apartado 695

2300 Curridabat

San José

Téléphone : (506) 255972

Télécopie : (506) 250940

\section{Côte-d'Ivoire}

$M$. le délégué

BP 6483

Abidjan 01

Téléphone : (225) 221869

Télécopie : (225) 214368

Télex : $23220 \mathrm{CI}$

\section{Etats-Unis}

M. le correspondant

Development Research Associates 2025 I Street, NW, Suite 524

Washington DC 20006

Téléphone : (1) 2028720576

Télécopie : (1) 2028728491

Télex : 440452 UI

\section{Gabon}

M. le correspondant

CATH

BP 643

Libreville

Téléphone : (241) 741766

Télécopie : (241) 746522

Télex : 5900 GO

\section{Guinée}

$\mathrm{M}$. le correspondant

c/o MCAC

Ambassade de France

BP 570

Conakry

Téléphone : (224) 444262

Télex : 22400 GE (att. CIRAD) 


\section{ANNEXES}

\section{Indonésie}

$M$. le délégué

Sutimah Building, 3rd Floor

Jalan Kemang Raya 2

Jakarta Selatan 12730

Téléphone : (62) 217992867

Télécopie : (62) 217993044

Télex : 47243 IA (att. CIRAD)

\section{Madagascar}

M. le délégué

BP 853

Antananarivo

Téléphone : (261) 227182

Télécopie : (261) 220999

Télex : 22591 MG

\section{Mali}

$M$. le délégué

BP 1769

Bamako

Téléphone : (223) 224293

Télécopie : (223) 228717

Télex : 2678 MJ

\section{Maroc}

M. le correspondant

Laboratoire national de production de vaccins vétérinaires

BP 585

Rabat-Chellah

Téléphone : (212) 690454

Télécopie : (212) 691689

Télex : 32052 M

\section{Philippines}

M. le correspondant

c/o PCARRD

Los Baños

Laguna

Téléphone : (63) 50014 ou 50020

Télex : 40860 PM

\section{République d'Afrique du Sud}

M. le correspondant

Agribis c.c.

PO Box 1435

Gallo Manor

Sandton 2052

Téléphone : (2711) 8043482

Télécopie : (2711) 8045190

\section{Sénégal}

$M$. le délégué

37, avenue Jean XXIII

BP 6189

Dakar-Etoile

Téléphone : (221) 224484

Télécopie : (221) 211879

Télex : 21562 SG

\section{Singapour}

M. le correspondant

Selegie Complex 14275

257 Selegie Road

Singapore 0718

Téléphone : (65) 3372600

Télécopie : (65) 3376269

Télex : 34563 RS

\section{Tchad}

M. le correspondant

Laboratoire de Farcha

BP 433

N'Djamena

Téléphone : (235) 513007

Télécopie : (235) 513302

Télex : 5340 KD (att. CIRAD)

\section{Thaïlande}

M. le délégué

c/o Franco Pacific Co. Ltd

8th Floor, Mahatun Plaza

888/88 Ploenchit Road

Bangkok 10500

Téléphone : (662) 2542083 à 88

Télécopie : (662) 2536841

Télex : $82108 \mathrm{TH}$

\section{Vanuatu}

M. le délégué

Station de Saraoutou

BP 231

Santo

Téléphone : (678) 36320

Télécopie : (678) 36355

Télex : $1001 \mathrm{NH}$ 


\section{Crédit photographique}

Couverture : B. Aubert/CIRAD-FLHOR ; p. 22 : E. Hainzelin/CIRAD-CA ; p. 24 : C. Poisson/CIRAD-CA ; p. 30 : R. Fauconnier/CIRAD-CA ; p. 31 : E. Hainzelin/CIRAD-CA ; p. 32 : D. Bordat/CIRAD-CA ;

p. 34 : C. Lanaud/CIRAD-GERDAT ; p. 35 : A. Rival/CIRAD-CP ; p. 38 : C. Lanaud/CIRAD-GERDAT ; p. 39 : C. Lanaud/CIRAD-GERDAT ; p. 42 : A. Rival/CIRAD-CP ; p. 46 : B. Aubert/CIRAD-FLHOR ; p. 48 : B. Aubert/CIRAD-FLHOR ; p. 51 : C. Lanaud/CIRAD-GERDAT ;

p. 52 : C. Lanaud/CIRAD-GERDAT ; p. 54 : D. Bordat/CIRAD-CA ; p. 56 : G. Tacher/CIRAD-EMVT ;

p. 57 : G. Herblot ; p. 60 : R. Lancelot/CIRAD-EMVT ; p. 61 : G. Saint Martin/CIRAD-EMVT ;

p. 62 : B. Truong/CIRAD-CA ; p. 66 : G. Pocthier/CIRAD-SAR ; p. 68 : B. Dupuy/CIRAD-Forêt ;

p. 71 : H.-F. Maitre/CIRAD-Forêt ; p. 73 : C. Weiss ; p. 78 : C. Lanaud/CIRAD-GERDAT;

p. 79 : M. Raunet/CIRAD-CA ; p. 82 : V. Dollé/CIRAD-SAR ; p. 84 : T. Ferre/CIRAD-SAR;

p. 86 : V. Dollé/CIRAD-SAR ; p. 88 : R. Hugon/CIRAD-FLHOR; p. 91 : C. Teisson/CIRAD-GERDAT ;

p. 94 : B. Aubert/CIRAD-FLHOR ; p. 96 : T. Erwin/CIRAD-GERDAT ; p. 97 : C. Poisson/CIRAD-CA ; p. 97 : T. Erwin/CIRAD-GERDAT ; p. 98 : T. Erwin/CIRAD-GERDAT.

$\begin{aligned} \text { Production } & \begin{array}{l}\text { Service central d'information } \\ \text { scientifique et technique }\end{array} \\ \text { Maquette et fabrication } & \text { José Rodrigues } \\ \text { Graphiques } & \text { Crayon \& Cie, Montpellier } \\ \text { Impression } & \text { Paragraphic, L'Union }\end{aligned}$

Dépôt légal $2^{\mathrm{e}}$ trimestre 1993

Cet ouvrage a été publié en anglais 


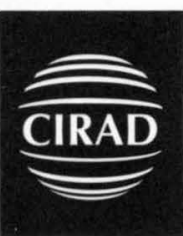

\section{Centre} de coopération internationale en recherche agronomique pour le développement

42, rue Scheffer 75116 Paris France

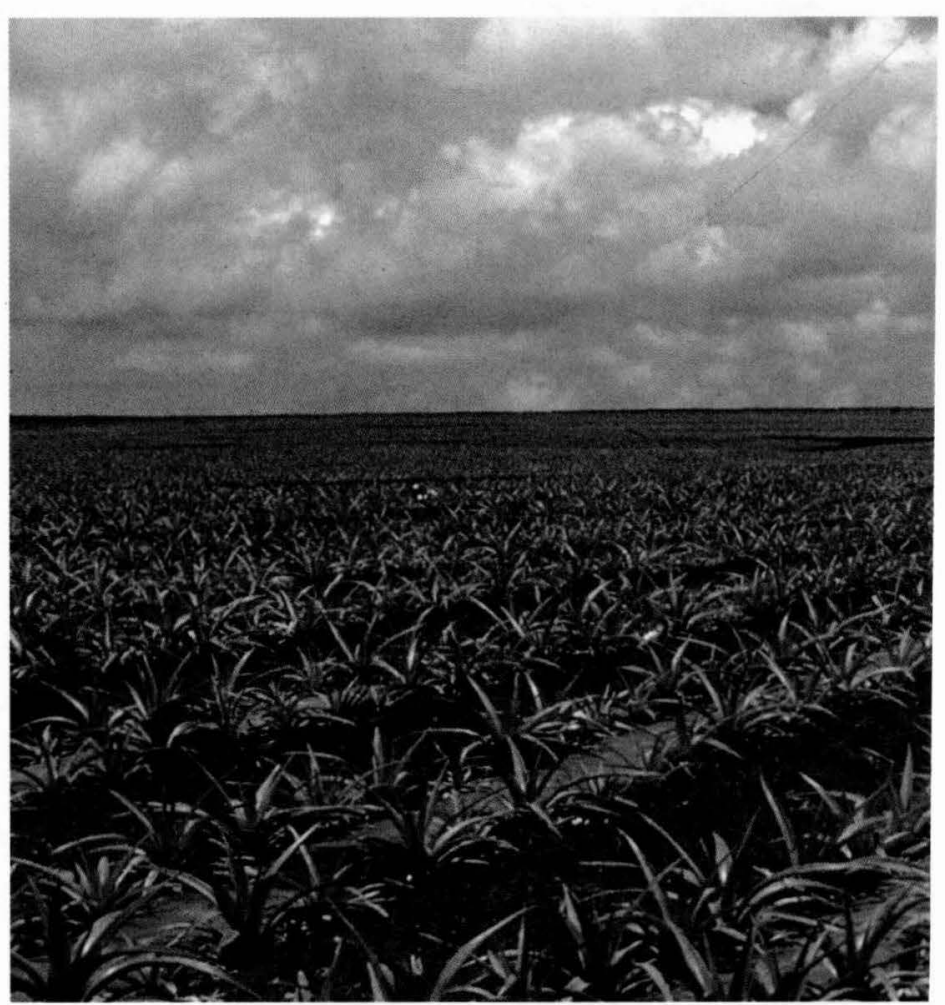

